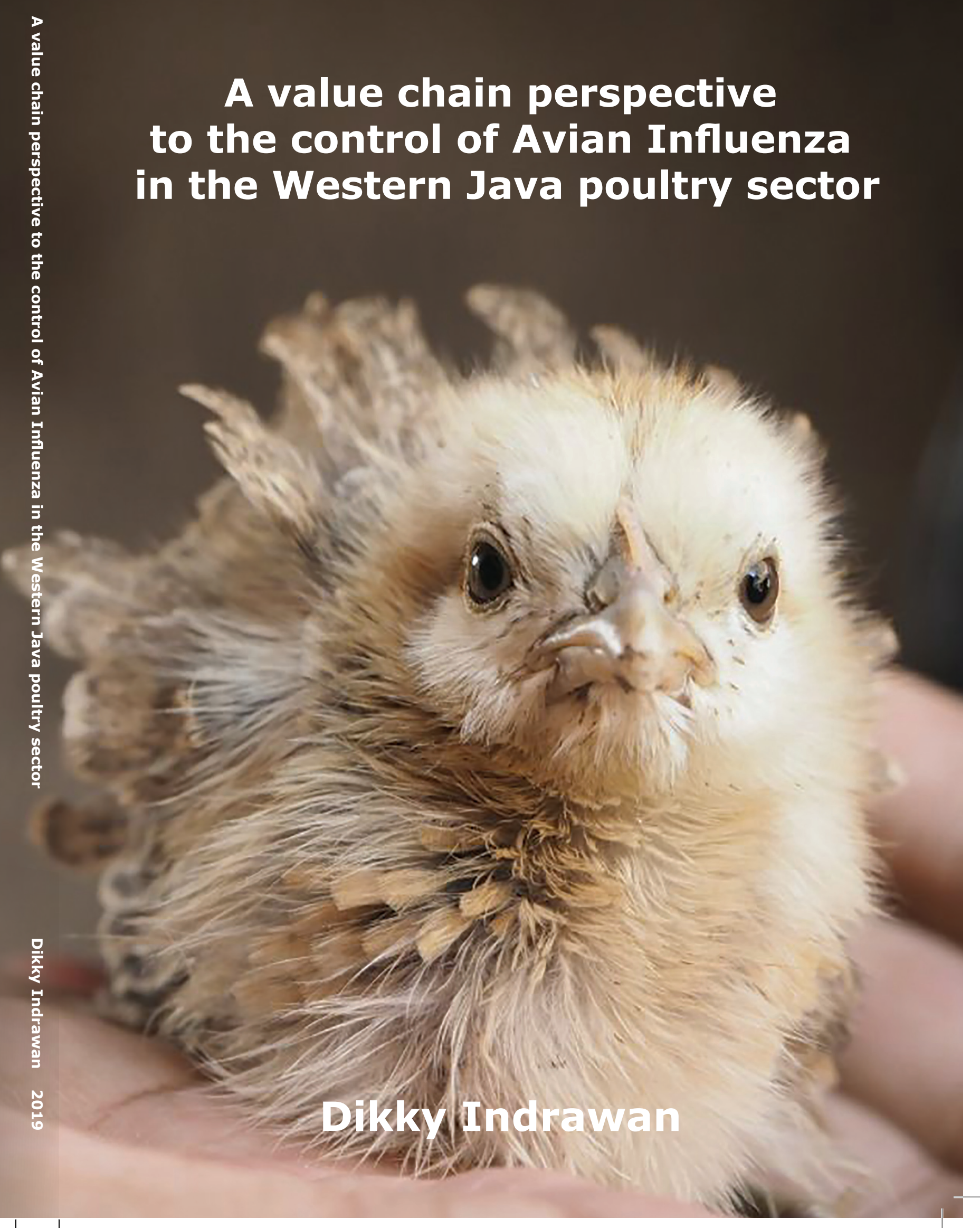




\section{Propositions}

1. The existence of a market for sick poultry is the main obstacle to eradicate HPAI in Western Java.

(this thesis)

2. In Western Java, redefining the consumers' perception of freshness of poultry meat is key to restructure the poultry supply chain.

(this thesis)

3. Virus mutations accelerate gene mutations in the human genome.

4. Governments need a proper knowledge of behavioral economics to successfully implement interventions based on an incentive mechanism.

5. In Indonesia, the apparently innocent habit to give presents to business contacts is the basis of corruption.

6. Passionate teaching is not only transfer of knowledge, but also shaping the future of humanity.

Propositions belonging to the thesis, entitled

"A value chain perspective to the control of Avian Influenza in the Western Java poultry sector"

Dikky Indrawan

Wageningen, 13 March 2019. 
A value chain perspective to the control of Avian Influenza in the Western Java poultry sector 


\section{Thesis committee}

\section{Promotor}

Prof. Dr H. Hogeveen

Personal Chair at Business Economics Group

Wageningen University \& Research

\section{Co-promotor}

Dr A. Daryanto

Associate professor, School of Business

Bogor Agricultural University, Bogor, Indonesia

\section{Other members}

Prof Dr M.A. Koelen, Wageningen University \& Research

Dr S.J. Oosting, Wageningen University \& Research

Dr J.L. Gonzales Rojas, Wageningen University \& Research

Prof Dr Wiku Bakti B. Adisasmito, University of Indonesia

This research was conducted under the auspices of the Wageningen School of Social Sciences (WASS) 


\title{
A value chain perspective to the control of Avian Influenza in the Western Java poultry sector
}

\author{
Dikky Indrawan
}

\section{Thesis}

submitted in fulfilment of the requirements for the degree of doctor at Wageningen University

by the authority of the Rector Magnificus,

Prof. Dr A.P.J. Mol,

in the presence of the

Thesis Committee appointed by the Academic Board

to be defended in public

on Wednesday 13 March 2019

at 4 p.m. in the Aula. 
Dikky Indrawan

A value chain perspective to the control of Avian Influenza in the Western Java poultry sector, 166 pages.

$\mathrm{PhD}$ thesis, Wageningen University, Wageningen, the Netherlands (2019) With references, with summary in English

ISBN 978-94-6343-599-4

DOI https://doi.org/10.18174/470900 


\section{Contents}

$\begin{array}{lll}\text { Chapter } 1 & \text { General introduction }\end{array}$

Chapter 2 Linking Supply Chain Governance and Biosecurity in the

Context of HPAI control in Western Java: A Value Chain

Perspective

Chapter 3

The probability of highly pathogenic avian influenza

introduction and transmission in Western Java poultry chain:

linking value chains and expert estimates

Chapter 4

Determinants of biosecurity practices in West Java broiler

farms: The role of farm business type in the control of

avian influenza

Chapter 5

What drives the choice of poultry market channel and

the change of purchase behavior due to Highly

Pathogenic Avian Influenza outbreaks?

Chapter 6

Willingness to pay for poultry meat attributes: A discrete

choice experiment in multi-market channels

Chapter 7

General discussion

References

Summary

Acknowledgements

About the author

Completed training and supervision plan 
Chapter 1

General Introduction 


\subsection{The poultry industry in Indonesia}

Indonesia's poultry sector is growing. The growth in poultry production is mainly taking place in Western Java, that consists of three provinces: Banten, DKI Jakarta and West Java. Western Java is the largest broiler production area in Indonesia and responsible for more than $43 \%$ of Indonesia poultry production in 2016.

Poultry is an important source of protein for Indonesian consumers, as the price of poultry is lower than the price of beef. Indonesian poultry meat production systems are diverse and vary from large (more than 100.000 chickens) to small-scale (less than 100 chickens) commercial poultry farms with broilers, and backyard farms with only a few village chickens, ducks, and geese. More than 3 million people are working in commercial broiler production, and approximately 22 million village households raise chickens in their backyards (United States Agency for International Development, 2013). Poultry production was estimated to reach 1,900,000 tons in 2016 (Statistics, 2018). In 2016, around 83\% of Indonesia's fresh poultry production was dominated by broiler meat (Statistics, 2018). The broiler production is increasing with approximately 5\% per year (Statistics, 2018), while native chicken and duck production is relatively stable. In 2013, the total poultry meat production reached Rp 41.600 trillion ( $€ 1=\operatorname{Rp} 15586$ in 2013) and according to the Survei Sosial Ekonomi Nasional (SSEN), Indonesians spent $9.6 \%$ of their total food budget on poultry consumption (USAID, 2013). Therefore, the poultry industry can be classified as an important sector, both for food security and the Indonesian economy.

However, in 2003, the development of the poultry industry in Western Java, as well as in most of Indonesia, encountered an important setback: the outbreak of Highly Pathogenic Avian Influenza (HPAI).

\subsection{Highly pathogenic avian influenza in Indonesia}

Avian influenza is an infectious viral disease occurring in birds. In aquatic birds the virus often does not cause any apparent signs of illness, but in domestic poultry it causes large-scale outbreaks of serious disease. Moreover, avian influenza can affect humans (Horimoto and Kawaoka, 2001; Tollis and Trani, 2002). Avian influenza viruses are classified as highly pathogenic (HPAI) or low pathogenic avian influenza (LPAI), based on the molecular 
characteristics of the virus and their ability to cause disease in poultry (Liu and Stelzer-Braid, 2014). Highly pathogenic viruses result in high death rates in some poultry species, while low pathogenic viruses cause outbreaks in poultry which are generally associated with mild disease and may even go undetected. Influenza A viruses belong to the Orthomyxoviridae family which are enveloped RNA viruses with an eight-segmented, single-stranded and negative-sense RNA genome. Sixteen hemagglutinin (HA: H1 to H16) and nine neuraminidase (NA: N1 to N9) surface protein subtypes are identified in Influenza A viruses from aquatic birds, however only a few subtypes have established themselves in mammalian species such as humans (HA [H1, H2, and H3]) (Peiris et al., 2007).

In 1997, an outbreak of the HPAI H5N1 virus appeared in Hong Kong. After that, HPAI H5N1 was introduced in Indonesia, initially in Pekalongan in Central Java in August 2003 (Sedyaningsih et al., 2007). The virus continued to spread across the country and infected 27 out of 33 provinces by the middle of 2008. Since then, HPAI H5N1 is considered endemic in Indonesian poultry and poses a major challenge to animal and human health authorities (Food and Agriculture Organization of the United Nation, 2011). The number of HPAI incidents in the Indonesian poultry sector was high until 2007 but, finally, after a decade the number of HPAI incidents decreased. In 2016 and 2017, West Java still had the highest number of incidents; 75 and 29 cases, respectively (Direktorat Jenderal Peternakan dan Kesehatan Hewan, 2017). However, this number may not be accurate, since Idris et al. (2010) found many cases of under-reporting. Therefore, after almost a decade, a combination of the incident cases and the knowledge of under-reporting may indicate that previous control measures were far from effective.

HPAI H5N1 outbreaks have an economic and societal impact, and impose a huge toll on the poultry industry in many developing countries (Peiris et al., 2007; Rushton et al., 2005). Consequences can be found in food security, public health, consumer fear, and economic disruption. In Indonesia, the HPAI H5N1 outbreak affected food security by a decreased poultry production (Basuno et al., 2010) and lowered dramatically the number of farm-raised poultry. After the outbreak in 2005, a decrease in production occurred in: (i) broiler farms by $25-80 \%$, (ii) layer farms: 7-93\% and (iii) duck farms: $48 \%$ (Basuno et al., 2010). Due to the outbreak, $30 \%$ of the Indonesian poultry farms had to close. The Indonesian population also suffered from the consequences of the HPAI H5N1 outbreak. Over one hundred people died because of crossspecies transmission from poultry to humans (Dolberg et al., 2009). The severity of the HPAI 
H5N1 threat to humans in Indonesia is clear from the high ratio of death cases from the human infection. In 2005-2008, 82\% of the reported human cases were lethal (Ministry of Health, 2018). Around $70 \%$ of the human casualties were in West Java.

One of the public health consequences of HPAI H5N1 outbreaks in poultry in Indonesia, is the creation of consumer fear because the disease is endemic. This raised awareness for food safety issues in the poultry meat market and changed the consumers' consumption. A study conducted by Muladno and Thieme (2009) in the Jakarta region, showed a slight change in consumers' purchase behavior as a consequence of the HPAI outbreaks. The number of consumers buying in traditional market channels decreased. The number of consumers who were buying from the wet market decreased from $47.6 \%$ to $42.2 \%$, and those buying from street vendors decreased from $19.3 \%$ to $17.7 \%$. While the number of consumers, buying in the modern channel, such as the supermarket, increased from $19.3 \%$ to $25.0 \%$, an increase of $10.2 \%$ to $11.5 \%$ was seen in dedicated poultry stores.

The government of Indonesia recognized these consequences and classified them as an economic disruption, since, in the short run, HPAI outbreaks changed the consumers' preference in poultry meat consumption (Muladno and Thieme, 2009). The change in consumers' consumption led to lower sale volumes and consequently lower prices, which in turn lead to lower incomes and decreased employment opportunities (Forster, 2014). Additionally, the HPAI outbreak reduced the amount of poultry farms (Basuno et al., 2010). Therefore, in the long run, HPAI could cause a decrease in poultry meat supply, which would result in a price increase for poultry meat as well as for poultry's substitutes and alternatives (Dolberg et al., 2009). This would affect many households with limited resources. Furthermore, the HPAI outbreak mandated the government to initiate restrictive policies and more stringent food safety standards. These policies discouraged new investments and employment initiatives in the poultry sector and its service sector (Rushton et al., 2005; Sofos, 2008).

\subsection{The need for knowledge on the poultry supply chain}

Although the Indonesian government formulated policies to manage the threats and consequences of HPAI, this approach was not holistic due to limited resources and little experience in handling zoonotic diseases. At first, since a contingency plan was lacking, the government set up new rules that implemented key elements to counteract an HPAI threat such 
as: surveillance and diagnosis, biosecurity, quarantine and depopulation, public awareness, capacity building, and vaccination (Dolberg et al., 2009; Swayne and Suarez, 2000). These key elements were costly and their implementation faced difficulties in Indonesia, resulting in a limited effect (Azhar et al., 2010; Ilham and Iqbal, 2011; Loth et al., 2011). Consequently, the Indonesian government switched their policy strategy and focused their efforts on the prevention of bird infections from poultry farms entering the live bird market (Samaan et al., 2011). However, also this approach to control HPAI was not sufficiently effective, because the chain actors did not comply. Reaching compliance was difficult because of the value chain structure, consisting of a high variation in marketing channels. The complexity of value chains with live bird markets, the sale of chickens from different poultry flocks, and the different stages of transport and collection make compliance very challenging (Dolberg et al., 2009). This complexity goes beyond a simple division between traditional (less safe) and modern channels (more safe). It limits biosecurity procedures and creates a continuous threat of HPAI virus spreading. This makes it difficult to implement sustained HPAI control. Moreover, a clear overview of the activities and expected effectiveness of public disease prevention and control activities is lacking.

The implementation of ineffective control measures suggests that the government failed to understand the relation between the governance within the complex poultry supply chain and HPAI introduction and transmission. In order to resolve this lack of knowledge, it is important to generate a comprehensive understanding about the complexity of the poultry supply chain before setting up any new intervention strategy. Previously generated knowledge can be used to identify incentives and to reduce the complexity of the supply chain, and to make the currently available governmental resources for HPAI control in Indonesia more effective. A clear understanding of the Indonesian poultry value chain will be a requisite to design a costeffective control strategy that encourages the actors in the poultry chain to control HPAI (Roche et al., 2014). Hence, it is essential to understand the motivation of the chain actors in the poultry supply chain.

A proper value chain analysis would reach this objective (Rich et al., 2011). Such an analysis will allow the identification of key control points as well as the important actors in the poultry chain (Rushton et al., 2005). The engagement of diverse stakeholders to tackle the disease will be different, depending on circumstances and constraints (Rich and Perry, 2011). Consequently, the development of an effective policy needs to integrate epidemiology and disease economics 
(Rich and Perry, 2011; Rich and Wanyoike, 2010). Integrating epidemiology within a value chain analysis enables a closer look at the coordination of production systems. As such, value chain analysis can reveal the entities that coordinate the interactions between actors in the poultry value chain. A leading entity may influence other actors to participate in a control strategy (Rushton et al., 2005). Identifying the leading entities is important for controlling HPAI. It might be more effective to convince leading actors within a value chain of the importance of HPAI control, than convincing the actors who are performing the actual control measures. Therefore, the combination of value chain governance knowledge and HPAI introduction and transmission, will provide insights in the critical actors involved in HPAI introduction and transmission. Such an analysis can form the basis of an incentive mechanism that influences the inter-relationship between actors and can convince chain actors to improve biosecurity procedures and to invest in disease protection. A comprehensive value chain description, linked with a risk analysis of introducing and transmitting HPAI through the poultry value chain, will provide a clear overview for the government to push changes towards a market structure with lower HPAI risks or to pull chain actors towards a market channel with lower HPAI risks.

Until now, available literature on the poultry supply chain in Western Java mainly describes HPAI transmission. Studies focused on transmission between poultry farms as well as on the movement of live birds (de Glanville et al., 2010; Durr et al., 2016; Henning et al., 2016; Idris et al., 2010; Indriani et al., 2010; Kurscheid et al., 2015; Wibawa et al., 2018). Sudarman et al. (2010) and McLeod et al. (2009) tried to use a value chain approach to examine HPAI transmission in the poultry supply chain. These studies explain the complexity of the poultry supply chain. However, none of these studies provide comprehensive knowledge on the interaction between the chain actors and its consequences for HPAI introduction and transmission. To date, no literature is available on the role of governmental mechanisms in the value chain regarding biosecurity procedures and HPAI control measures. Equally, there are no descriptions on integrating a value chain with risks of HPAI introduction and transmission.

\subsection{The need for knowledge on push and pull strategies to manage HPAI risks}

Efforts to reduce the risks of introduction and transmission of HPAI, either aimed to improve the value chain structure or to implement biosecurity procedures, can follow a push or pull strategy. A comprehensive overview of the value chain provides decision makers a clear 
framework to manage the endemicity of HPAI in the Indonesia poultry supply chain.

A push strategy can be seen as a way that stimulates governments or other value chain actors in poultry production to implement a new, improved, production technology. In this case, the consumers have to accept the final product as it enters the market place. Potential push strategies can be: (i) the implementation of a new technology or production method, (ii) investing in new technologies within the production chain and (iii) the subsidization of service related activities, such as laboratories and advisory services (Horbach et al., 2012; Nemet, 2009). An example of a push strategy to control HPAI spread in Indonesia, was to apply and improve biosecurity procedures in the farming and slaughtering process in the poultry supply chain (Azhar et al., 2010; Dolberg et al., 2009; Ilham and Iqbal, 2011; Loth et al., 2011; Swayne and Suarez, 2000). This included capacity building for the chain actors in the market channels that were thought to be less safe. Since many of the farmers and other chain actors were not actively implementing the proposed measures, it can be concluded that these pushing approaches failed. Governmental incentives did not stimulate the farmers to improve their production. The development of push strategies to control HPAI, should be based on available knowledge on the link and interaction between production activities, organization of the value chain and the economic relationships within the value chain (Kaplinsky and Morris, 2001).

A pull strategy is aimed to convince consumers, the stakeholders at the end of the value chain. Consumers' demand can drive an improved, higher quality poultry production within the supply chain. A pull approach has been described as a potentially successful strategy to induce adaptation and diffusion of innovations (Di Stefano et al., 2012; Horbach et al., 2012; Nemet, 2009). In reviews, the pull approach is described as an integrated approach with regards to policy rationale and consequences for controlling the disease (Daems et al., 2005; Remme et al., 2002). Since consumers are at the end of the chain, they can influence chain actors to improve their production methods and thus meet their preferences. In Western Java, one of the HPAI interventions aimed to move consumers from the less safe traditional channel to the safer modern channel. This intervention was implemented by increasing the consumer's awareness for poultry meat safety and by actively supporting the introduction of better market channels. Another effort was the development of the ASUH program by the Jakarta provincial government. ASUH is a program that educates the consumer to buy poultry meat that fulfills four criteria: Aman (Safe), Sehat (Healthy), Utuh (Wholesome) and Halal. However, these efforts had only limited success. The program was not based on a clear knowledge of the 
demand and behavior of the consumer. Moreover, there was no knowledge on the potential motivation of consumers to switch between market channels. Therefore, obtaining a better understanding of the behavior and preference of consumers in their market channel choice and the relationship between HPAI infection, are key to determine the potential success of a pull strategy. Such knowledge may define a strategy to influence the consumers and pull poultry producers towards a production system with reduced risk of introduction and transmission of HPAI, therefore improving the control of HPAI.

In theory, the push and pull strategies target different aspects: the push strategy is aimed at onfarm and production measures, while the pull strategy is aimed at the voluntary improvement in the chain. However, in practice, governmental interventions may aim for a combination of both approaches, where consumers are able to pull for a safer product, while push interventions create the same result from the other side of the value chain. It is doubtful, however, that a pull strategy would be able to completely move the poultry sector towards a situation of sufficient HPAI control. Therefore, a pull strategy should always be seen as an addition to a push for improved production circumstances. Like in many other countries, a combination of governmental mechanisms should push the production towards a certain level of disease control and food safety. While on the other side, the consumers' demand should initiate the implementation of certification programs to further improve food production safety.

In order to successfully implement a pull strategy, to improve the value chain structure regarding HPAI introduction and transmission, the government needs to understand the interrelationship between actors that influence human behavior and the organizational inter-linkages between market outlets and production (Rich and Perry, 2011). Such insights will highlight the impact of human behavior and their reaction to disease risks. Moreover, such insights should address how consumer behavior can influence poultry production and investments, and should encourage changes in the complex poultry chain (Chitchumnong and Horan, 2018; Gramig et al., 2009). Solid knowledge will provide clear information for the government to choose between a push strategy, pull strategy or a combination of both as to mitigate HPAI spreading.

\subsection{Problem statement}

The knowledge on mitigation of HPAI in the Indonesian poultry chain is scattered and not integrated. The complex structure of the Indonesian poultry meat value chain is an important 
reason for the limited efficacy of HPAI control in Indonesia so far, and future knowledge about control of HPAI should be developed in light of this value chain. The effect of possible intervention strategies should be studied in relation to integrated knowledge on HPAI transmission through the value chain in combination with knowledge on the behavior of the chain actors. Existing value chain analyses do not provide sufficient insights in human behavior related to HPAI introduction and transmission. Governmental efforts to mitigate HPAI can push and/or pull the supply chain towards better management. An important management area where the push strategy can focus on, is farm biosecurity. There is no structural information available on broiler farm biosecurity in West Java. Yet, this type of knowledge could be used to identify measures farmers implement to reduce the risk of HPAI introduction or transmission. Moreover, it would be interesting to establish which factors influence biosecurity levels on broiler farms, information that can be used to consider incentive mechanisms to improve the level of farm biosecurity. Another approach to reduce the probabilities of introduction and transmission of HPAI in the poultry chain, is via the consumers' demand: a pull approach. It is known that some consumers did change their behavior after the HPAI outbreak. When the demand of consumers changes, farmers and other actors are forced towards better management. Demand of consumers can be influenced by the government. In order to design an effective pulling strategy, the government needs more knowledge about consumers' behavior linked to their market channel choice and poultry meat consumption preferences; knowledge that is currently lacking in the Indonesian context.

\subsection{Research objectives}

The overall objective of this research is to improve our understanding of how to implement a push-and-pull strategy in the poultry supply chain to control HPAI infection in Western Java. More specifically, this study investigates the poultry value chain in Western Java in relation to consumers' behavior and governance of the value chain. Specific objectives of this thesis are:

1. To assess the complexity of poultry value chain structures and their influence on HPAI control in Western Java, paying particular attention to the relationship between value chain structures, actors, governance, and economic performance;

2. To assess the probability of HPAI introduction and transmission throughout the poultry value chain;

3. To assess how micro governance of the farms and other factors influence biosecurity procedures on broiler farms in Western Java; 
4. To assess the factors that influence the consumers' choice of poultry market channels and consumers' demand after the HPAI outbreak;

5. To evaluate consumers' preferences and willingness to pay for poultry meat attributes.

\subsection{Thesis Outline}

This thesis consists of seven chapters. It starts with a general introduction (this chapter) and closes with a general discussion. Each of the five other chapters, addresses one of the research objectives defined in section 1.6.

Chapters $\mathbf{2}$ and $\mathbf{3}$ provide insights in the poultry value chain. Chapter $\mathbf{2}$ provides an assessment of the complexity of the poultry value chain structures and their influence on HPAI control in Western Java (objective 1), based on existing literature and a number of workshops. Chapter 3 describes a qualitative assessment of the probability of HPAI introduction and transmission for all actors in the poultry value chain structure (objective 2). Chapter 4 is based on data collection on more than 400 broiler farms in the Western Java province and examines the uptake of biosecurity at broiler farms. Moreover, by looking at the determinants for the uptake of biosecurity measures, insights in the micro governance of the farm business types regarding the adoption level of biosecurity management were obtained (objective 3 ).

Chapters 5 and 6 aim to get a better understanding of the pull strategy and whether this strategy might be successful in the Western Java poultry value chain, by focusing on the purchasing behavior of consumers. Chapter 5 describes a consumers' study (with more than 1,000 respondents) providing the factors that influence the poultry market channel choice and the consumers' change of purchase behavior due to HPAI infection. Chapter 6 describes a consumer study (with 430 respondents) on preferences and willingness to pay for poultry meat attributes in two market channels in the Greater Jakarta area, namely the modern and traditional channel.

Finally, chapter 7 summarizes the findings described in this thesis and reflects on the integrated research approach and methods applied. Moreover, the implications for HPAI control in Western Java, as well as the future research directions, are discussed in the general discussion. 


\section{Chapter 2}

\section{Linking Supply Chain Governance and Biosecurity in the Context of HPAI control in Western Java: A Value Chain Perspective}

Authors: Dikky Indrawan, Karl M. Rich, Peter van Horne, Arief Daryanto, Henk Hogeveen

Published in Frontiers in Veterinary Science, Volume 5 (May 2018) Article 94 DOI: https://doi.org/10.3389/fvets.2018.00094 


\section{Abstract}

Despite extensive efforts to control the highly pathogenic avian influenza (HPAI), it remains endemic in Western Java, Indonesia. To understand the limited effectiveness of HPAI control measures, it is important to map the complex structure of the poultry sector. The governance of the poultry value chain in particular, could play a pivotal role, yet there is limited information on the different chain governance structures and their impacts on HPAI control. This article uses value chain analysis (VCA), focusing on an in-depth assessment of governance structures as well as transaction cost economics and quantitative estimates of the market power of different chain actors, to establish a theoretical framework to examine biosecurity and HPAI control in the Western Java poultry chain. During the research, semi-structured interviews were conducted with key value-chain stakeholders, and the economic performance of identified actors was estimated. Results indicated the co-existence of four different poultry value chains in West Java: the integrator chain, the semi-automated slaughterhouse chain, the controlled slaughter-point chain, and the private slaughter-point chain. The integrator chain was characterized by the highest levels of coordination and a tight, hierarchical governance. In contrast, the other three types of value chains were less coordinated. The market power of the different actors within the four value chains also differed. In more integrated chains, slaughterhouses held considerable market power, while in more informal value chains, market power was in the hands of traders. The economic effects of HPAI and biosecurity measures also varied for the identified actors in the different value chains. Implementation of biosecurity and HPAI control measures was strongly related to the governance structure of the chain, with interactions between different chains and governance structures accentuating the risk of HPAI. Our findings highlight that a proper understanding of the chain governance structure is vital to improve the effectiveness of HPAI control measures, by making the interventions more specific and fit-for-purpose given the incentive structures present in different chains.

Keywords: value chain analysis, HPAI, chain governance, diversity of transactions, transaction cost economics, biosecurity 


\subsection{Introduction}

Highly pathogenic avian influenza (HPAI) H5N1 is an important endemic disease in Indonesia (Eagles et al., 2009; Santhia et al., 2009). HPAI outbreaks negatively affect public health but also food safety, social wellbeing and the broader economy. HPAI has been difficult to control in Indonesia for a variety of reasons. These include the limited capacity for pre-requisite programs that address HPAI prevention, limited disease surveillance activities, and low levels of public health regulation. Likewise, the Indonesian government has had difficulties implementing its planned HPAI control programs. For instance, vaccination at the farm level has not been effectively implemented (Ilham and Iqbal, 2011), while surveillance activities for HPAI through the Participatory Disease Surveillance and Response program have had only limited success (Azhar et al., 2010; Loth et al., 2011). There were many cases of under-reporting of HPAI due to farmer fears for mandatory culling without proper compensation (Idris et al., 2010). Efforts to apply biosecurity measures in both the small-scale commercial (termed "sector 3 " by the Food and Agriculture Organization (FAO) of the United Nations) and backyard (sector 4) poultry farms were largely unsuccessful. The proximity and mutual interaction of both types of smallholder poultry systems often reinforce disease dynamics and perpetuate recurrent "infection cycles" of HPAI (Idris et al., 2010).

An important underlying reason for the failure of HPAI control programs in Indonesia lies in the organizational and institutional structure of the poultry sector (FAO, 2011). The structure of rearing and selling poultry comprises all activities and interactions from farmer to consumer, and in Indonesia, that structure is complex with multiple links and interactions. Although the Indonesian poultry sector consists of a number of different value chains, there is a noteworthy lack of understanding of the structure of the existing value chains, the nature of value chain links and interactions, and how the poultry sector structure affects efforts to control HPAI. As noted by Rich and Perry (2011), "weak" links in the chain can compromise control efforts at other stages, and as such, it is crucial to identify the incentives and pressures that drive these actors to work in "sub-optimal" ways from a disease control standpoint (even if economically rational). Therefore, understanding poultry value chain structures and their influence on HPAI control is important to develop incentives that drive chain actors to implement control measures. This can be achieved by employing value chain analysis (VCA) to analyze the marketing and governance structure of value chains. 
An often overlooked aspect of the value chain is its governance structure, defined as the mechanisms that drive the coordination of transactions between actors. Value chains can be tightly governed through contracts or vertical integration where demands for quality or other product attributes are necessary. By contrast, transactions in traditional chains are simply governed by price and availability. Insight into the governance structure further reveals the power relations, which can be expressed in terms of diversity of transactions. When transactions are coordinated by a dominant chain actor, the ability of, or incentives for certain actors to comply with disease control will be affected.

Given our interest in linking VCA results to the control of HPAI, we used transaction cost economics (TCE) to relate governance to biosecurity practices (Williamson, 1989). Which type of governance minimizes transaction costs depends on the relationship-specific investments (asset specificity) (Williamson, 1989). Investments in biosecurity are one form of assetspecificity. In the case of HPAI control, these investments can be seen as risk mitigation practices that bind partners into tighter forms of coordination and improve incentives to control disease. In Indonesia, biosecurity investments and practices vary across different forms of value chain governance. Differences in biosecurity practices cause different risks of HPAI incursion within and between poultry chains. Moreover, where multiple types of value chain governance co-exist, there could be a variety of market and governance failures that spill over across different chains, driving the endemicity of HPAI. Since dominant actors may have a more significant role in the control of HPAI, we need to identify those actors that govern the chain. One approach to identify the dominant actor is by evaluating the chains' economic performance and the distribution of profits over the various actors within the value chain (Kaplinsky and Morris, 2001). A proper understanding of the poultry value chain and its governance is vital to drive improved adoption of HPAI control strategies of different value chain stakeholders (Rich and Perry, 2011).

Research applying VCA in the context of animal diseases has emphasized the importance of the value chain perspective to evaluate livestock disease management strategies. VCA provides information on the flow of materials, resources, commodities, and value-adding activities between the different parts of the value chain (e.g. Rich and Wanyoike (2010), Rich et al. (2011), FAO (2011), Martin et al. (2011), Paul et al. (2013), Antoine-Moussiaux et al. (2017)). In the context of HPAI in Indonesia, research adopting a value chain perspective has been limited. Existing literature includes study chronicling the HPAI situation on Java (Sumiarto and 
Arifin, 2008); a case study of HPAI in Bogor (Sudarman et al., 2010); a qualitative risk assessment of HPAI (Idris et al., 2010); a study examining the alignment of poultry sector actors with avian influenza control in Indonesia (Willyanto et al., 2010); and a study identifying risk factors of HPAI (Loth et al., 2011). These research outputs from the International Livestock Research Institute (ILRI) and the FAO highlight the complexity of different poultry value chains in Indonesia, but do not provide an in-depth assessment of governance structures or the diversity of transactions with respect to HPAI control. Sudarman et al. (2010) come closest in this regard, but their focus is more holistic, zooming on the chain rather than on governance as such.

The objective of this study is to assess the complexity of poultry value chain structures and their influence on HPAI control in Western Java, paying particular attention to the relationship between value chain structures, actors, governance, and economic performance. The study focuses on relations across different types of actors and does not explore the horizontal links within different chain nodes or public governance. The study provides an in-depth discussion of the poultry chain that explains critical control points for HPAI and where policy can more effectively intervene taking the complexity of the marketing chain into account. More detailed information about governance and transaction diversity in Western Java will improve our understanding of the poultry value chain, and the role governance plays in shaping economic motivations and behavior of value chain actors. Thus, such information can be used to incentivize all actors to participate in fit-for-purpose HPAI control strategies in Western Java.

\subsection{Analytical and theoretical framework}

To understand the diversity of transactions and governance structures of the poultry value chain, we used three complementary approaches. We first performed a value chain analysis (VCA), following Kaplinsky and Morris (2001), and applied it in an animal health context as in Rich and Wanyoike (2010). This was followed by an analysis where we linked governance typologies to biosecurity practices (Gereffi et al., 2005; Kaplinsky and Morris, 2001; Williamson, 1989). Finally, from the first two approaches, we derived quantitative estimates of economic performance (Kaplinsky and Morris, 2001). The results from these three approaches were combined to assess the risk factors of HPAI introduction and transmission, and the consequences of HPAI in the absence of government intervention. 
First, VCA was used to construct the network of input-output relationships of the poultry supply chain. VCA tools allow practitioners to create a value chain map for the traditional and modern channels describing the actors and the nature of value chain governance structures. Value-chains represent the various processes involved in producing goods in the supply chain based on the notion of value-added at the production level. Once a value chain map has been identified, other approaches can be used together with VCA to obtain more insight into the poultry chain.

Second, governance structures were classified through the typology of Gereffi et al. (2005). This typology illustrates the diversity of transactions triggered by the dominant actor's needs, shifting the degree of coordination, the capabilities in the supply base, the ability to codify transactions and the complexity of transactions in the value chain. In this typology, Gereffi et al. (2005) identified five types of governance structures based on the degree of transaction coordination between value chain actors. The most loosely coordinated mode of governance is through markets, i.e. on the basis of price and availability. A modular form of governance involves customization of a product by a seller to a buyer without any other form of explicit coordination. Relational governance involves transactions facilitated through specific relationships and mutual dependence between buyers and sellers (e.g., family ties). Captive governance typically involves the direct coordination of transactions by the buyer through contracts and the provision of inputs and technical support. Captive governance is often required when product specifications are exacting, necessitating tighter control of transactions by the buyer to ensure quality control. Finally, vertical integration involves transactions taking place solely within one organization or firm to ensure compliance with internal processes, rather than taking the risk of working with independent suppliers.

Using insights from TCE, we identified how different types of value chain governance patterns influence biosecurity practices. TCE helps to justify the rationale associated with different types of coordination (governance) mechanisms (Williamson, 2002). The underlying assumption of the TCE approach is that the actors will choose the governance form that minimizes transaction costs. Three aspects of transaction cost underpin these decisions: the level of asset specificity, the level of uncertainty, and the frequency of transaction. Asset specificity refers to the degree of relationship-specific investments made by two parties to facilitate their transactions. Investments that are highly specific are unlikely to be productively re-used for other purposes, serving to bind actors more closely together. In such cases, tighter forms of coordination, such 
as contracts or vertical integration are required to protect those investments. Similarly, as the level of uncertainty (risk) and the transaction frequency (e.g., the intensity of exchange, number of times the same transactions take place) increase, greater coordination and tighter governance structures may be necessary. We posit that different types of biosecurity practices in different chains may be influenced by the coordination mechanisms associated with the governance structure of the value chain.

Third, we estimated economic performance via VCA to quantify the value added for each channel. Kaplinsky and Morris (2001) define power as the ability of one party "to force other parties to take particular actions" or "to be deaf to demands of others". Our power estimation used the value chain structure to estimate chain conduct in terms of price and quantity decisions. The estimated profits and the profitability were used as a measure of economic performance. Economic performance is an essential parameter to understand the pattern of returns as part of distributional outcomes in the value chain, showing the added value (output value minus input costs) for each link of the chain (Kaplinsky and Morris, 2001). The share of chain value added can be an indicator of a firm's power, but qualitative indicators can be more relevant. Chain actors with a relatively high economic performance (profitability) can be seen as actors with a relatively high market power. They are able to exploit high prices and/or create barriers to entry (Kaplinsky, 1998). Knowledge about the share of chain value added can support other indicators that analyze power asymmetries such as the market structures (the number of buyers versus the number of sellers), the degree of dependence between buyers and sellers, and the characterization of the governance structures.

Finally, we assessed the risk factors of HPAI introduction and transmission and the consequences of failure to control HPAI in the chain. We looked at the enabling conditions generated under the different forms of value chain governance. Four factors can be used to identify the risk of HPAI introduction and transmission in relation with the value chain map, governance structure and the implementation of biosecurity: (1) the number of actors involved (Ssematimba et al., 2013), (2) the frequency of contacts with a possible source (Ssematimba et al., 2013; Van Kerkhove et al., 2009), (3) the number of links within the chain stages (Martin et al., 2011) and (4) the contact structure in the poultry chain (Loth et al., 2011; Martin et al., 2011; Paul et al., 2013; Ssematimba et al., 2013; Van Kerkhove et al., 2009). These four factors can be assessed based on the value chain map, the governance typologies present in each chain, and how they relate to the biosecurity practices in place. 


\subsection{Materials and methods}

Table 2.1 shows the relation between the theoretical framework and the data collection process, and provides details on the specific actors interviewed during the study. We carried out three workshops, seven site visits and 26 in-depth interviews with several key value chain stakeholders, to assess the governance and biosecurity practices in the different identified poultry value chains. The data collected during the early phases of our research were validated in later steps. This enabled us to make a thorough assessment of governance in the poultry value chain, as compared to more conventional VCA studies. The interviews were based on semistructured questionnaires. We specified the questions for the typology according to Gereffi et al. (2005) on the degree of coordination, the capabilities in the supply base, the ability to codify transactions and the complexity of transactions. Questions regarding TCE were aimed at three aspects: the level of asset specificity, the level of uncertainty, and the frequency of transactions within each chain. We interviewed the respondents about biosecurity practices based on the FAO poultry biosecurity guidelines.

The different workshops also provided information about (1) actor roles in coordination mechanisms such as the setting of product and process standards (for biosecurity and food safety); (2) the monitoring of performance, environmental standards, labor standards and conformance to ISO and HACCP standards; and (3) the different roles of actors in the implementation of sanctions whenever the performance of other actors within their chain does not meet the pre-specified requirements.

The key value chain stakeholders interviewed in this study were the Federation of the Indonesian Poultry Society (FMPI) (the only organization uniting all poultry actors in the region), the slaughter-house association (ARPHUIN) that represents the modern chain, the Union of Farmers Association (GOPAN) in Indonesia, the Poultry Farmers Association (PINSAR) representing the major group of farmers in Indonesia, the traditional private slaughter-point associations, and two government agencies (the agricultural agency and a regional office). We also interviewed other actors such as consultants and representatives from meat-specialty stores, the banking sector and academia. 


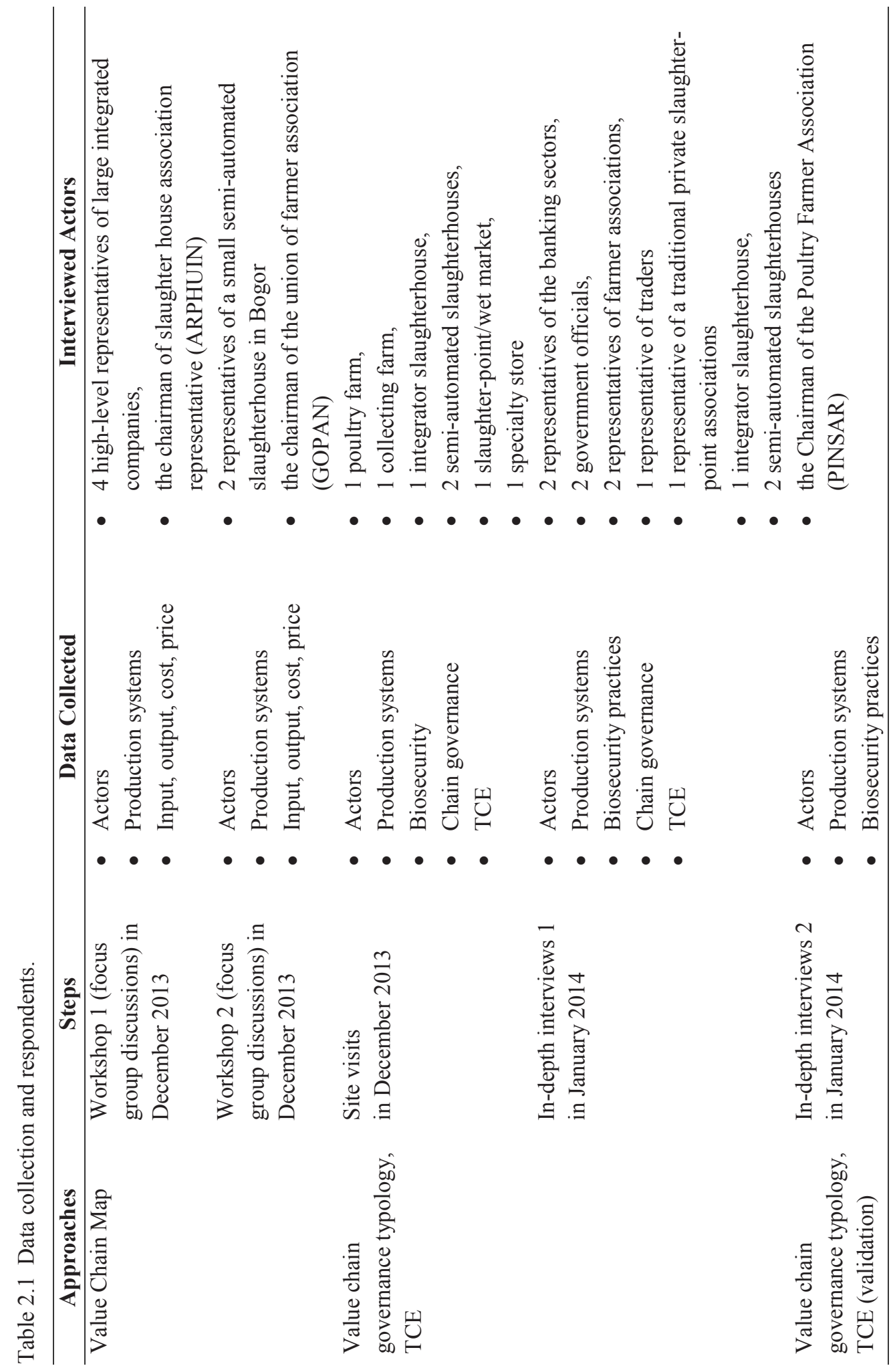


Chapter 2

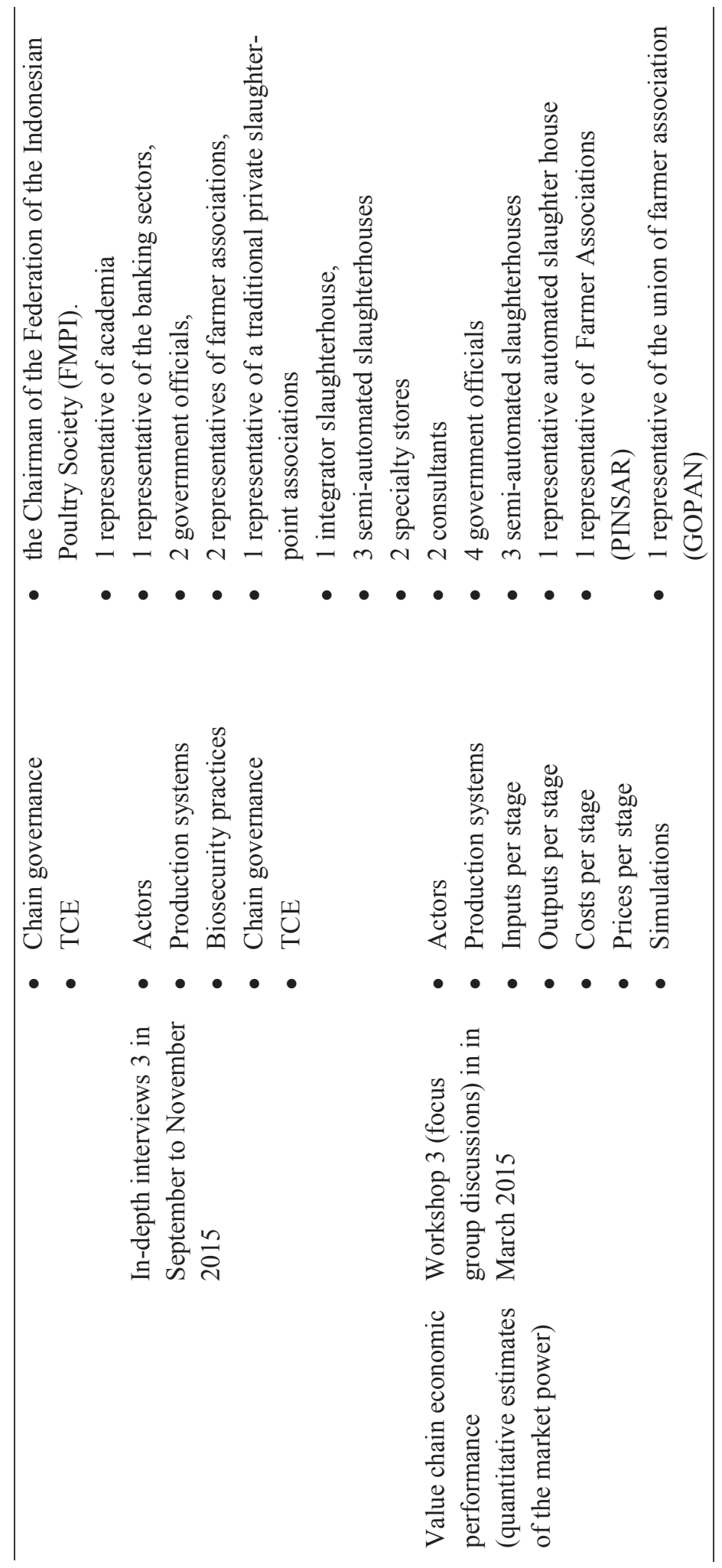


The data were processed in five steps. First, the value chain map was drawn and completed with the number of actors. Subsequently, the map was classified based on the governance typology. Third, we calculated the economic performance of the governance structure using quantitative estimates. Fourth, we linked details on the value chain governance structure using TCE and the assessment of biosecurity practices. Lastly, we linked the governance structure with the economic consequences of HPAI in the absence of government intervention.

Quantitative estimates of the market power of different chain actors were based on enterprise budgets for each chain actor group by estimating costs of input, returns, and added value.

1. The output of Western Java poultry production was estimated based on the situation in 2013 using secondary data from the Agricultural Census (Statistics, 2014). Total farm output was based on the number of broilers in three provinces: West Java, Banten, and DKI Jakarta.

2. The total farm output of Western Java was divided over the traditional and the modern channels. Since no exact information on the distribution of output over the chains was available, we made an estimation based on the focus group discussions and interviews. We assumed that farms in sectors 1 (industrial and integrated farms) and 2 (commercial poultry production with high biosecurity farms) served the modern channel and that farms in sectors 3 (commercial poultry production with low biosecurity farms) and 4 (village or backyard poultry farms) served the traditional channel. The output of these four farm types was distributed over the slaughterhouses and collecting points in their respective value chains.

3. For each actor group in the identified value chains, we calculated output in kilograms of poultry products based on the available knowledge on production size. Since weight was used as the unit of output, farm output was measured in terms of weight of delivered poultry, while slaughterhouse output depended on the carcass weight

4. For each actor, we calculated fixed costs, variable costs, and added value based on the situation in 2013, using secondary data from the Agricultural Census (Statistics, 2014).

5. Revenues were calculated as the output of products multiplied by the product market price (average yearly price in 2013).

6. Finally, for each actor group, we calculated the profitability per chain stage (based on a cycle of production activity for farmers, and on a day of selling and production activities for collecting farms and slaughterhouses) by subtracting the costs from the returns. A cycle of production activity for a farmer refers to the growth cycle of poultry from day 1 until harvest. 
7. All calculations were made in Indonesian Rupiah and then converted into Euro using the December 2013 exchange rate.

8. The results are presented as a comparison of total profit margin relative to the total turnover in a given chain. The total turnover was defined as the total sales revenue.

\section{$2.4 \quad$ Results}

\subsubsection{Mapping the poultry value chain}

The analysis revealed two main marketing channels for poultry in West Java, which are illustrated in Figure 2.1. These channels were classified as the modern and traditional channels only serving the domestic market. The two marketing channels provide poultry meats with different characteristics. The modern channel produces cooled and frozen poultry meat, while the traditional channel produces freshly cut poultry meat without refrigeration or freezing. Therefore, these channels attracted different consumers with different preferences for poultry meat. Within these two channels, four specific chains could be distinguished: the integrator chain and the semi-automated slaughterhouse chain in the modern channel, and the controlled slaughter-point chain and the private slaughter-point chain in the traditional channel. Figure 2.1 illustrates the production and financial flows of the four different chains, and identifies the different links within and between the different value chains. The production flows are represented by the downward arrows, while the financial flows are represented by the dashed upward arrows. Stakeholders were characterized as internal or external actors, based on their involvement in the physical transport in the production flows. All stakeholders had both a direct and an indirect influence on the poultry transactions.

Most actors in the Western Java poultry chain were internal chain actors who are physically involved in the meat production and distribution, such as farms, collecting farms, transporters, slaughterhouses, slaughter-points, food processors and retails. These actors differed in number (Figure 2.1) and in their production characteristics. They were involved in transporting live birds and carcasses, using different transportation modes to end consumers. Live birds were produced at farms, and the mode of production depended on the farming system (sectors 1-4). The live birds from sector 1-2 that go to the modern channel were transported directly to the slaughterhouses, while the live birds from sector 2-4 that go to the traditional channel were transported through collecting farms. We noticed a relationship between sector 2 farms from 
the modern channel and the collecting farms from the traditional channel. Transport tools were owned by both slaughterhouses and collecting farms. Collecting farms are poultry shelters where live birds are brought together and sold. There are two types of collecting farms: controlled collecting farms and private collecting farms. The controlled collecting farms operate in a centralized government area, set up by the government to control the spread of HPAI. The government relocated many private collecting farms to a location owned by the government in order to control live bird movements. By contrast, private collecting farms operate in private locations or through home slaughtering. The average weight of live birds was $2.15 \mathrm{~kg}$ for sector $1,1.5 \mathrm{~kg}$ for sector 2 and $1.3 \mathrm{~kg}$ for sectors 3 and 4 . The average carcass weight by sector was $1.46 \mathrm{~kg}$ for sector $1,1.13 \mathrm{~kg}$ for sector 2 and $0.98 \mathrm{~kg}$ for sectors 3 and 4.

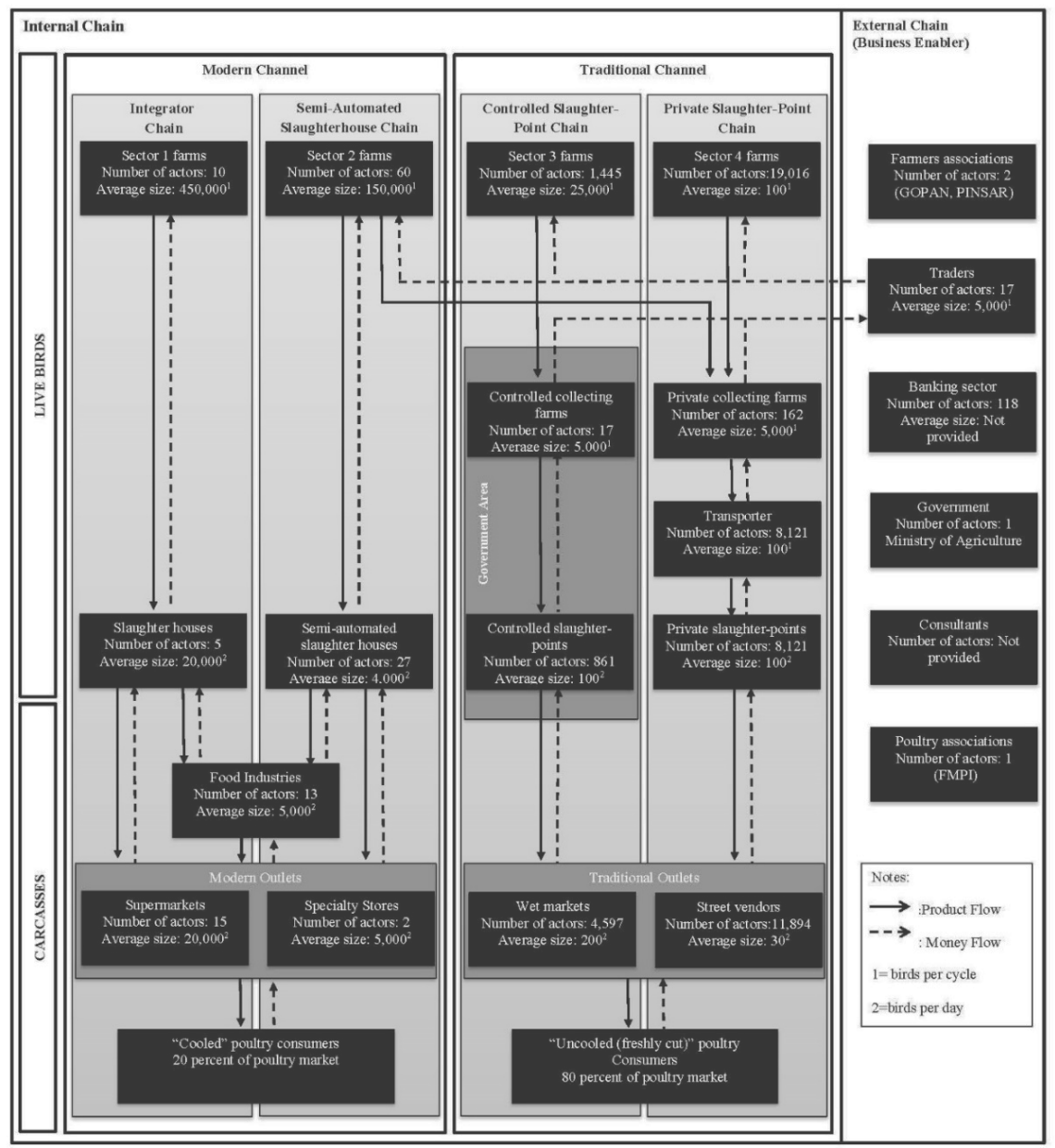

Figure 2.1 Mapping and approximate number and size (in birds per chain stage) of the actors poultry value chain in Western Java. 
Live birds were collected and processed in a slaughterhouse (automated or semi-automated) or slaughter-point (manual process), after which they were sold on the market. Live birds from private collecting farms that were to be slaughtered in private slaughter-points were transported by motorcycle. The transporters were informal actors, working part-time and receiving fees from the private slaughter points for their services. There were four types of slaughterhouse systems: the integrator slaughterhouse, the semi-automated slaughterhouse, the controlled slaughter-points, and the private slaughter-points. The integrator slaughterhouses consists of slaughter plants with modern equipment and holding HACCP, ISO, and state (NKV) certificates. The slaughter process at semi-automated slaughterhouses involves automated general stunning (water bath) and plucking, and transportation in shackles, but with all other work in the plant conducted manually. At controlled slaughter-points an actor that bought poultry from the controlled collecting farms, slaughters it in a centralized government area. Private slaughter-points are private houses in front of which workers slaughter poultry.

The total output was distributed in accordance to the focus group discussion results. The total output from sector 1 was distributed to the integrator chain. We assumed that the excess supply from sector 2 was distributed over the two chains in the traditional channel. Therefore, the higher quality output from sector 2 was distributed to the automated slaughterhouse $(50 \%)$, while the lower quality was distributed to the controlled slaughter-point chain (5\%), and the private slaughter-point chain (45\%). Next, the output from sector 3 was distributed to the controlled slaughter-point chain (10\%), and the private slaughter-point chain (90\%). The total output from sector 4 was distributed to the private slaughter-point chain.

From the slaughterhouses, poultry meat was transported and sold to food processors, modern outlets such as supermarkets, and meat specialty stores. These outlets applied a cold chain and adhered to specific quality standards. Poultry meat from slaughter-points, however, was transported and sold through traditional channel outlets, such as wet markets and street vendors. These outlets sold fresh poultry meat using a temporary structure or mobile stall.

The transaction product flows in the internal chain differed across the modern and traditional chains. In the modern channel, the transactions were coordinated with rules and standards, while the traditional channel engaged in on-the-spot transactions, with low entry barriers but asymmetries in information among actors. 
We identified a number of external actors that played a role in the value chain as business enablers, but were not necessarily physically involved in the production or distribution of poultry meat. One important example are traders at live bird markets. Traders are the individual actors between farmers and collectors. They play a critical intermediary role in terms of providing informal financial support in liaising transactions between farmers and collectors, and secondly they act as brokers matching farmers and collectors. Traders provide farmers with cash payments, and receive payments from collecting farms. This role started after the banking sector left the small and medium scale poultry business without support during the economic crisis of 1997. Transactions were based on the daily spot market, and there were no formal contracts or informal relations between traders and other actors. The banking sector provides business services such as the holding of financial assets and financial services for large companies, but far fewer services for farmers. There was no direct involvement from the banking sector to support investments to control HPAI. A number of organizations worked together with the government to address HPAI. PINSAR and GOPAN are the poultry farmer associations that advocate and support farmers, while ARPHUIN is the slaughterhouse union. FMPI is a poultry federation that facilitates communication and advocates for the poultry business on behalf of all poultry actors. The government plays a role in the food safety system to control the transmission of HPAI in the poultry sector production and market. Independent consultancy companies also played a role in the system through the provision of expert advice on the poultry business or on food safety in the modern channel, for example regarding ISO standards and HACCP certification.

\subsubsection{Governance structures in the poultry value chain}

We found a wide range of governance structures in the different poultry value chains. Based on the typology of Gereffi et al. (2005), we observed the presence of a hierarchy type governance in the integrator chain, modular governance in the semi-automated slaughterhouse chains, and market governance in the controlled slaughter-point and private slaughter-point chains. The other two typologies, the relational and captive governance structure, were not identified in these chains (Table 2.2).

In the hierarchical form of governance in the integrator chain, slaughterhouses acted as the lead firms with explicit coordination of the other actors in the chain. This chain was vertically integrated, employing full managerial control to produce products in-house. The level of 
coordination between actors was high because of the complexity in the requirements for meat quality, including standards for cold and frozen products, size/weight, biosecurity, halal certification, NKV certification, HACCP certification, and ISO certification. Only NKV and HACCP certification standards induced the slaughterhouse as the leader of the chain to control HPAI. These certificates are required for doing business in this chain. Prices and volumes were arranged via material requirement planning to ensure timely supply.

Table 2.2 Types of value chain governance in the poultry meat value chain of West Java.

\begin{tabular}{|c|c|c|c|c|}
\hline \multirow{3}{*}{$\begin{array}{l}\text { Chain } \\
\text { governance } \\
\text { structure } \\
\text { determinants } \\
\text { (Diversity of } \\
\text { transactions } \\
\text { Criteria) }\end{array}$} & \multicolumn{2}{|c|}{ Modern channel } & \multicolumn{2}{|c|}{ Traditional channel } \\
\hline & $\begin{array}{l}\text { Integrator } \\
\text { chain }\end{array}$ & $\begin{array}{l}\text { Semi- } \\
\text { automated } \\
\text { slaughterhouse } \\
\text { chain }\end{array}$ & $\begin{array}{l}\text { Controlled } \\
\text { slaughter- } \\
\text { point chain }\end{array}$ & $\begin{array}{l}\text { Private } \\
\text { slaughter- } \\
\text { point chain }\end{array}$ \\
\hline & Hierarchy & Modular & Market & Market \\
\hline $\begin{array}{l}\text { - Degree of } \\
\text { coordination }\end{array}$ & High & Low & Low & Low \\
\hline $\begin{array}{l}\text { - Capabilities in } \\
\text { the supply } \\
\text { base }\end{array}$ & Low & High & High & High \\
\hline $\begin{array}{l}\text { Ability to } \\
\text { codify }\end{array}$ & Low & High & High & High \\
\hline $\begin{array}{l}\text { transactions } \\
\text { - Complexity of } \\
\text { transactions }\end{array}$ & High & High & Low & Low \\
\hline
\end{tabular}

The modular form of governance was found in the semi-automated slaughterhouse chain, where suppliers had a responsibility to make products or provide services to meet customer expectations. For instance, farmers needed to meet buyer requirements with regard to size, weight and on-farm biosecurity (e.g., isolation, traffic control and sanitation), and the semiautomated slaughterhouses had to provide a product specified by the retailers. In this chain, no private or public standards induced the slaughterhouse as the leader of the chain to control HPAI. A form of contract was used, but the buyer-supplier interactions were limited to the delivery specifications and prices and not via specific, long-term coordination. The traditional channels were characterized by market governance. In these two value chains, transactions were relatively simple, with no formal cooperation between actors. These channels had a low mutual dependence related to reputation, or family and ethnic ties between actors in vertical chain 
stages. The buyers provided suppliers with limited or no information about product specifications. We found diseased poultry was sold in these chains, therefore we labeled them as a "sick" poultry market. Traders had a relatively larger role coordinating the chain as external actors.

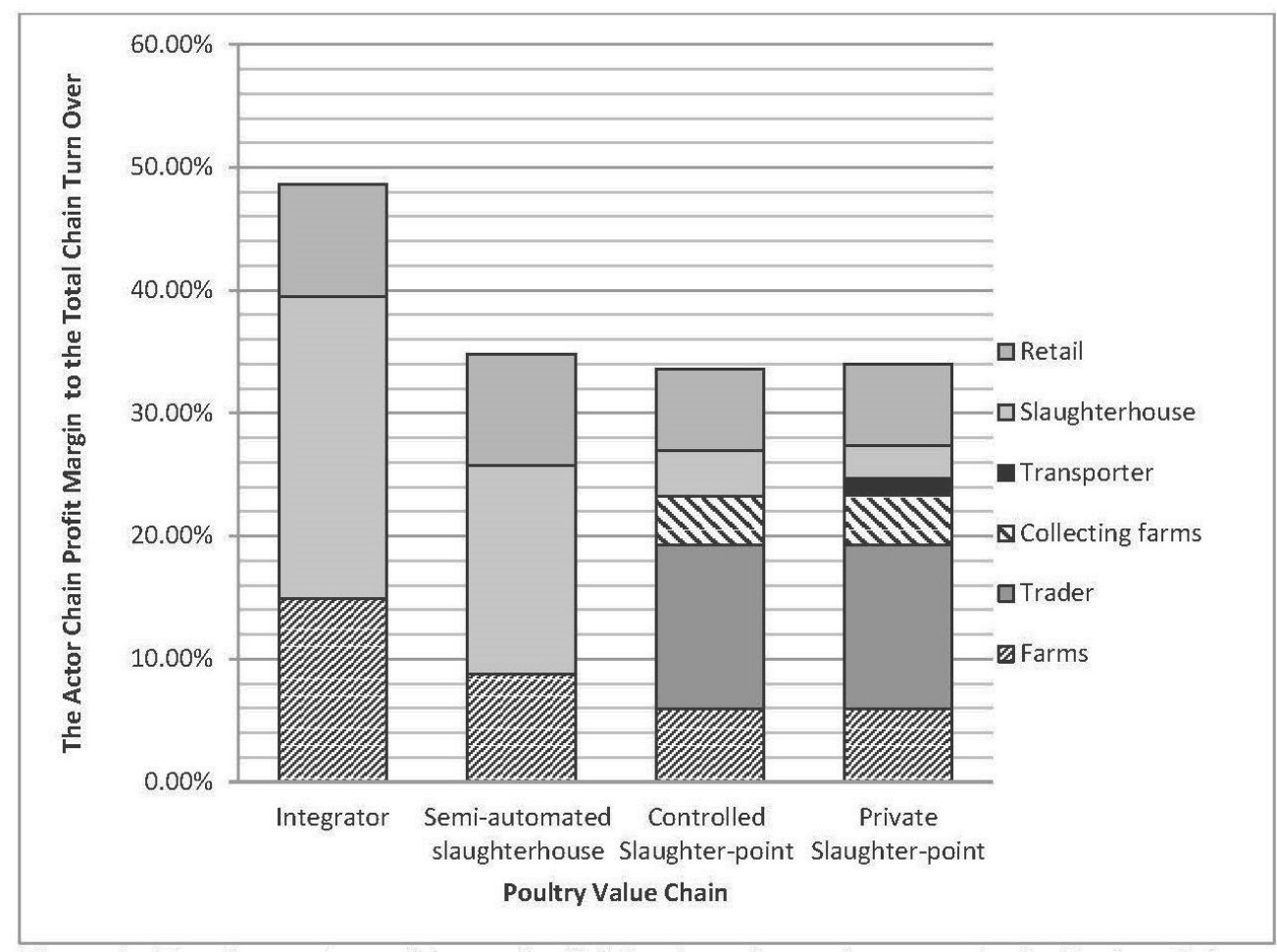

Figure 2.2 The Comparison of Actors Profit Margin to the total turnover in the Poultry Value Chain. The graphic bars represent the joint profit margin contributed by each actor groups to total turnover (total sales revenues) in different chain governance. Each block in the graphic bars represents each actor group profit margin to the total turnover.

\subsubsection{The economic performance of the poultry value chain in West Java}

As illustrated in Figure 2.2, we computed economic performance at chain level as the share of the total profit margin relative to the total turnover in a given chain. We found that the integrator chain had the highest economic performance, because the share of the total profit margin relative to the total turnover was the highest (Figure 2.2). The other three chains had similar but lower profit margins. 
If we look at the distribution of profit within and across the different groups, a number of interesting results emerge. In the modern channels, slaughterhouses had a higher share of the profit margin than farmers and retailers. By contrast, in the more traditional channels, the total profit margin was distributed over more actors, with the largest share captured by the traders. The comparison of actor profit margins within the different chains may illustrate the power of a specific chain actor. In this case, the slaughterhouse seemed to have the highest power in modern channels, while in traditional channels, the highest power was held by traders. Consequently, those who had market power were acting as the chain leader and had the largest influence on chain governance. Indeed, the presence of only a handful of traders compared to the significantly larger number of other actors (Figure 2.1), suggests a form of oligopolistic power held by traders in the traditional channel. The ability of slaughterhouses and traders to drive the value chain is the key determinant to impose biosecurity standards and control HPAI in all forms of chain governance.

\subsubsection{Biosecurity}

We looked at the role of chain governance in the application of biosecurity practices for the four different value chains we identified. We assumed that differences in chain governance influence the risk of HPAI transmission (Martin et al., 2011). In this context, we took a transaction cost economics approach to test our hypothesis as to whether more coordinated chains lead to more investments in biosecurity practices. We differentiated two aspects of biosecurity: (1) the risk of disease introduction, and (2) the risk of disease transmission. The risk of HPAI introduction is the likelihood that the virus enters the value chain, for instance from another value chain. The risk of HPAI transmission is the likelihood of HPAI being transmitted within the value chain, for instance from one stage to the next after introduction of the virus.

Table 2.3 summarizes the biosecurity practices for each value chain type. While three transaction characteristics were observed, the level of asset specificity was most strongly related to the application of biosecurity practices. The other characteristics of transactions, uncertainty and frequency, were not considered by the actors as drivers for the application of biosecurity measures. Inciting suppliers to adopt biosecurity practices could be a way to mitigate uncertainty in the supply chain. Strong hierarchies and tight coordination amongst actors within the integrator chain facilitated a variety of specific investments, including those on biosecurity. 
These included maintaining biosecurity through a compartment system at the farm level (among section 1 farms), while slaughterhouses had stringent quality processes, which were HACCP, ISO and NKV certified. In a well-coordinated value chain, such as for the hierarchical form of governance, it was easier to implement and maintain biosecurity practices and, therefore, wellcoordinated chains were better protected against HPAI introduction and transmission.

Table 2.3 Biosecurity practices and governance forms in the poultry value chains of West Java

\begin{tabular}{|c|c|c|c|c|}
\hline \multirow{3}{*}{$\begin{array}{l}\text { Chain } \\
\text { Governance } \\
\text { Structure } \\
\text { determinants } \\
\text { (TCE } \\
\text { Criteria) }\end{array}$} & \multicolumn{2}{|c|}{ Modern Channel } & \multicolumn{2}{|c|}{ Traditional Channel } \\
\hline & $\begin{array}{l}\text { Integrator } \\
\text { Chain }\end{array}$ & $\begin{array}{l}\text { Semi- } \\
\text { automated } \\
\text { Slaughterhouse } \\
\text { Chain }\end{array}$ & $\begin{array}{l}\text { Controlled } \\
\text { Slaughter- } \\
\text { point Chain }\end{array}$ & $\begin{array}{l}\text { Private } \\
\text { Slaughter- } \\
\text { point Chain }\end{array}$ \\
\hline & Hierarchy & Modular & Market & Market \\
\hline $\begin{array}{l}\text { - Level of } \\
\text { Asset } \\
\text { Specificity }\end{array}$ & High & Medium & Low & Low \\
\hline $\begin{array}{l}\text { - Level of } \\
\text { Uncertainty }\end{array}$ & Low & High & High & High \\
\hline $\begin{array}{l}\text { - Transaction } \\
\text { frequency }\end{array}$ & Low & High & High & High \\
\hline $\begin{array}{l}\text { Biosecurity } \\
\text { Practices }\end{array}$ & High & Medium to low & Low & Low \\
\hline
\end{tabular}

Asset specific investments in the semi-automated slaughterhouse chain (modular governance) were lower than in the integrator chain, because a form of contract (limited to price and weight specifications with general disease status) was used to support transactions within this chain. While contracts between actors included product specifications with regard to disease status, there were no efforts to support the supplier to increase biosecurity in order to fulfill these requirements. Therefore, biosecurity measures were limited in this chain and depended on the efforts of each individual actor to fulfill the contract requirements. Because of the low level of asset specificity in the semi-automated chain, chain actors were able to trade more freely with other partners, increasing the scope of the transaction but with less coordination. Consequently, investments to promote biosecurity were lower. In this chain, sector 2 farms even traded live birds with collecting farms in traditional channels where biosecurity practices were much lower still. As the risk of HPAI introduction in the controlled and private slaughter-point chains was higher than in the semi-automated slaughterhouse chain, sector 2 farms were at relatively high risk of introducing HPAI in their value chain (Figure 2.1). Improving coordination in the semi- 
automated slaughterhouse chain and cutting off trade with the controlled and private slaughterpoint chains would most likely have a large effect on overall HPAI incidence in this chain.

There were no relation-specific investments in traditional channels. Transactions in these chains were based on price and convenience, in the absence of specific biosecurity requirements or coordination. Sick poultry was traded in these channels, and a sick poultry market was established that was also used by the semi-automated chain upon HPAI occurrence. The intensity of physical exchange and thus the risk of HPAI transmission was high. In the controlled slaughter-point chain, limited levels of biosecurity were applied in the sector 2 farms, that also delivered to the collecting farms. The majority of the live birds that came from sector 3 farms were mixed with those of sector 4 farms which applied only a minimal level of biosecurity. No biosecurity measures were applied in the collecting farms, during transport, or at the private slaughter-points.

Other researchers have shown that the type of governance affects actor perceptions of the importance of biosecurity (Paul et al., 2013; Van Kerkhove et al., 2009). This difference in perception influences the implementation of biosecurity practices and hence the risk of HPAI introduction and transmission in the different poultry value chains. We assessed this influence based on the four factors that affect the risk of HPAI introduction and transmission in relation to the value chain map, governance structure and the implementation of biosecurity. As shown in table 2.4, each of the four factors that influenced the risk of HPAI introduction and transmission had a stronger effect in the less coordinated chains. This means that the risk of introduction and/or transmission of HPAI was much higher in the traditional channels as compared to the modern channels. Moreover, the links and contacts between the semiautomated chain and traditional channels created an additional layer of risk of disease transmission. Therefore, the integrator chain provided better protection against HPAI outbreaks as compared to chains with other forms of chain governance.

A TCE perspective highlights that many routes for disease transmission in the value chain were mediated at least in part by investments in biosecurity that arise from the types of governance that exist in the value chain. We found an important risk of backward transmission, e.g., from the markets to the farms or from the slaughterhouses to the farms. Crates and other materials used to transport poultry could act as vectors in the transmission of HPAI. Slaughterhouses were indeed reported to be associated with HPAI outbreaks (Yupiana et al., 2010). Poor 
biosecurity practices at the collecting farms, slaughterhouses, and slaughter-points could lead to infection of farms through interactions between humans, vehicles and crates, especially during the process of returning poultry crates from the market or the slaughterhouses to farms. In order to decrease the risk of introduction or infection in the less coordinated chains, the chain leaders (traders) would need to invest in more formal relationships that include biosecurity requirements, since traders were the only actors with the financial and management capabilities to invest in new production assets. This means that traders should upgrade their role from informal financers of the transaction into more formalized commercial agents, such as financial institutions or collecting farms. This could reduce the number of "infection cycles" in the complex and poorly-coordinated poultry chains. However, traders have no incentive to do so, as improved biosecurity practices do not affect their profits. Indeed, removing the "sick poultry market" would rather reduce trader profitability. This is in contrast with the chain leaders in the modern channels (slaughterhouses) who have incentives (economic performance to protect) to maintain improved biosecurity practices in their chains.

Table 2.4. Risk factors of HPAI introduction and transmission in different poultry value chains in West Java

\begin{tabular}{|c|c|c|c|c|}
\hline \multirow{3}{*}{$\begin{array}{l}\text { Enabling } \\
\text { condition of HPAI } \\
\text { introduction and } \\
\text { transmission in } \\
\text { the chain } \\
\text { governance }\end{array}$} & \multicolumn{2}{|c|}{ Modern Channel } & \multicolumn{2}{|c|}{ Traditional Channel } \\
\hline & $\begin{array}{l}\text { Integrator } \\
\text { chain }\end{array}$ & $\begin{array}{l}\text { Semi- } \\
\text { automated } \\
\text { slaughterhouse } \\
\text { chain }\end{array}$ & $\begin{array}{l}\text { Controlled } \\
\text { slaughter-point } \\
\text { chain }\end{array}$ & $\begin{array}{l}\text { Private } \\
\text { slaughter- } \\
\text { point chain }\end{array}$ \\
\hline & Hierarchy & Modular & Market & Market \\
\hline $\begin{array}{l}\text { 1. Number of } \\
\text { actors involved }\end{array}$ & + & ++ & +++ & ++++ \\
\hline $\begin{array}{l}\text { 2. The frequency } \\
\text { of contact }\end{array}$ & + & ++ & +++ & ++++ \\
\hline $\begin{array}{l}\text { 3. Number of } \\
\text { links in chain } \\
\text { stages }\end{array}$ & + & ++ & ++ & +++ \\
\hline $\begin{array}{l}\text { 4. Contact } \\
\text { structure }\end{array}$ & + & +++ & +++ & ++++ \\
\hline $\begin{array}{l}\text { Total risk of } \\
\text { HPAI }\end{array}$ & + & ++ & +++ & ++++ \\
\hline
\end{tabular}

Note: $+=$ the least likelihood of risk,$++++=$ the highest likelihood of risk 


\subsubsection{The economic consequences of HPAI in different poultry value chains}

The economic consequences of HPAI were influenced by the biosecurity practices in the value chains (Van Kerkhove et al., 2009; Van Steenwinkel et al., 2011; Yupiana et al., 2010). HPAI incidents increased the mortality rate of poultry. Hence, the number of live birds that could be sold was reduced. In theory, a lower supply of poultry, will lead to increased prices at the farm gate in all value chains, and eventually the retail price will increase as well. We assessed these consequences based on the information gathered for the production related to disease incidents, including inputs, outputs, and prices per stage in different chains. Our research, however, indicated different consequences of HPAI incidents in the different value chains. The consequences of HPAI incidents in different identified poultry value chains in Western Java are illustrated in table 2.5 .

Table 2.5 Consequences of HPAI without government intervention.

\begin{tabular}{|c|c|c|c|c|}
\hline \multirow{3}{*}{$\begin{array}{l}\text { Consequences } \\
\text { types (Losses) }\end{array}$} & \multicolumn{2}{|c|}{ Modern Channel } & \multicolumn{2}{|c|}{ Traditional Channel } \\
\hline & $\begin{array}{l}\text { Integrator } \\
\text { Chain }\end{array}$ & $\begin{array}{l}\text { Semi- } \\
\text { automated } \\
\text { Slaughterhouse } \\
\text { Chain }\end{array}$ & $\begin{array}{l}\text { Controlled } \\
\text { Slaughter- } \\
\text { point Chain }\end{array}$ & $\begin{array}{l}\text { Private } \\
\text { Slaughter-point } \\
\text { Chain }\end{array}$ \\
\hline & (Hierarchy) & (Modular) & (Market) & (Market) \\
\hline Production & ++++ & +++ & ++ & + \\
\hline Farm Price Effect & ++++ & +++ & ++ & + \\
\hline $\begin{array}{l}\text { Retail Price } \\
\text { Effect }\end{array}$ & ++++ & +++ & + & + \\
\hline Overall & ++++ & +++ & ++ & + \\
\hline
\end{tabular}

Note: $+=$ the least likelihood of consequences, $++++=$ the highest likelihood of consequences

In the most coordinated chain (integrator chain) HPAI incidents had the most severe consequences (Table 2.5). Because of the biosecurity practices in place, farms were forced to remove sub-clinically infected poultry from their flocks. The removal caused shortages in the supply of live birds (high quality poultry) to the slaughterhouses. Consequently, given the larger volumes traded by integrators, such shortages affected the price at the farm gate and ceased production at the slaughterhouse. The subsequent shortage in meat supply would increase prices at the retailer level. Thus, the reduction in activity would reduce profitability within this chain. 
In less coordinated chains, the consequences of HPAI incidents were less severe (Table 2.5). For those actors ordinarily selling to formal markets, incidents of HPAI allowed actors to switch sales to the traditional channel (Paul et al., 2013), making these chains more resilient to fluctuations in the supply of poultry, but also more prone to new HPAI occurrences. Indeed, the private slaughterhouse chain assisted farmers in the semi-automated slaughter chain to trade their sub-clinically infected poultry. Therefore, during an HPAI outbreak, farmers under modular and market forms of governance (sector 2, 3 and 4 farms) were able to sell their poultry to the sick poultry market and thus mitigate the economic consequences of HPAI at a nodal level. However, the ability to trade across channels depended on the size of the outbreak. When HPAI outbreaks were large, farms in the semi-automated slaughterhouse chain were unable to supply enough poultry to the semi-automated slaughterhouse. In these cases the semiautomated slaughterhouses saw a decrease in production, affecting the farm price of poultry.

In general, the overall consequences of HPAI in situations where market governance prevails were lower than in situations of hierarchy and modular governance. The existence of a sick poultry market in this chain partially mitigated the production consequences of HPAI, leading to smaller effects on farm and retailer prices. Because consumers in traditional channels were less informed about the quality of the product, retailers could sell sick poultry, having only to accept a slightly lower price.

\subsection{Discussion}

In this study, we carried out an extensive value chain analysis, paying much attention to the governance structures in the Western Java poultry system. Our results indicate that the economic consequences of an HPAI outbreak vary for different governance structures. In particular, chains that were more tightly coordinated had more incentive to implement HPAI control measures compared to traditional channels. Therefore, the risk of HPAI introduction and transmission was lower.

Like all value chain studies, our approach was limited by its sampling frame. We implemented a convenience sampling framework for the different actors, given the complexity of value chains and the difficulties in obtaining representativeness among certain types of actors, particularly traders, wholesalers, and processors. Rich and Wanyoike (2010) used a similar approach to extrapolate the broader value chain impact of Rift Valley Fever in Kenya. Although 
a larger sample would allow for a more detailed quantitative validation, our goal was to offer a qualitative view of the governance structure of the poultry sector. Moreover, resource constraints limit the ability of practitioners to carry out extensive informant-based data collection. Therefore, a relatively limited number of semi-structured interviews with key informants is justified for this study.

A number of issues with regard to the effectiveness of HPAI control measures and how they are related to governance can be identified. First, the effectiveness of HPAI control measures depends on the removal of the sick poultry market from the poultry chain. Without this, efforts to control HPAI will not be effective, since the existence of this market has largely removed the economic motivation of farmers and other actors to improve biosecurity. Traders will need to included, but it is unclear whether they will have the economic incentives to cooperate. Without this intervention, motivating actors, upstream and downstream in the chain will be difficult. Second, because of their higher risk of disease introduction and transmission as well as the limited economic incentives to prevent and control outbreaks, government interventions should focus on the less coordinated chains. Nonetheless, more moderately coordinated chains (e.g., the semi-automated chain) should receive particular attention, as they sell to both formal and informal markets, presenting a greater transmission risk. Third, the value chain map shows that traders play an important role as external actors in HPAI transmission. Analyzing chain governance shows that traders have an important decision-making role regarding the distribution of sick poultry to the market. Many control measures did not involve the participation of traders; therefore sick poultry markets have remained viable. Government intervention should aim at upgrading the role of traders from informal to formal commercial agents, such as financial institutions or collecting farms.

Existing coordination mechanisms have resulted in a lack of effective interventions within the traditional poultry sales channels, and improving coordination could lead to better HPAI control. Higher levels of coordination are correlated with improved application of biosecurity measures, thus strengthening coordination will likely reduce the risk of HPAI introduction and transmission in the poultry chains (Martin et al., 2011). Contracts can be implemented, as one form of a coordination mechanism, to improve meat quality and actor revenues (Paul et al., 2013). In turn, contract farming would create incentives to increase biosecurity and remove the sick poultry market. 
On the other hand, increased coordination comes with higher transactions costs. It is not clear whether chain actors possess either the supply-side or demand-side incentives to address coordination without some form of government intervention or regulation. In order to create effective incentives, an intervention policy tailored to different value chains will be required (Paul et al., 2013; Rich and Perry, 2011). For the situation in Western Java, a pull-and-push strategy could be applied. This approach uses economic performance as the main driver to stimulate chain actors to invest in improved coordination mechanisms and to produce healthier, higher quality poultry. The push strategy attempts to give greater incentives to chain actors in poultry production. Such incentives can take the form of bottom-up entrepreneurial support to encourage change (financial, organizational or technical incentives, or market access, property rights, and contracts) or a more direct, top-down regulatory approach. Neither approach is mutually exclusive, and indeed a combination of incentives and penalties is crucial where transactions costs and information asymmetries are high (Gramig et al., 2009). The pull strategy is an incentive mechanism that is aimed at consumers. The pull strategy would try to convince consumers to change their preference towards higher quality poultry. Changes in consumer buying preferences would drive actors in poultry chains to meet consumer demand by improving the coordination of transactions (asset specific investments). Both intervention strategies are costly, therefore proving that the regulatory cost of improving standards and controls is a major consequence of HPAI.

\subsection{Conclusions}

An extensive value chain analysis showed that four different poultry value chains can be distinguished in Western Java: the integrator chain, the semi-automated slaughterhouse chain, the controlled slaughter-point chain and the private slaughter-point chain. These four chains differ in structure, number and size of actors, economic performance, and in governance mechanisms. Moreover, the effects of HPAI vary in the different value chains as well as the effectiveness of HPAI control measures.

A close relationship was found between the poultry chain structure, coordination mechanisms, and the risk of HPAI introduction and transmission. First, the relationship between poultry chain structure and chain governance influences the effectiveness of current HPAI control measures. Second, the diversity in governance implies that there is no "one-size-fits-all" strategy for HPAI control measures that can be applied across different poultry value chains. 
Third, there are fewer economic incentives in less-coordinated chains (traditional channels) to participate in HPAI control programs. This means that in order to improve the HPAI situation in Western Java, it would be advantageous if government intervention improved incentives for better coordination of the different value chains. Improving the institutional infrastructure is a crucial condition for HPAI control to be effective.

\section{Authors Contributions}

DI designed the study, collected and analyzed the data, and drafted the manuscript. The remaining authors provided input on the design of the study, helped interpreting study results, and critically revised the manuscript. All authors have read and approved the final manuscript.

\section{Funding}

DI is funded by an LPDP scholarship. The funder had no role in this study.

\section{Acknowledgments}

The authors would like to acknowledge the Dutch-Indonesian Food Security Program: Poultry \& Dairy Sector (2013-2016), SPIN3-JRP-61 Project and CENTRAS IPB for the data support and collection. DI is thankful to Eko Sugeng Pribadi, Asep Rakhmat and Indhy Aidha for organizing the workshops and field visits.

\section{Conflict of Interest Statement}

The authors declare that the research was conducted in the absence of any commercial or financial relationships that could be construed as a potential conflict of interest. 


\section{Chapter 3}

The probability of highly pathogenic avian influenza introduction and transmission in Western Java poultry chain: linking value chains and expert estimates

Authors: Dikky Indrawan, Arjan Stegeman, Henk Hogeveen 


\begin{abstract}
In Indonesia, several poultry value chains exist in conjunction with each other. The introduction and transmission routes of highly pathogenic avian influenza (HPAI) may differ between these different poultry chains. Consequently, critical areas for control may differ between the poultry value chains and the actors within these chains. However, there is no estimation of the relative importance of the different actors in the Indonesian poultry value chains regarding the probability of HPAI introduction and transmission. To fill this gap, a qualitative risk assessment of HPAI introduction and transmission was employed and linked with a previously established value chain map of poultry production in Western Java. Introduction and transmission probability estimates were determined through expert knowledge elicitation. Results indicated variable HPAI introduction and transmission risks in the different value chains in West Java, ranging from low to very high. Critical actors were all farming sectors, private collecting farms, traditional outlets, and semi-automated slaughterhouses. Linking value chain with an expertisebased estimation for introduction and transmission is an efficient and systematic way to identify opportunities for control measures for developing countries.
\end{abstract}

Keywords: qualitative assessment, HPAI introduction and transmission, value chain map, HPAI, critical control 


\subsection{Introduction}

In 2003, Indonesia experienced an HPAI (highly pathogenic avian influenza) H5N1 epidemic that posed a major challenge for animal and human health (Dolberg et al., 2009). Regardless of the many control measures that were put in place, HPAI is still endemic with continued reports of outbreaks. The Food and Agriculture Organization (FAO) of the United Nations reported that the failure of HPAI control programs in Indonesia was caused by the country's complex poultry production structure (FAO, 2011). The complexity of the poultry production structure generates many routes for HPAI introduction and transmission. A recent study identified that the HPAI introduction and transmission routes and risks differ between marketing channels, each characterized by different governance structures (Indrawan et al., 2018a).

An in-depth overview of probabilities of HPAI introduction and transmission across poultry chains is essential to design effective control measures. Proper knowledge about the importance of the various actors in the value chain can be applied to define strategies and incentives for the reduction of HPAI introduction and transmission risk. However, limited data is available on the influence of various value chain actors on HPAI introduction and transmission and it is unclear what the critical control points are in the value chain. A previous study attempted to examine HPAI transmission and possible critical points for intervention by using value chain mapping (McLeod et al., 2009), however, the overall actors' probabilities of HPAI introduction and transmission remain unclear. As a consequence, we don't know which actors are most important and at what stages of the value chain authorities should control.

Many studies have evaluated HPAI transmission for specific parts of the Indonesian poultry value chain. The main objective of these studies was to analyze poultry farms and the movement of live birds in the market as the source of HPAI transmission. Durr et al. (2016), de Glanville et al. (2010), Idris et al. (2010) and Wibawa et al. (2018) focused on HPAI transmission between poultry farms, while Indriani et al. (2010) and Kurscheid et al. (2015) examined HPAI transmission in live bird markets. Henning et al. (2016) looked specifically at the role of poultry movements in HPAI transmission. Gilbert and Pfeiffer (2012) looked beyond the farms and live birds and described the role of different agro-ecological systems in HPAI transmission. A more comprehensive study in the poultry supply chain used a value chain approach to examine HPAI transmission (Sudarman et al., 2010) and McLeod et al. (2009). Furthermore, Indrawan et al. (2018a) evaluated the role of governance in the value chain with regard to biosecurity and HPAI 
control measures. However, this study only looked at the interaction between different chains and their governance structures. An overall overview of the value chain and its critical actors regarding HPAI introduction and transmission is not available.

The objective of this study is to assess the probabilities of HPAI introduction and transmission for all actors in the poultry value chain. Therefore, we elicited expert knowledge on the probability of HPAI introduction and transmission and linked this information to the value chain map to generate a holistic overview of HPAI in the poultry value chain. This effort bridges the knowledge gap between the poultry value chain and its specific components. The framework will allow a systematic assessment of (i) the probability of HPAI introduction and transmission for individual actors in the poultry value chain, and (ii) identification of the critical actors in the poultry value chain for HPAI introduction and transmission. The study provides an in-depth discussion on the critical value chain actors affecting HPAI introduction and transmission routes.

\subsection{Material and Methods}

\subsubsection{Expertise-based estimation of HPAI introduction and transmission probabilities}

Risk assessment entails the systematic identification and assessment of the probability of an unwanted event and its follow-up consequences (Costard et al., 2014). A poultry value chain map developed by Indrawan et al. (2018a) was used to outline the assessment for the probabilities of HPAI introduction and transmission (Figure 3.1). The poultry map consists of two types of marketing channels: modern channels, which include slaughterhouses and cold chains, and traditional channels, which include live bird markets. Within each channel, two chains can be distinguished based on their governance, resulting in four poultry chains with different governance schedules that manage the interaction among actors. The modern channel consists of the integrator chain and the semi-automated slaughterhouse chain. The traditional channel comprises the controlled slaughter-point chain and the private slaughter-point chain. The integrator chain is the most coordinated one, with a medium-to-high biosecurity practice, directed by the slaughterhouse. The semi-automated slaughterhouse chain is also relatively coordinated with medium-to-low biosecurity control, and is governed by the semi-automated slaughterhouse. The controlled slaughter-point chain is a daily-based transaction chain, directed by traders. The government controls the location for live birds markets and imposes some 
biosecurity measures on the slaughter-points. The private slaughter-point chain is the least coordinated chain with daily-based transactions governed by traders in the absence of any control. Using this map of four chains, we outlined the three different pathways of possible HPAI introduction and transmission in the value chain: HPAI introduction sources from an external chain, HPAI transmission sources from different actors within the chain, and HPAI transmission sources from the same type of actor within the value chain (Figure 3.1).

In the absence of sufficiently detailed quantitative information on HPAI introduction and transmission in the poultry value chain, we used a qualitative risk assessment to create an overall overview of the probabilities for the different poultry chains. A qualitative assessment is commonly used to measure risk in the context of animal diseases and HPAI (de Glanville et al., 2010; Desvaux et al., 2016; Idris et al., 2010; Kelly et al., 2018; Onkundi et al., 2010; Wieland et al., 2011). In a similar approach, we designed a questionnaire for the expertise-based assessment of two indicators: (i) the probability of HPAI introduction or transmission for the defined pathways, and (ii) the uncertainty of the probabilities.

The probability question was designed to elicit estimates on HPAI introduction and transmission for the defined pathways in the value chain. Table 3.1 presents the quantitative interpretation of probability classes used in this study, similar to previous studies by the European Food Safety Authority (2006) and Kasemsuwan et al. (2009). The probability assessment questions were: (i) "what is the probability of HPAI introduction from outside the chain into the chain?" and (ii) "If HPAI is introduced in a farm, what is the probability of transmission to another specific actor (e.g.: farms or collecting farms)?”. Both questions were based on a one-year time period.

Since the respondent's estimate of the probability may be uncertain, we also asked the experts for an estimation of the uncertainty in order to map the quality of the probability estimates for each pathway. Definitions of these uncertainty categories were based on Kasemsuwan et al. (2009) and are presented in Table 3.2. The uncertainty question was combined with the probability question and took the following form: "what is the uncertainty of your answer on the probability estimate?". 
Table 3.1 Quantitative interpretation of defined probability categories in the qualitative assessment.

\begin{tabular}{cc}
\hline Risk & $\begin{array}{c}\text { The probability of HPAI transmission to poultry within a chain } \\
\text { given that the virus has been introduced }\end{array}$ \\
\hline Negligible & $<1 \%$ \\
Very Low & $1-5 \%$ \\
Low & $6-25 \%$ \\
Medium & $26-50 \%$ \\
High & $51-75 \%$ \\
Very High & $76-100 \%$ \\
\hline
\end{tabular}

Table 3.2 Definition of the uncertainty categories associated with the probability estimates.

\begin{tabular}{cl}
\hline $\begin{array}{c}\text { Uncertainty } \\
\text { Category }\end{array}$ & \multicolumn{1}{c}{ Interpretation } \\
\hline Low & $\begin{array}{l}\text { There are solid and complete data available; strong evidence is } \\
\text { provided in multiple references; authors report similar conclusions. } \\
\text { Medium } \\
\text { There are some but not complete data available; evidence is provided } \\
\text { in a small number of references; authors report conclusions that vary } \\
\text { from one another. } \\
\text { There is scarce or no data available; evidence is not provided in } \\
\text { references but rather in unpublished reports or based on observations, } \\
\text { or personal communication. } \\
\text { Authors report conclusions that vary considerably; } \\
\text { there is no data available, no reference, no personal communication, no } \\
\text { experience }\end{array}$ \\
\hline
\end{tabular}

\subsubsection{Data Collection}

The assessment form was filled out by experts, who were selected or recommended during two workshops on HPAI in Western Java, held in October 2017. The first workshop was held with the veterinary faculty at Bogor Agricultural University, and the second workshop with poultry chain stakeholders at the Center for Veterinary Subang. Experts were identified during these workshops based on their knowledge about: 1) veterinary epidemiology, 2) the poultry value chain in Western Java and 3) HPAI. Of the total group of identified experts, 18 were present at one of the workshops, while 75 were not. The former filled out the questionnaire during the workshop. The latter group were sent the questionnaire by email or regular mail. From the second group, 34 experts filled in and returned the questionnaire, of which 29 completely. In total, 47 experts filled in the questionnaire and provided data to estimate HPAI introduction and transmission. Table 3.3 lists background information on participating experts. 
Table 3.3 Background of the experts participating in the qualitative assessment.

\begin{tabular}{cc}
\hline Background & n \\
\hline Animal Health Company & 10 \\
Government officer & 10 \\
Lecturer & 14 \\
Sector 1 Farm & 5 \\
Sector 2 Farm & 2 \\
Sector 3 Farm & 6 \\
\hline Total & 47 \\
\hline
\end{tabular}

\subsubsection{Data Analysis}

As a first step in analyzing the questionnaire results, we compared the median of the estimated probabilities of HPAI introduction and transmission routes through the chain and of the associated uncertainties. We summarized the estimated probabilities in a table, and represented the level of uncertainty with a color code. Via the Mann-Whitney U test we determined whether the probabilities of HPAI introduction and transmission were significantly different between types of farms, categorized as sector 1 (industrial and integrated farms), sector 2 (commercial poultry production with high bio-security farms), sector 3 (commercial poultry production with low bio-security farms) or sector 4 (village or backyard poultry farms).

Secondly, each pathway probability in the value chain was mapped and colored according to the probability of introduction or transmission of HPAI. The association between the mean probability estimate and the mean uncertainty for each chain actor was summarized in a Cartesian diagram.

Finally, we determined which actors are critical in the control of HPAI by examining the probability of HPAI introduction and transmission for different actors in different chains. The selection of critical actors for each chain was based on probability for HPAI introduction from an external chain, probability of HPAI transmission within the chain and the probability of HPAI transmission across actors of the same type in the chain. 
Table 3.4 The comparison between Q25, median and Q75 of the expertise-based estimates of the probabilities of HPAI introduction and transmission and its associated uncertainty. The colors represent the uncertainty level.

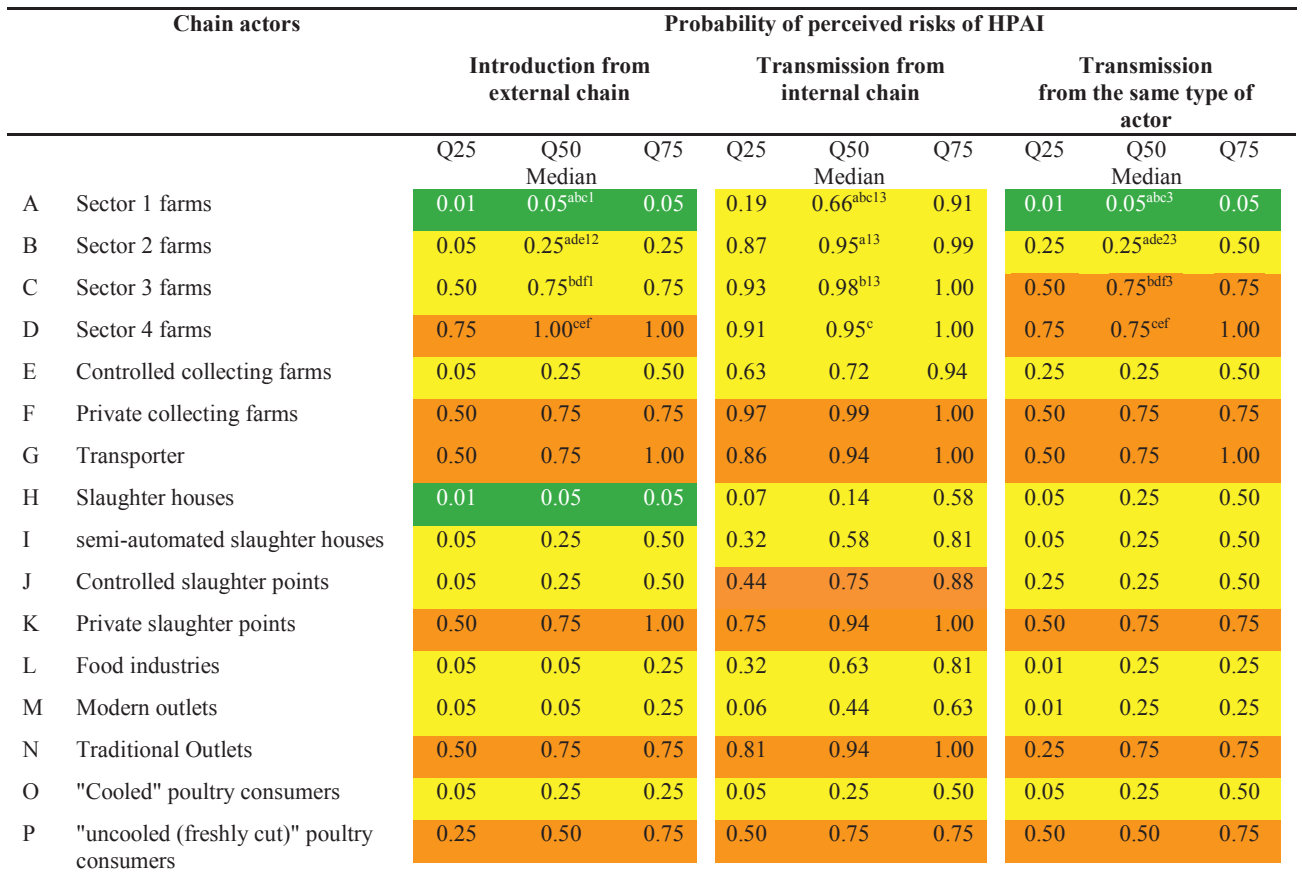

- Mann-Whitney U test. There is a significant difference at the $5 \%$ level between Sector 1 and Sector 2 farms (a), between Sector 1 and Sector 3 farms (b), between Sector 1 and Sector 4 farms (c), between Sector 2 and Sector 3 farms (d), between Sector 2 and Sector 4 farms (e), and between Sector 3 and Sector 4 farms (f).

- Mann-Whitney U-test . There is a significant difference at the $5 \%$ level between the probabilities of HPAI introduction from an external chain and HPAI transmission from an internal chain (1), between the probabilities of HPAI introduction from an external chain and HPAI transmission from the same actor type (2), and between the probabilities of HPAI transmission from an internal chain and transmission across the same actor type (3).

- Color scheme represents uncertainty level:

low uncertainty;
medium uncertainty;
high uncertainty;
unknown uncertainty;

\subsection{Results}

\subsubsection{Probabilities of HPAI introduction and transmission in the poultry value chain}

There was a wide range of expertise-based probability estimates for the three different pathways for each chain actor: HPAI introduction sources from an external chain, HPAI transmission sources from an internal chain and HPAI transmission sources from the same type of actor in 
the value chain (Table 3.4). For all chain actors, except for consumers that consumed "cooled" poultry, the probability of HPAI transmission within the chain was higher than the probability of transmission across actors of the same type or the probability of introduction.

The expertise-based probabilities of HPAI introduction and transmission are categorized into low, medium, high or unknown uncertainty, represented by different colors in Table 3.4. The probability estimates for introduction from an external chain for sector 1 farms had a low level of uncertainty. The majority of probability estimates were associated with a medium level of uncertainty, especially in the transmission from an internal chain. The probability of introduction and/or transmission for the actors in the private slaughter-point chain were mostly associated with a high level of uncertainty.

Differences in the probabilities for HPAI introduction and transmission for each pathway can be described as follows. The probability of HPAI introduction from an external chain was significantly different across different farm types $(\mathrm{P}<0.05)$. Similarly, the probability of HPAI transmission from the same type of actor in the value chain, was significantly different across different farm types $(\mathrm{P}<0.05)$. However, in terms of HPAI transmission within the chain, only sector 1 stood out $(\mathrm{P}<0.05)$ from the other farm sectors. Furthermore, only for sector 2 farms, all introduction and transmission probabilities were significantly different across the three different pathways $(\mathrm{P}<0.05)$.

\subsubsection{Mapping HPAI introduction and transmission in the value chain}

As illustrated in Figure 3.1, the expertise-based probability estimates for HPAI introduction and transmission in Western Java poultry chains were low, medium, high or very high. Negligible and very low probabilities did not occur. The pathways related with the actors in the integrator chain had a low probability of introduction or transmission (represented by a light green arrow). The pathways related to the actors in the semi-automated slaughterhouse chain and the controlled slaughter-point chain had a medium probability (represented by a yellow arrow). All other probabilities were estimated as high or very high by the experts (represented by orange and red arrows).

Figure 3.1 reveals three important findings. First, three very high-risk transmissions could be distinguished: HPAI introduction from an external chain into sector 4 farms, HPAI transmission 
between actors in sector 4 farms, and HPAI transmission from transporters to private collecting farms in the private slaughter-point chain. Second, a high probability of transmission in sector 4 farms may be associated with a high probability of HPAI introduction and transmission to a private slaughter-point chain. Third, there is a substantial probability of transmission between the modern channel and the traditional channel, caused by sector 2 farms and trading activities. The highest probability of transmission was from sector 4 farms to sector 2 farms.

Figure 3.2 represents a plot of the mean probability of introduction or transmission and its associated mean uncertainty. In three different transmission pathways, we found in general that a higher probability estimate is associated with a higher level of uncertainty. The estimated probabilities for transmission within the chain were relatively uncertain. The estimate for transmission sources from an internal chain had a higher uncertainty for all actors. The estimated probabilities for introduction sources from an external chain and transmission sources from the same type of actor in the value chain had a low uncertainty for modern channel actors such as sector 1 farms, sector 2 farms, slaughterhouses, food industries and modern channel outlets. 


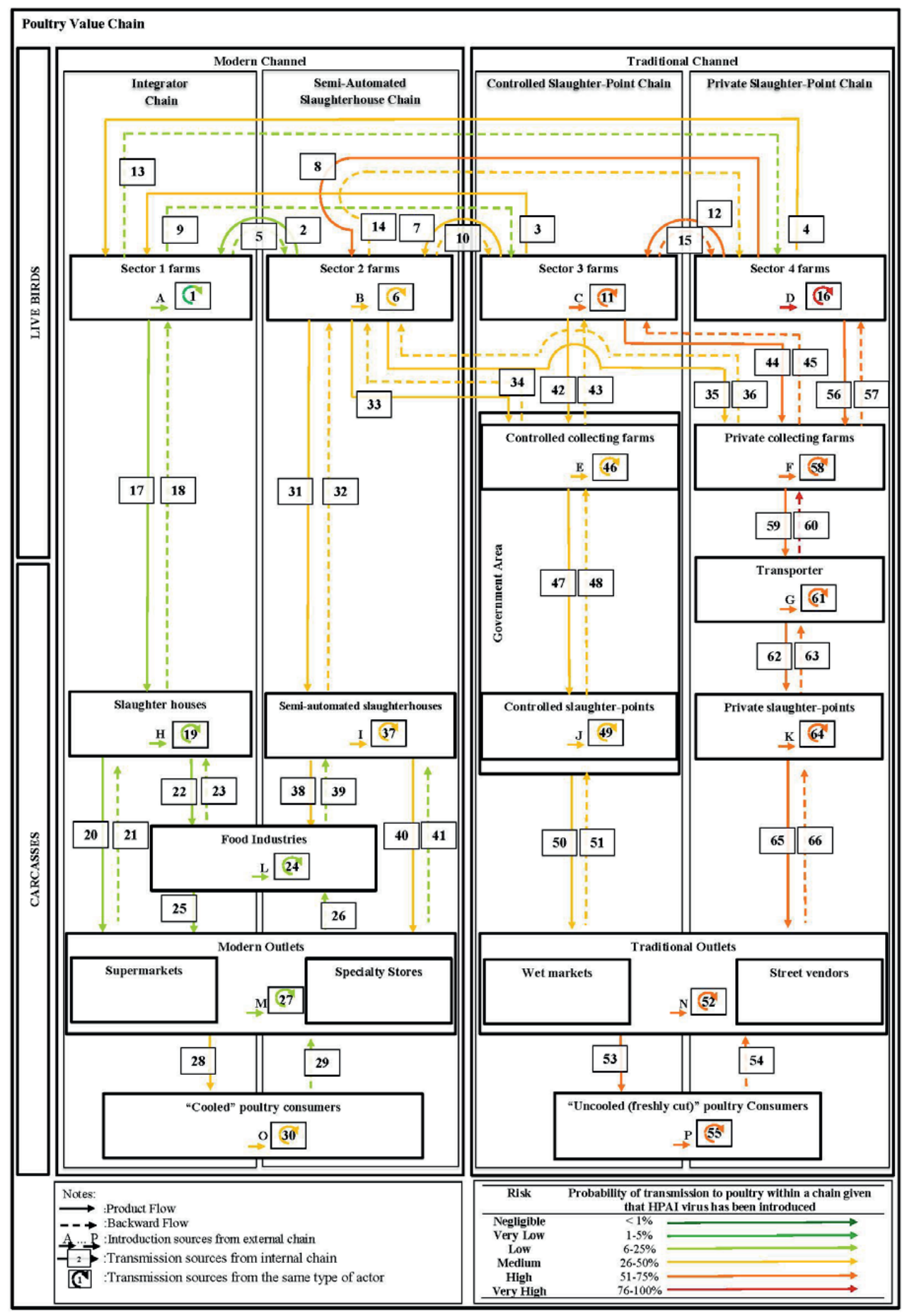

Figure 3.1 Mapping the expertise-based probabilities of HPAI introduction and transmission in the poultry value chains. Capital letters refer to introduction from an outside source, numbers refer to transmission from inside the chain. Colors represent the probability level. 

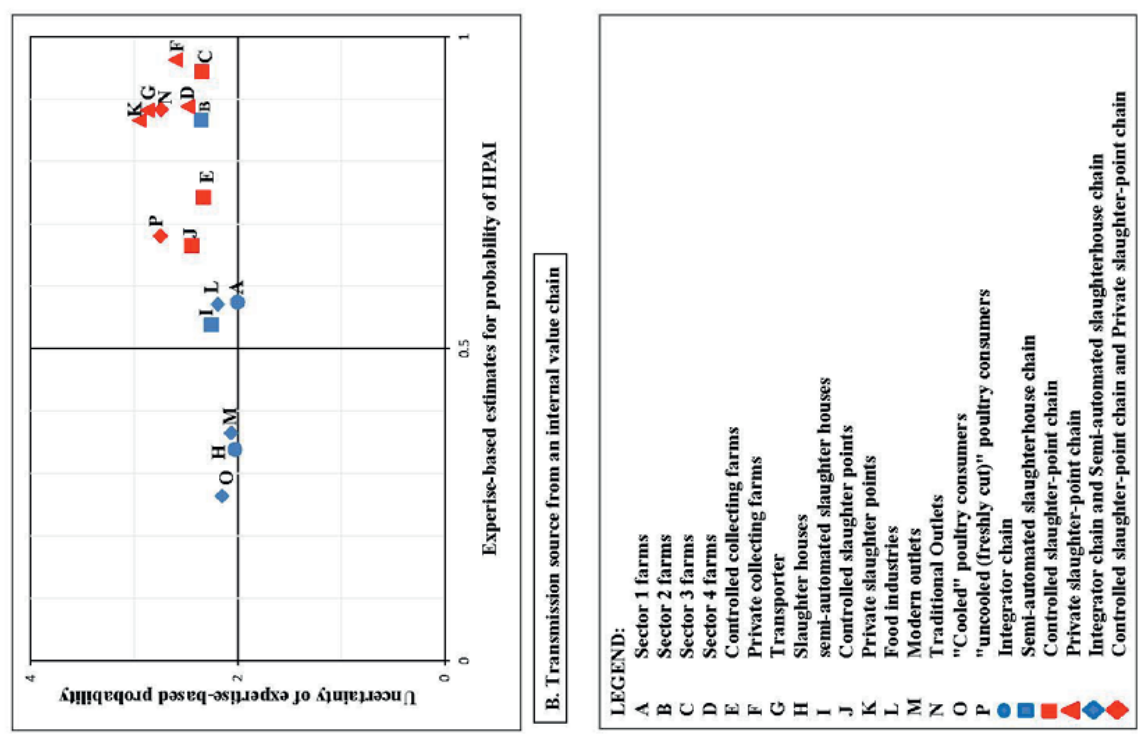

.

త్

光 


\subsubsection{Identification of critical chain actors in the introduction and transmission of HPAI}

Farms were the most critical actors for introduction and transmission of HPAI within the chain (Table 3.5). Sector 4 farms were also the most critical actor for the introduction of HPAI in the private slaughter-point chain. In other chains, various other actors were critical. Sectors 1, 2 and 3 farms were identified as the critical actors for transmission within their chain. In the private slaughter-point chain, the private collecting farms were the critical actor for transmission within the chain. Sector 2, 3 and 4 farms were the critical actors for transmissions across the same type of actor. The traders were not mentioned since they were not involved physically in producing, transporting or processing the live birds.

Table 3.5 Critical actors in the expertise-based probability of HPAI introduction and transmission in the poultry value chains of West Java.

\begin{tabular}{lllll}
\hline Critical actors & \multicolumn{2}{l}{ Modern Channel } & \multicolumn{2}{l}{ Traditional Channel } \\
\cline { 2 - 5 } & $\begin{array}{l}\text { Integrator } \\
\text { Chain }\end{array}$ & $\begin{array}{l}\text { Semi- } \\
\text { automated } \\
\text { Slaughterhouse } \\
\text { Chain }\end{array}$ & $\begin{array}{l}\text { Controlled } \\
\text { Slaughter- } \\
\text { point Chain }\end{array}$ & $\begin{array}{l}\text { Private } \\
\text { Slaughter- } \\
\text { point Chain }\end{array}$ \\
\hline $\begin{array}{l}\text { Introduction sources } \\
\text { from an external chain }\end{array}$ & $\begin{array}{l}\text { All actors that } \\
\text { are involved } \\
\text { with live birds }\end{array}$ & $\begin{array}{l}\text { semi-automated } \\
\text { slaughterhouses }\end{array}$ & $\begin{array}{l}\text { Traditional } \\
\text { Outlets }\end{array}$ & Sector 4 farms \\
\hline $\begin{array}{l}\text { Transmission sources } \\
\text { from an internal chain }\end{array}$ & Sector 1 farms & Sector 2 farms & Sector 3 farms & $\begin{array}{l}\text { Private } \\
\text { collecting } \\
\text { farms }\end{array}$ \\
\hline $\begin{array}{l}\text { Transmission sources } \\
\text { from the same type of } \\
\text { actor in the value chain }\end{array}$ & $\begin{array}{l}\text { All actors that } \\
\text { are involved } \\
\text { with live birds }\end{array}$ & Sector 2 farms & Sector 3 farms & Sector 4 farms \\
\hline
\end{tabular}

\subsection{Discussion}

By combining a value chain analysis with a qualitative risk assessment, a systematic overview of the relation between disease risk, and the actors in and organization of the chain can be obtained. Rich and Perry (2011) emphasized the use of value chain thinking in the integration between disease epidemiology and its relationships with economic behavior. In this line of thinking, Irvine (2015) showed that value chain analysis is a robust systematic framework to evaluate a health surveillance system for poultry. Later on, Antoine-Moussiaux et al. (2017) developed an analysis tool for HPAI surveillance constraints by integrating the value chain with participatory approaches. Indrawan et al. (2018a) were able to link chain governance with HPAI 
biosecurity and this study adds to this line of work. We provided a systematic approach to assess the probability of HPAI introduction and transmission in the poultry value chain. Our study implemented a qualitative risk estimate, based on available expert knowledge. Although there are a number of quantitative studies on transmission of HPAI in the Western Java poultry chain (de Glanville et al., 2010; Durr et al., 2016; Idris et al., 2010; Indriani et al., 2010; Wibawa et al., 2018), there is not enough data to provide a complete overview of the probabilities of introduction and transmission across the different actors and sectors. However, a qualitative approach can be used to organize available transparent information in a setting with unknown risks, when complete data are unavailable (Wieland et al., 2011). Qualitative estimate studies do have limitations, for instance due to an over or under-estimation in the context of a judgement or rough calculation (Wieland et al., 2011). Although it is possible for experts to make probability estimates, they are always associated with a certain level of uncertainty. Therefore, we asked the experts to also estimate their uncertainty about their judgement. In this way, we were able to identify the critical actors with regard to the introduction and transmission of HPAI in the Western Java poultry sector. The obtained knowledge about uncertainty is important in the interpretation of the results, and critical actors, especially those where the level of uncertainty is high, should be the main target of further quantitative research that can confirm the findings or reduce the level of uncertainty. Such results can in turn be the basis for policies that reduce the risk of HPAI introduction and transmission.

Our results indicate that the critical actors differed between the various poultry chains. This might be because of differences in chain governance structures. Various actors involved in live bird production and processing were critical actors in the less coordinated chains such as the semi-automated slaughterhouse chain, or the controlled and the private slaughter-point chains. In the two latter, collecting farms and slaughterhouses were also critical actors. Since the less coordinated poultry chains are characterized by a medium-to-low level of biosecurity, the probability of HPAI introduction and transmission was higher (Indrawan et al., 2018). In contrast, most actors in the more coordinated chains, such as the integrator chain, were estimated to have a low probability for HPAI introduction and transmission. Because of the clear governance in the integrator chain, combined with the obvious economic advantage of biosecurity, the probability of HPAI introduction and transmission was the lowest for sector 1 farms and other actors that handled live birds. While consumers had the highest estimated probability and thus may be considered as the main actors, it is not clear how critical they are in HPAI introduction and transmission. We excluded them from the critical actors, since they 
were at the end of the chain and had no direct impact.

With regard to the critical actors for HPAI introduction and transmission in the poultry value chain, a number of issues can be identified. First, the expertise-based probability estimates in the value chain are linked to the level of governance: HPAI introduction or transmission may be more likely as a consequence of a lower level of governance. The most critical actors in the controlled and private slaughter-point chains are those who have most contact with different batches of live birds. Most of them are practicing a low level of biosecurity (de Glanville et al., 2010; Indriani et al., 2010; McLeod et al., 2009). There is limited coordination and governance by traders in these two specific chains. Traders do have a lot of influence, but are not physically in contact with live birds. Moreover, they have no incentive to reduce the risk of introduction and transmission since their income is hardly affected by HPAI occurrence. Therefore, any effort to control HPAI that is not considering their influence in the chain will be ineffective (Indrawan et al., 2018a). Second, private collecting farms were seen as critical actors in the transmission of HPAI. This may be because they play a role as a market for sick poultry. Since the consumers in the private slaughter-point chain may be less aware of the safety of their food, this sick-poultry market remained viable over the past years. Third, sector 2 farms were considered important contributors to the probability of transmission within the less coordinated chains. Their trading activities with private collecting farms might involve sick poultry, to reduce farms' financial risks during an outbreak of HPAI (Indrawan et al., 2018a). Moreover, there is also risk of introducing HPAI on sector 2 farms by trading with less coordinated chains.

Since increased HPAI biosecurity measures apply to those who handle live birds, the effectiveness of HPAI control measures depends on the involvement of those actors (McLeod et al., 2009). An important measure would be to remove the sick-poultry market. However, this will not be an easy task, since the traders - as the most influential actors within some of the chains - do not have an incentive to quit trading HPAI-affected birds (Indrawan et al., 2018a). Tighter government regulation and law enforcement, including penalties for chain actors, may need to be established to engage the private sector in prevention and control (Kurscheid et al., 2015; McLeod et al., 2009).

The current study provides a complete overview of the probabilities of HPAI introduction and transmission in the Western Java poultry system. The results demonstrate that the risk across various poultry chains is interrelated and that, even for the more integrated poultry chains, it is 
important to control HPAI in the less coordinated poultry chains. Not only because HPAI can transmit without direct poultry contact (e.g., by wildlife), but especially since there is direct contact between the actors in the various poultry chains.

Using a value chain analysis as a foundation of food system analysis and linking it with a qualitative assessment of HPAI introduction and transmission enabled us to suggest critical actors for future mitigation plans and research. This is helpful for a country with limited resources to control HPAI, such as Indonesia. Priority in HPAI mitigation and control should be given to the most critical actors in the value chain, actors that have a relatively high probability of introduction and transmission. For control measures to be successful, it is important that actors are intrinsically motivated. Without intrinsic motivation, such as incentives, health authorities should think about a change in the chain. However, there is not much knowledge on the motivation of actors in controlled and private slaughter-point chains. However, before even considering measures for mitigation and control, further research should first confirm the critical actors' estimated probabilities that are flagged as highly uncertain. In general, attention should be given to the higher probability of introduction of HPAI in the semiautomated slaughterhouse chain, caused by trade connections with the controlled and private slaughter-point chains. Further quantitative epidemiological work should give more insight into the magnitude of those risks, adding to previous epidemiological studies in Indonesia related to HPAI transmission in live bird markets from sector 3 and 4 farm sectors (Indriani et al., 2010; Kurscheid et al., 2015; Wibawa et al., 2018).

This study has a few limitations. The study was designed to estimate HPAI introduction and transmission based on the model of poultry value chain in the Western Java, adapted from an earlier study (Indrawan et al., 2018a) that focus on the transactional relationship between actors and which may not be appropriate for the real epidemiological situation. Therefore, we only looked at the introduction and transmission for a specific chain governance, making this study rather descriptive. We did not consider the pathways that might exist beyond that governance. Furthermore, the questions with regard to HPAI introduction and transmission were general. It may be necessary to look into biosecurity practices for each actor to get a more accurate estimation for each probability. Finally, the high level of uncertainty implies that it is crucial to carry out a quantitative analysis. In future studies, other explanatory variables, specifically related to the epidemiology and biosecurity, can be added to each chain governance. 


\subsection{Conclusions}

This research generated an overview of the probability of HPAI introduction and transmission in the Western Java poultry system. The probabilities of HPAI introduction and transmission were estimated for all actors in the four different poultry chains. Expertise-based estimates for HPAI introduction and transmission identified critical actors affecting HPAI risk in Western Java. Critical introduction sources in an external chain are semi-automated slaughterhouses, traditional outlets and sector 4 farms. Critical transmission sources in an internal chain are sector 1 farms, sector 2 farms, sector 3 farms, and private collecting farms. Sources critical transmission sources from the same type of actor in the value chain are sector 2 farms, sector 3 farms, and sector 4 farms. Involving all stakeholders in the development and implementation of control measures is necessary for successful HPAI control. Finally, the high levels of uncertainty associated with expertise-based probability estimates imply that it is necessary to carry out quantitative research in the future. This study provides an important starting point.

\section{Acknowledgements}

The authors would like to acknowledge the SPIN3-JRP-61 Project for the data support and collection. The first author was funded by an LPDP scholarship. The funder had no role in the contents of this study. We are thankful to Eko Ruddy Cahyadi and Okti Nadia Poetri for organizing the interviews.

\section{Conflict of Interest Statement}

The authors declare that there is no conflict of interest 
Chapter 3

60 


\section{Chapter 4}

Determinants of biosecurity practices in West Java broiler farms:

The role of farm business type in the control of avian influenza

Authors: Eko Ruddy Cahyadi, Dikky Indrawan, Arief Daryanto, Henk Hogeveen

Submitted for publication 


\begin{abstract}
Biosecurity is important to prevent the introduction and reduce the spread of infectious diseases, including Highly Pathogenic Avian Influenza (HPAI). HPAI is currently endemic in Indonesia. Although there is anecdotal evidence about the level of biosecurity on Indonesian broiler farmers, a formal evidence is lacking, as well as knowledge about determinants of low levels of biosecurity. This paper has two main objectives: 1) to assess the adoption levels of biosecurity management across different farm business types, and (2) to analyze the determining factors, with a special reference to farm business type, for the adoption of biosecurity practices and the availability of biosecurity infrastructure in West Java poultry farms. A multi-stage sampling procedure was applied to collect data from approximately 400 broiler farmers in four districts in West Java province, namely Ciamis, Tasikmalaya, Subang and Sukabumi. Data were collected by interviewing farmers and directly observing the farms. The Biosecurity Control Score (BCS), consisting of 16 practice indicators, and Farm Infrastructures for Biosecurity (FIB) consisting of 16 biosecurity facilities were used to measure adoption levels of biosecurity. Determinants of biosecurity adoption were analyzed via tobit regression analysis. The results show that biosecurity practices across various business types of broiler producers in West Java are limited. The poorest biosecurity adoption was found for traffic control practices and facilities. The results of this study suggest that business types play a significant role in biosecurity practices; a makloon farm (farming for fee) tends to have a lower adoption than other business types due to lack of incentives. Consequently, policy makers should take farm business type into consideration when developing incentives for improved biosecurity.
\end{abstract}

Keywords: biosecurity, broiler, farm business types, West Java 


\subsection{Introduction}

Indonesia is the country with the highest number of human and poultry cases of High Pathogenic Avian Influenza (HPAI) worldwide, highlighting the need to reduce the risks of HPAI spread (Sedyaningsih et al., 2008; World Health Organization, 2013). In the period of 2003 to 2009, HPAI outbreaks were reported in 31 of the 33 provinces which led to 155 fatal human cases and the death of 11 million chickens due to sickness or culling(Office International des Epizooties, 2006; Sims et al., 2005). The 2005 HPAI outbreak had a severe socio-economic impact on small-scale farmers with $60 \%$ of poultry farms ceasing their operation (Basuno et al., 2010). HPAI cases occurred especially in West Java province, where $50 \%$ of the national broiler production takes place (Direktorat Jenderal Peternakan, 2015). During the 2003-2008 period, 794 HPAI outbreaks were reported in 24 of the 25 districts, resulting in 34 cases of human HPAI infection in 12 districts (Yupiana et al., 2010). Outbreaks of HPAI frequently coincide with other fatal infectious diseases such as Chronic Respiratory Disease (CRD), colibacillosis, Infectious Bursal Disease (IBD), coryza, and Newcastle Disease (NCD).

Even though the official prevalence reports of HPAI indicate an improved situation in broilers (Azhar et al., 2010), the control HPAI spread in broilers is still challenging due to the short production cycle of 25 to 35 days, making vaccination less efficient (Poetri et al., 2011). Therefore, the application of reliable biosecurity practices in farms is considered to be an effective preventive control measure of HPAI and other infectious diseases (Food and Agriculture Organization of the United Nation, 2007; Food and Agriculture Organization of the United Nations, 2006; Honhold et al., 2008). The three major principles of biosecurity, i.e. isolation, sanitation and traffic control, provide improved security against biological agents, including bacteria, viruses or other pathogenic agents (Cardona, 2012).

A previous study in Western Java reported varying levels of biosecurity practices between poultry farm sectors, related to the governance mechanism within their value chain (Indrawan et al., 2018). Further variations between farms within the different value chains may be expected. This is partly due to the farmers' attitude or socio-demographic circumstances, but additionally, the different farm business types, such as independent farming, makloon farming (farming for fee), contract farming and company business farming, may also influence the level of biosecurity (Ilham and Iqbal, 2011). Different farm business types may adopt different 
incentives for biosecurity. Understanding this variation and its causes will be useful for animal health authorities to suggest proper measures related to biosecurity adoption. However, there is only limited knowledge on this subject (Martindah et al., 2014). Moreover, there is no knowledge about determinants of biosecurity behavior on West Java poultry farms.

This paper has two main objectives: (1) to assess the levels of biosecurity management and biosecurity infrastructure, and (2) to analyze the determining factors, with a special reference to farm business type, for the adoption of biosecurity practices and the availability of biosecurity infrastructure in West Java broiler farms.

\subsection{Materials and Methods}

\subsubsection{Study location}

A cross-sectional survey of broiler producers was performed by eight trained enumerators in four districts in West Java province, namely Ciamis, Tasikmalaya, Subang and Sukabumi, from September to October 2016. Those districts were selected as they are major broiler producers with frequent HPAI outbreaks reported during the five years prior to data collection. Ciamis is located in the southeast of West Java province, bordering with Central Java. Ciamis is wellknown as a leading broiler producer in the province, with more than 14 million broilers per year held by approximately 4000 farmers. Tasikmalaya is situated near Ciamis, with 6.4 million broilers per year held by 1875 farmers. Subang is located in the northern part of the West Java province, with more than 7 million broilers per year held by 723 farmers. Sukabumi is located $96 \mathrm{~km}$ from Bandung (the capital of the West Java province), relatively close $(119 \mathrm{~km})$ to Jakarta, the capital of Indonesia, with a very large chicken meat market. Sukabumi produces 8.6 million broilers per year held by 874 farmers.

We tried to capture all types of poultry farm businesses existing in these four districts. Therefore, as a first step, we defined the different types of poultry farm business as follows: (1) independent farming: smallholders, who buy inputs and sell chicken in free markets; (2) makloon farming: smallholders who are paid by the broiler-producing company for provision of cages and labor; (3) contract farming: smallholders with a contractual arrangement with a company to obtain inputs and technical assistance on credit basis and an obligation to sell their chickens to the company at a certain contract price; and (4) company business farming: 
advanced legal organizations with large production networks, operating their own farms.

\subsubsection{Sampling}

We calculated the required sample size using the Slovin formula with a margin error of 5\%, based on total number of 17,988 commercial broiler producers in the West Java province (Statistics, 2013), as follows:

$$
n=\frac{N}{\left(1+N e^{2}\right)}=\frac{17,988}{\left(1+17,988 * 0.05^{2}\right)}=391.3 \sim 392
$$

The calculated result was raised by $5 \%$ as an additional backup in anticipation for respondent absence during the interview process, leading to a total sample size of 412. During the survey, six out of 412 respondents were not available, consequently they were removed from our sample. Finally, we retained a total of 406 interview respondents with around 100 respondents per district.

We applied a multistage stratified sampling procedure to select respondents from poultry business farm databases. First, we selected four districts in West Java by considering the broiler population and broiler farmers as previously explained. Second, for each district, upon our request, livestock agencies selected sub-districts with a high number of small commercial broiler producers and a high exposure to disease outbreaks. As a consequence, a varying number (two to nine) of sub-districts were selected for each district. In the next step, we created lists of farmers per sub-district. In Sukabumi, the livestock agency was able to provide a list of individual farmers. In the other three districts, such a list was not available and the agencies provided a list of poultry nucleus companies only. These companies were solicited to provide lists of their clients, and five companies in Ciamis, six in Tasikmalaya and two in Subang were found willing to cooperate in this survey. The company lists per sub-district were merged, and individual farmers were randomly selected. We used different sampling strategies. In Sukabumi, the farm business type information was not available, hence farms were selected randomly. In the other three districts, the farm business type was available and we took a stratified sample.

Since no independent farmers were present in the original lists, these farms were selected and 
added to the sample using a snowball sampling technique: in each sub-district, the livestock agencies recommended an independent farmer to be visited first. Per sub-district, the sample number for independent farmers was determined proportionally to the livestock agency's estimate of the number of independent farmers, varying from 1 to $15 \%$ of the total sample.

Almost all interviewed respondents in Ciamis, Tasikmalaya and Subang were farmers or owners. In those three districts, the farmers run their own farm and live in the local village. The respondents of poultry farms in Sukabumi, were mostly farm managers, since the owners lived outside the village or district. We decided to also accept farm managers as our respondents because they are involved in operational and investment decisions for the farm owners.

\subsubsection{Questionnaire design}

We designed a structured questionnaire, consisting of three parts, to capture potential drivers of biosecurity adoption, assess biosecurity practices and infrastructure. The first part gathered information on farmer characteristics such as gender, age, education, household income, poultry experience, contribution of poultry farm to household income, production scale, official registration, farm location, and the farmer's experience with and awareness of diseases (Susilowati et al., 2013). Additionally, farmers were asked to subjectively assess their risk preference using a rating scale from 1 to 10 (from perfectly risk averse to perfectly risk seeking). In the second part, we designed a check list to assess the adoption of biosecurity measures, namely the Biosecurity Control Score (BCS) which is based on a set of Biosecurity Control Indicators (BCI). BCI were adapted from previous studies in several other countries, including Negro-Calduch et al. (2013) in Central Egypt, Hernandez-Jover et al. (2015) in Australia, Birhanu et al. (2015) in Ethiopia, Ajewole and Akinwumi (2014) in Nigeria, Van Steenwinkel et al. (2011) in Belgium, and Martindah et al. (2014) in West Java. Sixteen BCI were defined (Table 4.1) to comprehensively capture three principles of biosecurity practices: isolation, sanitation and traffic control. Then we added one indicator for biosecurity procedures. During farm visits, each BCI was assessed and scored from 0 to 3 , with 0 meaning no biosecurity at all, and 3 meaning a high or advanced biosecurity level (Table 4.1). Based on the $16 \mathrm{BCI}$, the $\mathrm{BCS}$ was calculated:

$$
B C S=\sum_{i=1}^{i=16} B C I_{i}
$$




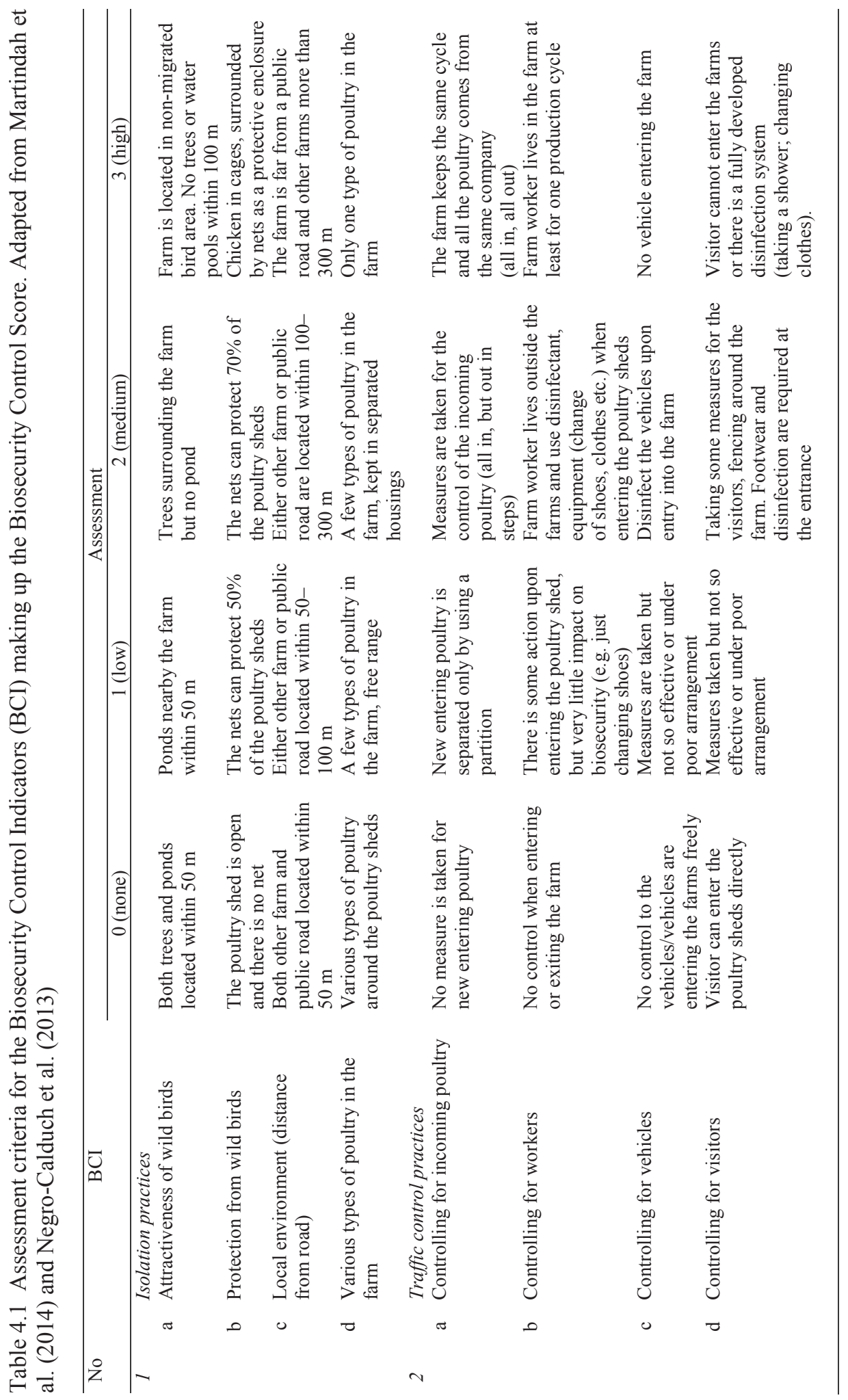




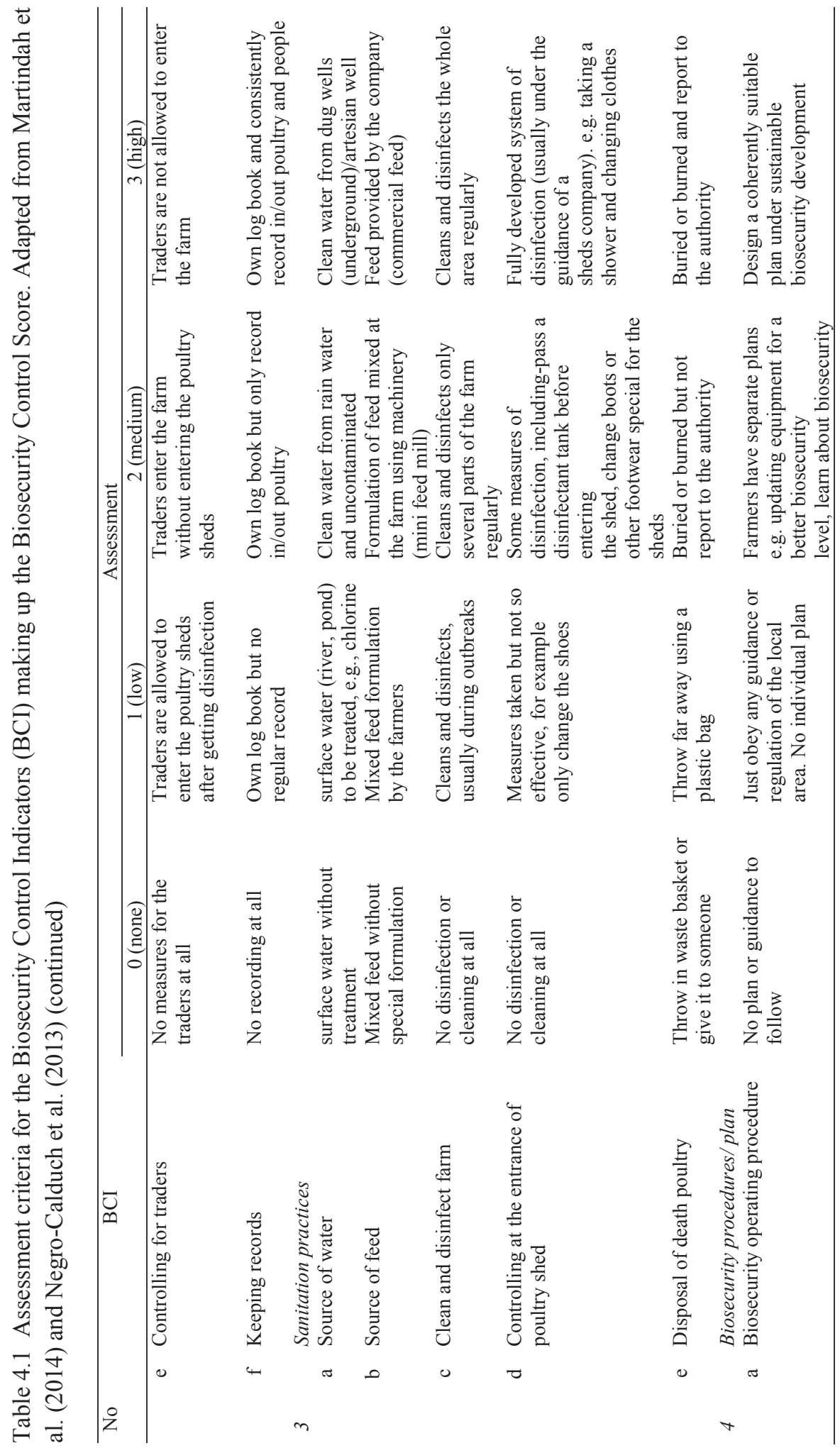


The third part of the questionnaire intended to assess Farm Infrastructure for Biosecurity (FIB). The FIB questionnaire enables a detailed investigation on physical aspects of the farm with regard to the same three principles of biosecurity. We adapted a list of 16 potential facility items (Table 4.2) from previous studies (Fasina et al., 2012; Martindah et al., 2014) and checked the availability (available $=1$, not available $=0$ ) of the listed biosecurity infrastructure items by direct farm observations.

Table 4.2 Farm Infrastructure for Biosecurity (FIB) items to measure the availability of biosecurity infrastructure

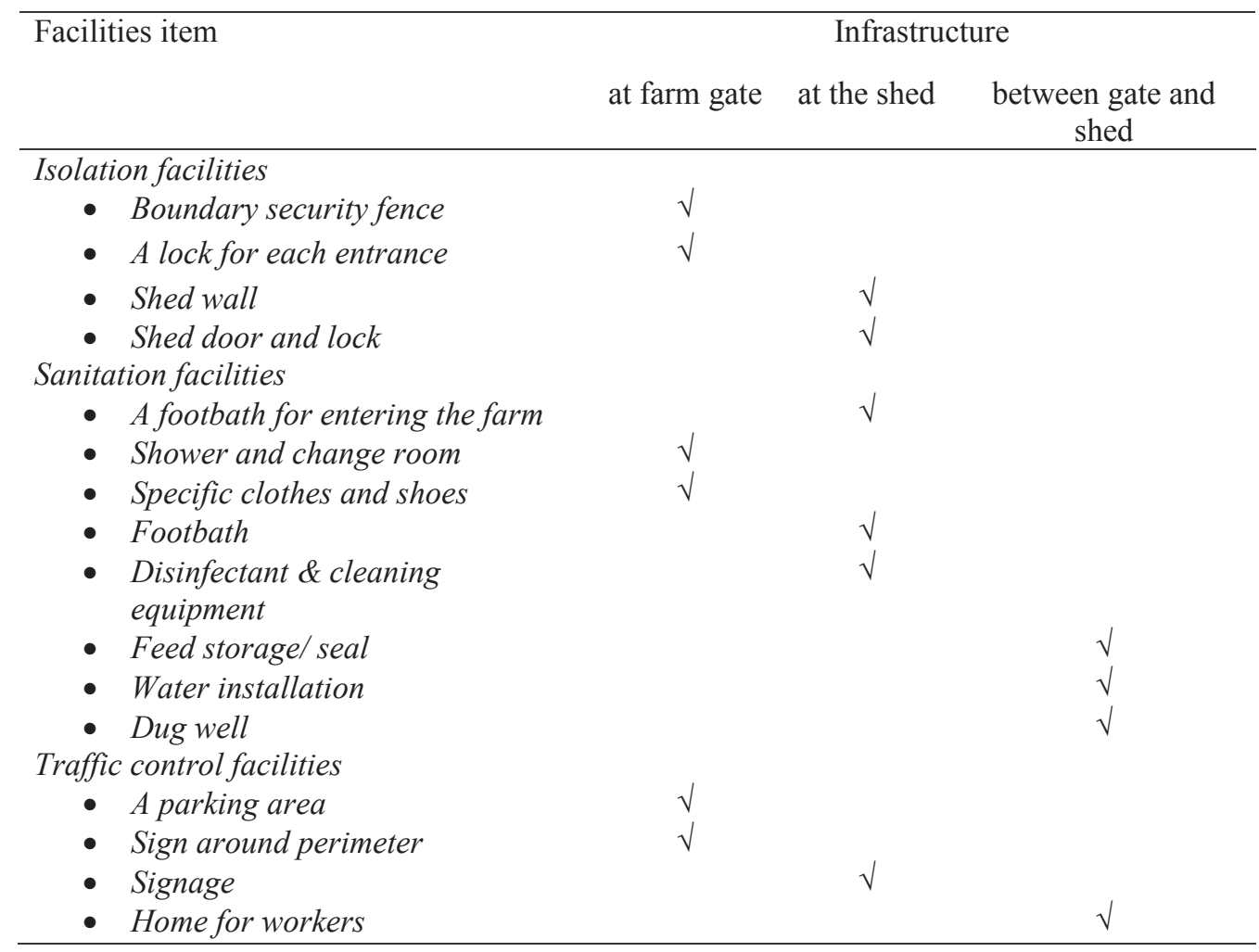

The summarizing Farm Infrastructure for Biosecurity (FIB) score was calculated as the proportion of the available infrastructure for biosecurity (IB) in physical aspects $\left(\sum_{i=1}^{n} I B_{i}\right)$ over the total number $(\mathrm{n}=16)$ of possible infrastructure items:

$$
F I B=\frac{\sum_{i=1}^{n} I B_{i}}{n}
$$




\subsubsection{Data analysis}

We calculated descriptive statistics to obtain insight into the characteristics of broiler producers and production. We calculated means and standard deviations for the total sample as well as for each farm business type. Differences between farm business types were analyzed using ANOVA in combination with a Bonferroni correction.

Next, using tobit models, we analyzed determinants (farmer characteristics, production characteristics, farmer experience and awareness towards diseases and risk perception) for BCS and FIB. Since Ordinary Least Square (OLS) multiple regression might produce inconsistent estimators, as the value of the dependent variable can fall outside the range of observations, a tobit model or censored regression would be a suitable solution as the model is a hybrid between a standard regression model and a binary choice model (Dougherty, 2011).

Suppose that $Y^{*}$ is an estimator for BCS or FIB, determined by a set of covariates $\mathrm{X}$ as follows:

$$
Y^{*}=\alpha+\beta X+\mu
$$

$Y^{*}$ is subject to a lower bound $\mathrm{Y}_{\mathrm{L}}$, which equals to 0 and an upper bound $\mathrm{Y}_{\mathrm{U}}$, which equals to 48. $\mathrm{X}$ is a set of explanatory variables including farmer characteristics, production characteristics, diseases experience and awareness, risk preference and district location, while $\mu$ is an error term and $\beta$ is a vector with the regression parameters of the explanatory variables. The model can be characterized as follows:

$$
\begin{gathered}
Y^{*}=\alpha+\beta X+\mu \\
Y=Y^{*} \text { for } Y_{L}<Y^{*}<Y_{U)} \\
Y_{B C S}=Y_{L} \text { for } Y^{*} \leq Y_{L} \\
Y=Y_{U} \text { for } Y^{*} \geq Y_{U}
\end{gathered}
$$

The expected BCS in a tobit model will equal the predicted BCS in multiple regression, as long as the predicted value falls between 0 and 48 . The expected BCS equals to zero in case the predicted value of OLS is negative; and equals to 48 if the predicted value of OLS is higher than 48. Similarly, for FIB, the thresholds are 0 and 100 . Data processing was run by STATA IC.14 (Stata Corp - Texas, USA). 


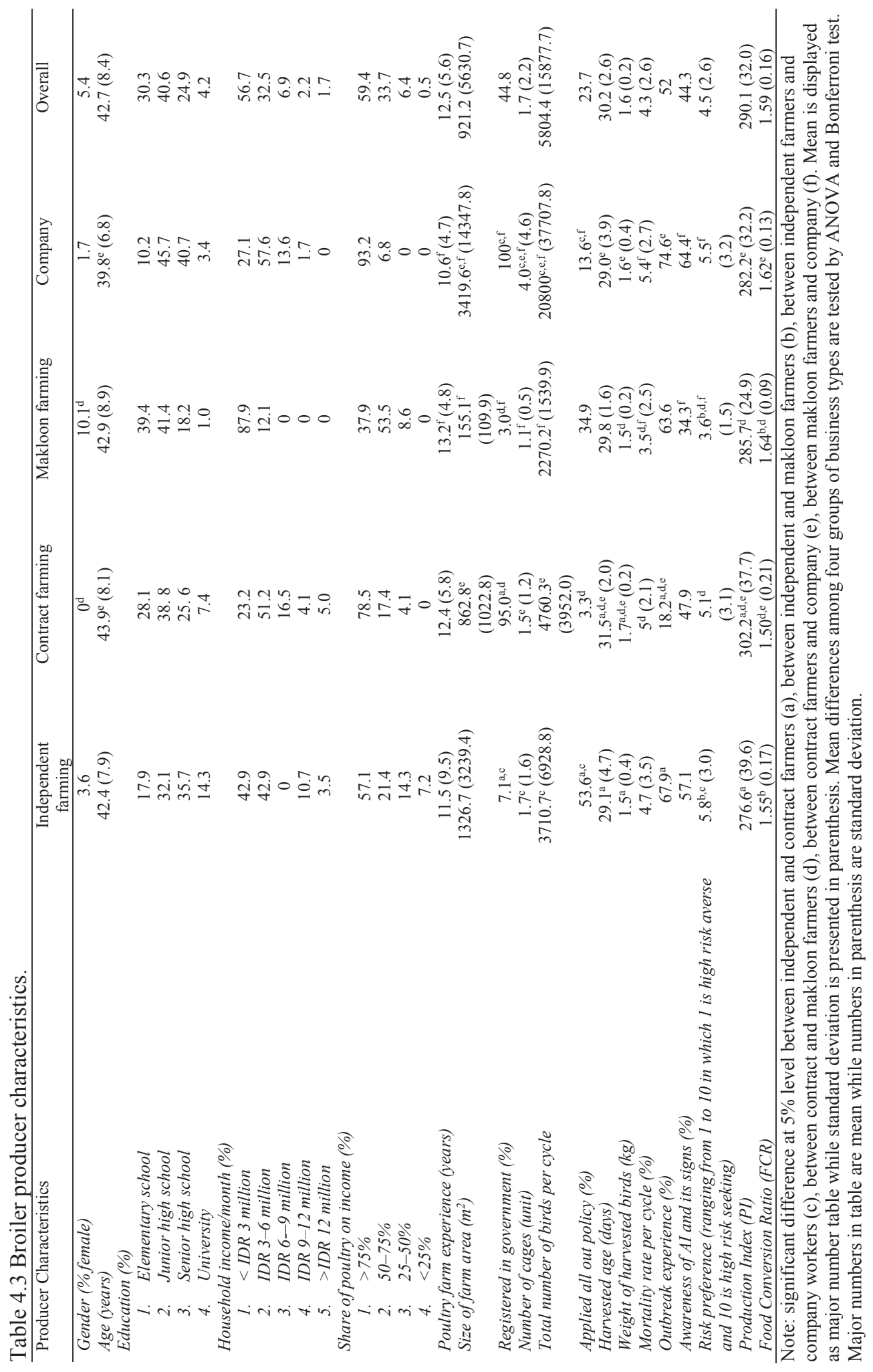




\subsection{Results}

\subsubsection{Descriptive statistics}

The basic and production characteristics of broiler farms across the four districts are presented in Table 4.3. We found a different composition of farm business types among the four districts. Ciamis and Tasikmalaya are dominated by makloon farmers with very few independent farmers. Subang, on the other hand, is dominated by contract farmers, also with few independent famers. In Sukabumi, the majority of broiler producers are companies, followed by contract farmers and independent farmers in almost equal proportion (20\% and $18 \%$, respectively). Farmers in Ciamis, Tasikmalaya and Sukabumi tend to be more risk averse than those in Subang.

On average, the production cycle was 30 days, with no noticeable differences between farm business types. The farm size differed significantly between districts. Farmers in Sukabumi held on average more than 15,000 birds per cycle, which is the largest among the four districts. Farmers in Subang held on average 3,700 birds per cycle, while those in Ciamis and Tasikmalaya held on average only 2,000 birds per cycle. The lowest mortality rate for each producing cycle was in Tasikmalaya $(3.7 \% \pm 2.3 \%)$. A little less than half of the farmers were aware of AI and its symptoms. Farmers in Subang and Sukabumi were more aware of AI than farmers in Ciamis and Tasikmalaya.

\subsubsection{Biosecurity assessments for different farm business types}

The BCS for the various farm business types are presented in Table 4.4. Average scores for $\mathrm{BCI}$ were in general low (below 2), representing a low level of adoption of biosecurity practice principles. The results show that, in general, makloon farms had the lowest BCS score compared to other farm business types. Company business farms had, on average, the highest BCS score. The BCS for makloon farms and company business farms were significantly different from other farm business types. The adoption of four biosecurity principles in all farm business types demonstrated that only indicators regarding sanitation practices came close to meeting a minimum standard. Indicators regarding traffic control practices showed the lowest values. Company business farms had a significantly different level of adoption of traffic control practices than other farm business types. 
Table 4.4 Mean and standard deviation (in parentheses) of adoption level of biosecurity practices indicators between farm business types, tested by one-way ANOVA and Bonferroni test.

\begin{tabular}{lcccc}
\hline \multicolumn{1}{c}{ BCI } & $\begin{array}{c}\text { Independent } \\
\text { farming }\end{array}$ & $\begin{array}{c}\text { Contract } \\
\text { farming }\end{array}$ & $\begin{array}{c}\text { Makloon } \\
\text { farming }\end{array}$ & Company \\
\hline Isolation practices $_{\text {Traffic control practices }}$ & $1.9(0.4)$ & $2.0(0.4)^{\mathrm{d}}$ & $1.7(0.4)^{\mathrm{d}, \mathrm{f}}$ & $2.1(0.4)^{\mathrm{f}}$ \\
Sanitation practices & $0.8(0.3)^{\mathrm{c}}$ & $0.8(0.21)^{\mathrm{e}}$ & $0.7(0.6)^{\mathrm{f}}$ & $1.1(0.4)^{\mathrm{c}, \mathrm{e}, \mathrm{f}}$ \\
Biosecurity procedures/ plan & $2.0(0.4)^{\mathrm{a}, \mathrm{b}, \mathrm{c}}$ & $2.2(0.2)^{\mathrm{a}, \mathrm{d}}$ & $1.7(0.4)^{\mathrm{b}, \mathrm{f}}$ & $2.3(0.2)^{\mathrm{c}, \mathrm{f}}$ \\
\hline Total $\boldsymbol{B C S}$ & $1.4(1.0)^{\mathrm{b}}$ & $1.2(0.7)^{\mathrm{d}}$ & $0.5(0.6)^{\mathrm{b}, \mathrm{d}, \mathrm{f}}$ & $1.3(0.9)^{\mathrm{f}}$ \\
\hline St, & $23.4(4.0)^{\mathrm{b}, \mathrm{c}}$ & $24.7(3.1)^{\mathrm{d}, \mathrm{e}}$ & $20.0(5.4)^{\mathrm{b}, \mathrm{d}, \mathrm{f}}$ & $27.6(3.9)^{\mathrm{c}, \mathrm{e}, \mathrm{f}}$ \\
\hline
\end{tabular}

Statistically $(\mathrm{P}<0.05)$ significant difference between independent and contract farmers (a), between independent and makloon farmers (b), between independent farmers and company workers (c), between contract and makloon farmers (d), between contract farmers and company (e), and between makloon farmers and company (f).

Table 4.5 summarizes the BCS levels for the four farm business types. None of the farms had a high level of biosecurity. The best scoring farm business type were the contract farms: $46 \%$ of the farms had a medium level of biosecurity. For makloon farms, this was $17 \%$, while only $11 \%$ of makloon farms had a minimum biosecurity level. The independent farms and the company farms were quite similar in their biosecurity level. Overall, independent farms had the highest proportion of farms at a medium biosecurity level (46\%).

Table 4.5 The comparison of biosecurity levels (BCS) in different farm business types (\%)

\begin{tabular}{lcccc}
\hline Biosecurity level & $\begin{array}{c}\text { Independent } \\
\text { farming }\end{array}$ & Contract farming & $\begin{array}{c}\text { Makloon } \\
\text { farming }\end{array}$ & Company \\
\hline High & 0 & 0 & 0 & 0 \\
Medium & 32 & 46 & 17 & 27 \\
Low & 68 & 54 & 72 & 73 \\
Minimum & 0 & 0 & 11 & 0 \\
\hline
\end{tabular}

The FIB assessment on physical aspects in each district is presented in Table 4.6. Compared to other types of facilities, isolation facilities were most commonly implemented in the biosecurity infrastructure. Two out of the four listed isolation facilities, namely shed wall and shed door and lock, were almost always present on all farm business types. Other infrastructure was not well adopted in any of the four farm business types. Traffic control facilities had the worst availability of biosecurity infrastructure. On average, company farms had the highest availability of farm infrastructure for biosecurity (51\%), only $44 \%$ of contract farms had infrastructure available, followed by independent farms with $40 \%$. Equal to BCS, makloon 
farms had the lowest FIB, as only $30 \%$ of the standard infrastructure for biosecurity was present.

Table 4.6 The availability of Farm Infrastructure for Biosecurity (FIB) (\%)

\begin{tabular}{lcccc}
\hline Facilities item & $\begin{array}{c}\text { Independent } \\
\text { farming }\end{array}$ & $\begin{array}{c}\text { Contract } \\
\text { farming }\end{array}$ & $\begin{array}{c}\text { Makloon } \\
\text { farming }\end{array}$ & Company \\
\hline Isolation facilities & $\mathbf{6 1}$ & $\mathbf{5 0}$ & $\mathbf{5 3}$ & $\mathbf{6 5}$ \\
Boundary security fence & 14 & 2 & 2 & 25 \\
A lock for each entrance & 29 & 1 & 9 & 36 \\
Shed wall & 100 & 100 & 100 & 100 \\
Shed door and lock & 100 & 98 & 99 & 100 \\
& & & & \\
Sanitation facilities & $\mathbf{3 6}$ & $\mathbf{5 0}$ & $\mathbf{1 9}$ & $\mathbf{5 1}$ \\
A footbath for entering the farm & 4 & 0 & 1 & 12 \\
Shower and change room & 4 & 0 & 0 & 7 \\
Specific clothes and shoes & 4 & 2 & 4 & 0 \\
Footbath & 14 & 0 & 17 & 51 \\
Disinfectant \& cleaning & 86 & 100 & 54 & 90 \\
equipment & & & & \\
Feed storage/ seal & 68 & 100 & 11 & 98 \\
Water installation & 46 & 96 & 22 & 61 \\
Dug well & 61 & 98 & 44 & 90 \\
Traffic control facilities & $\mathbf{8}$ & $\mathbf{2 7}$ & $\mathbf{1}$ & \\
A parking area & 11 & 8 & 1 & $\mathbf{3 3}$ \\
Sign around perimeter & 0 & 0 & 0 & 29 \\
Signage & 0 & 1 & 1 & 2 \\
Home for workers & 21 & 98 & 1 & 100 \\
\hline Number of owned items over total & 40 & 44 & 30 & 51 \\
listed items (\%) & & & & \\
\hline
\end{tabular}

\subsubsection{Determinant factors of biosecurity practices and facilities availability}

No observations were censored either in the left (lower bound) or in the right (upper bound) of the tobit models explaining BCS and FIB using potentially determinant factors. Therefore, tobit regression and OLS multiple regression produced the same results. The results and the goodness of fit of both models are presented in Table 4.7. For both models, the total number of birds per cycle, risk preference and the farm business type were a statistically significant determinant. The results showed that an independent farm had a significantly better BCS and FIB than other farm business types. Makloon farms (the baseline farm business type) had 
significantly lower BCS and FIB than other farm types. Farmers' experience with AI outbreaks had a negative association with BCS. Registration of a farm was positively associated with FIB.

Table 4.7 Determinants of biosecurity practices and facilities availability

\begin{tabular}{|c|c|c|}
\hline Variables & $\begin{array}{l}\text { Biosecurity Control } \\
\text { Score (BCS) }\end{array}$ & $\begin{array}{l}\text { Farm Infrastructure } \\
\text { for Biosecurity (FIB) }\end{array}$ \\
\hline Gender & 1.043 & -0.019 \\
\hline Age & -0.043 & 0.000 \\
\hline Education (schooling years) & -0.114 & -0.001 \\
\hline Household income level & -0.521 & 0.000 \\
\hline Dependency level on poultry & $-1.110 * *$ & -0.012 \\
\hline Officially registered or not & -1.143 & $0.067 * *$ \\
\hline Total number of birds per cycle & $2.065 * *$ & $0.029 * *$ \\
\hline Outbreak experience & $-2.753 * *$ & 0.007 \\
\hline Awareness to AI signs & $1.589 * *$ & 0.008 \\
\hline Farming experience & $0.130 * *$ & -0.001 \\
\hline Risk preference & $0.645 * *$ & $0.011 * *$ \\
\hline \multirow{2}{*}{\multicolumn{3}{|c|}{$\begin{array}{l}\text { Dummy of farm business types } \\
\text { (baseline: makloon farming) }\end{array}$}} \\
\hline & & \\
\hline 1. Independent farming & $4.680 * *$ & $0.101 * *$ \\
\hline 2. Contract farming & $3.310 * *$ & $0.059 * *$ \\
\hline 3. Company & $4.318 * *$ & $0.074 * *$ \\
\hline Constant & 5.441 & 0.079 \\
\hline \multicolumn{3}{|l|}{ Tobit } \\
\hline Log likelihood & -1121.25 & 503.55 \\
\hline P chi-square & 0.000 & 0.000 \\
\hline Pseudo $R$ square & 0.112 & 0.672 \\
\hline Left-censored observations & 0 & 0 \\
\hline Right-censored observation & 0 & 0 \\
\hline \multicolumn{3}{|l|}{$O L S$} \\
\hline R square & 0.501 & 0.631 \\
\hline Prob $>F$ & 0.484 & 0.618 \\
\hline Root MSE & 3.902 & 0.071 \\
\hline
\end{tabular}

\subsection{Discussion}

This study provides insight into the biosecurity practices and infrastructure on poultry farms, related to transmission of $\mathrm{AI}$ and other contagious diseases in West Java. Through a 
questionnaire and farm observations, we used a structured framework to evaluate the biosecurity by BCS and FIB. In general, adoption of biosecurity measures was very low. The descriptive statistics already showed that farm business type is associated with BCS and FIB. These results were confirmed by the multivariable analyses. We found that independent farms had the highest on BCS and FIB score, whereas makloon farms were associated with the lowest BCS and FIB score. These findings suggest that different types of farm business in West Java province have different levels of biosecurity and therefore carry different risks of HPAI introduction. These findings are partly in line with the FAO biosecurity classification, highlighting the low level of adoption of biosecurity practices among small-scale commercial farmers. Descriptive statistics (Tables 4.4 and 4.6) show that commercial companies perform best for both biosecurity practices and infrastructure, while the makloon farms perform worst. Further analysis using tobit and OLS regression confirms that such performance was driven by farm business type, where other business types tend to have better biosecurity practices and infrastructure than makloon farming.

The difference in biosecurity for the different farm business types can be explained by the different incentives for farmers with different farm business types (Basuno et al., 2010; Gerdoçi et al., 2018; Wacker et al., 2016). At a makloon farm, the farmer provides the chicken housing and labor for an often prepaid amount of money. That means that the income of the farmers is not dependent on morbidity and mortality of the poultry. Consequently, makloon farmers have no incentive for good biosecurity. In contrast, independent and company farms had the highest level of biosecurity adoption and biosecurity facilities. Within these two farm systems, all of the negative consequences of AI (morbidity and mortality) are assumed by the farmer. Consequently, these independent and industrial size farms have the highest incentive to have good biosecurity, leading to a lower risk of introduction of HPAI (Boni et al., 2013) and optimization of the level of biosecurity relative to the prevented costs of outbreaks of diseases. This suggests that farms where the farm owner is independent, irrespective of the farm size, have a better incentive for a high level of biosecurity. However, it is surprising that the biosecurity level is the same for independent and industrial farms, even though the former are generally much smaller. It was expected that, because of the scale advantages and governance within the channel, biosecurity would have been better at company farms in the modern poultry marketing channel, and therefore at a lower risk of AI introduction (Indrawan et al., 2018). It was generalized that all farms in the traditional channel, among which the independent farms, are performing worse in terms of biosecurity than farms in the modern channel. This study 
shows this generalization is invalid, and proves that independent farms have the same level of biosecurity as company farms.

For both makloon farms and contract farms, the consequences of disease outbreaks do not affect the farmers, as they both have a similar type of contract with the nucleus companies. However, makloon farms, when compared to contract farms, have a lower BCS as well as FIB. The difference is explained by the fact that contract farms' transaction contracts are a good incentive for biosecurity, while makloon farms have no incentive at all. Although contract farmers, just like makloon farmers, obtain all major inputs including chicks, feed and medicine from a company, they own the input on credit basis and settle the credit when selling the production to the company at an agreed contract price. This gives them more responsibilities and incentives for better results, as contract farm' incentives and specific biosecurity instructions are integrated in the contract (Boni et al., 2013).

Disease outbreak experience is another interesting factor significantly associated with the level of biosecurity. We hypothesized that farmers with a past experience of disease outbreaks would have a higher level of biosecurity, since they were aware of the consequences (Dorea et al., 2010; Scudamore and Harris, 2002). This was not the case. Apparently, experience with disease outbreaks did not provide an incentive to improve biosecurity. Either, farmers did accept the (economic) consequences of an outbreak, or those consequences were not very large for them, for instance because of their contract or because of the existence of a market for sick chickens (Boni et al., 2013). In that case, the lower level of biosecurity was a risk factor, leading to a higher risk of disease outbreaks and therefore to a higher level of disease outbreak experience.

The government plays a role in ensuring the presence of biosecurity infrastructure in the farm, as measured by the FIB scoring (Kurscheid et al., 2015; McLeod et al., 2009). Registered farmers will be subject to more attention from government officials. This might explain the association between official registration and the FIB. Registration enables a government agency to monitor farms with regard to their biosecurity infrastructure. Farmers on contract farms and company farms in the Subang and Sukabumi districts were mostly registered and had a higher FIB than other farmers in the same districts. In contrast, makloon farmers in the Tasikmalaya district were not registered and had the lowest value of FIB. This result suggests the importance for the government to motivate farmers to register their business. Our results suggest that registration may lead to better monitoring and therefore improved biosecurity 
(Barnes et al., 2015; Gramig and Horan, 2011). A push strategy would help to motivate poultry farmers to apply more biosecurity practices and reduce the risk of disease introduction.

Risk preference toward business significantly affects a farmer's decisions on biosecurity practices and facilities in which a farmer with a higher risk tolerance tends to have better biosecurity. Farmers hesitate to spend more efforts and investments for biosecurity practices now, in anticipation of uncertain disease outbreaks in the future. A risk-averse farmer tends to keep a "status quo" and does not invest in improving biosecurity—increase production costswhile its benefit is still unsure.

\subsection{Conclusions}

A low adoption level of biosecurity practices and infrastructure was demonstrated in West Java poultry farms across various business types, even in commercial companies. The lowest biosecurity performance was found in traffic control practices and facilities. Determinants of biosecurity practices (BCS) and infrastructure availability (FIB) are the farm business types, the total number of birds per cycle, and the risk preference. The farm business type was the most important determinant to BCS and FIB; a makloon farm tends to have lower biosecurity practices and facilities than other business types. This observation suggests that the adoption of biosecurity practices and infrastructure are most likely caused by the incentive mechanism, differing between the farm business types. Thus, in order to improve biosecurity in the West Java broiler industry, policy makers can consider to specifically support a certain type of business.

\section{Acknowledgements}

The authors would like to acknowledge the SPIN3-JRP-61 Project for the funding, data support and collection. The second author was funded by an LPDP scholarship. The funder had no role in the contents of this study.

\section{Conflict of interest}

The authors declare that there is no conflict of interest. 


\section{Chapter 5}

\section{What drives the choice of poultry market channel and the change of purchase behavior due to Highly Pathogenic Avian Influenza outbreaks?}

Authors: D. Indrawan, G. Tacken, H. Hogeveen

Published in Poultry Science, Volume 97, Issue 10, 1 October 2018, Pages 3652-3660, DOI: https://doi.org/10.3382/ps/pey222 


\begin{abstract}
In Indonesia, market channels play an important role in food security in poultry meats. This review explains Indonesian consumers' choice of market channels to purchase poultry, and consumer concern of food scares and food safety in their consumption due to Highly Pathology Avian Influenza (HPAI) outbreak. The survey was conducted for the traditional and the modern channels and involves a sample of 1096 respondents in the Greater Jakarta Area. The logistic regression analysis reports the model proved that the substantial findings in the choice for the modern poultry market channel are the price/quality relationship, the safety feature, and the level of consumer trust. Some variables explaining the change in purchase behavior due to HPAI outbreaks are similar to the results of the choice of market channel. This study shows that the developed assessment can be used by the government to make the poultry supply more safe.
\end{abstract}

Keywords: consumers' choice, poultry market channel, purchase behavior, avian influenza 


\subsection{Introduction}

The Indonesia poultry supply chain is selling poultry meat in 2 main market channels: the traditional channels such as street vendors and wet market, and modern channels such as supermarket, hypermarket and specialty stores. The traditional channel mainly provides uncooled poultry meat, whereas the modern channel provides cooled and frozen poultry meat products. Even though the government of Indonesia regulated the poultry chain with food safety requirements, the traditional channel still applied not as much food safety as compared to the modern channel. Therefore, these channels attract different consumers with different preferences for poultry meat and for food safety. In order to improve the safety of the Indonesian poultry supply, it would be better if consumers would purchase their poultry from the modern channel. For a government to influence the preference of consumers for a market channel, it is necessary to know more about consumers' preferences and their purchase behavior with regard to poultry.

Only one study could be found on Indonesian consumers' decision making with regard to poultry consumption (Muladno and Thieme, 2009). It showed that the majority of consumers in the Jakarta region purchased their poultry meat from the traditional channel. Moreover, it showed that concerns about food scares and disease threats, amongst which highly pathogenic avian influenza (HPAI), made consumers change the venue of purchasing poultry meat.

Most studies on the consumers' choice for a market channel were done by looking directly at their choice as to the type of retail (outlet) store, without associating the market channel of the retail (outlet) store. These studies examined the factors that influence the consumers' choice of a type of retail (outlet) store. The literature study of Spiggle and Sewall (1987) translated those different studies to a general model of retail selection research. The model illustrated that the determinant factors in retail (outlet) choice are consumer psychological factors, consumer characteristics, and retail outlet features. Consumer psychological factors are found by many recent studies shaping the consumers' choice of retail (outlet) store in the market channels (Chamhuri and Batt, 2013a; Iton, 2015; Krystallis et al., 2007). One of the psychological factors is the consumer's confidence in the market channel. In some studies, trust was studied as consumer perception that shows the consumer confidence in food chain actors, such as retail, to provide safety in their food product (Arnot et al., 2016; de Jonge et al., 2007; de Jonge et al., 2008; Drescher et al., 2012). Furthermore, the consumer characteristics have shown to 
influence the consumers' choice of retail (outlet) store (Bonne and Verbeke, 2006; Florkowski et al., 1999; Krystallis and Arvanitoyannis, 2006; Pechey and Monsivais, 2015). Lastly, retail outlet features were also found to have influence on the consumer choice of retail (outlet) store (Chamhuri and Batt, 2013a; Sinha and Banerjee, 2004; Solgaard and Hansen, 2003). Because these factors are considered as the relevant determinants of the consumers' choice of retail (outlet) store, they can be considered as the relevant determinants of the consumers' choice of market channel as well. These determinants are still relevant for the current study, because a recent study on outlet choice by Heider and Moeller (2012) used a similar approach. This study illustrated the consumer's decision to choose retail outlet using consumer preference drivers for outlet patronage: outlet-specific drivers (e.g. assortment, quality and effortless consumption of product), lifestyle-specific drivers (e.g. time pressure, health orientation and price sensitivity), and social-demographic drivers (e.g. gender, age, income, civil status, employment status, and place of residence).

Environmental circumstances such as economic factors, political factors, social factors and technological factors can influence the consumers in their choice behavior. Outbreaks of HPAI have an influence on all of these factors. However, social factors can explain the change of behavior of consumers during or after HPAI outbreaks. Social factors, such as public health perspective that upsurge the consumers' perceived risk, can influence the consumers to be concerned about food scares (de Jonge et al., 2007). Many incidents of microbiological hazards, chemical hazards and technological changes have shown to have influenced consumer perception of food safety risks, and are thus impacting their purchase behavior (Yeung and Morris, 2001). In the situation of food unsafety, the consumers will relieve their perceived risk by modifying their purchasing decision, for instance by reducing, shifting or postponing the purchase of the offending product (Yeung and Morris, 2001). Similar responses occur in case of a zoonosis threat such as an HPAI outbreak. It has been shown that consumers stopped consuming poultry for different lengths of time because of their fear of HPAI (Figuié and Fournier, 2008). This means that a zoonosis threat is a factor that affects the purchase behavior of consumers.

A thorough assessment of the consumers' choice behavior regarding the poultry market channel selection and the influence of HPAI outbreaks on this choice behavior under Indonesian circumstances has not been performed before. Related studies did not focus on explaining consumers' decision making in the poultry market channel. Most of the studies that 
analyzed influencing factors in consumers' decisions to buy products were associated with the store choice. Moreover, studies that were closely related to the problems in Indonesia, were focusing on a broader definition of fresh meat, and not specifically on poultry meat (Chamhuri and Batt, 2013b; Krystallis et al., 2007). Finally, we did not find any studies on the factors that influenced consumer behavior due to HPAI outbreaks.

Therefore, this study is aiming at finding the determinant factors that influence the choice of poultry market channel and the consumers' change of purchase behavior due to HPAI. The model framework was based upon western-oriented studies that we adjusted to the Indonesian situation. First, the study analyzed the relation of those determinants to the consumer choice of market channel. Second, the study analyzed the relation of those determinants to the consumer purchase behavioral changes due to HPAI outbreaks.

\subsection{Material and methods}

The survey used in this study was developed to investigate the food market channels and poultry consumptions in the Greater Jakarta Area. It was implemented on a representative sample of different social and economic strata in the urban communities in and around Jakarta. The sample considers 2 types of market channels: the traditional channel and the modern channel. The survey was conducted via face-to-face interviews in December 2013. Details of the questionnaire, the sampling and the statistical analyses are provided in the next paragraphs.

\subsubsection{Questionnaire design and measurement}

The questionnaire consisted of 5 parts following a research framework adapted from earlier retail selection research (Heider and Moeller, 2012; Spiggle and Sewall, 1987) shown in figure 5.1. The trust model by de Jonge et al. (2008) was used to define the psychological questions on their trust in the market channel (part 1 of the questionnaire). Previous studies have confirmed trust in food as an important psychological factor (de Jonge et al., 2007; de Jonge et al., 2008; Van Kleef et al., 2007). In the questionnaire, trust was measured using 7 questions (on a 5-point Likert scale varying from "totally disagree" to "totally agree") on care, competence and openness of the market channel regarding the food safety in poultry meat. 


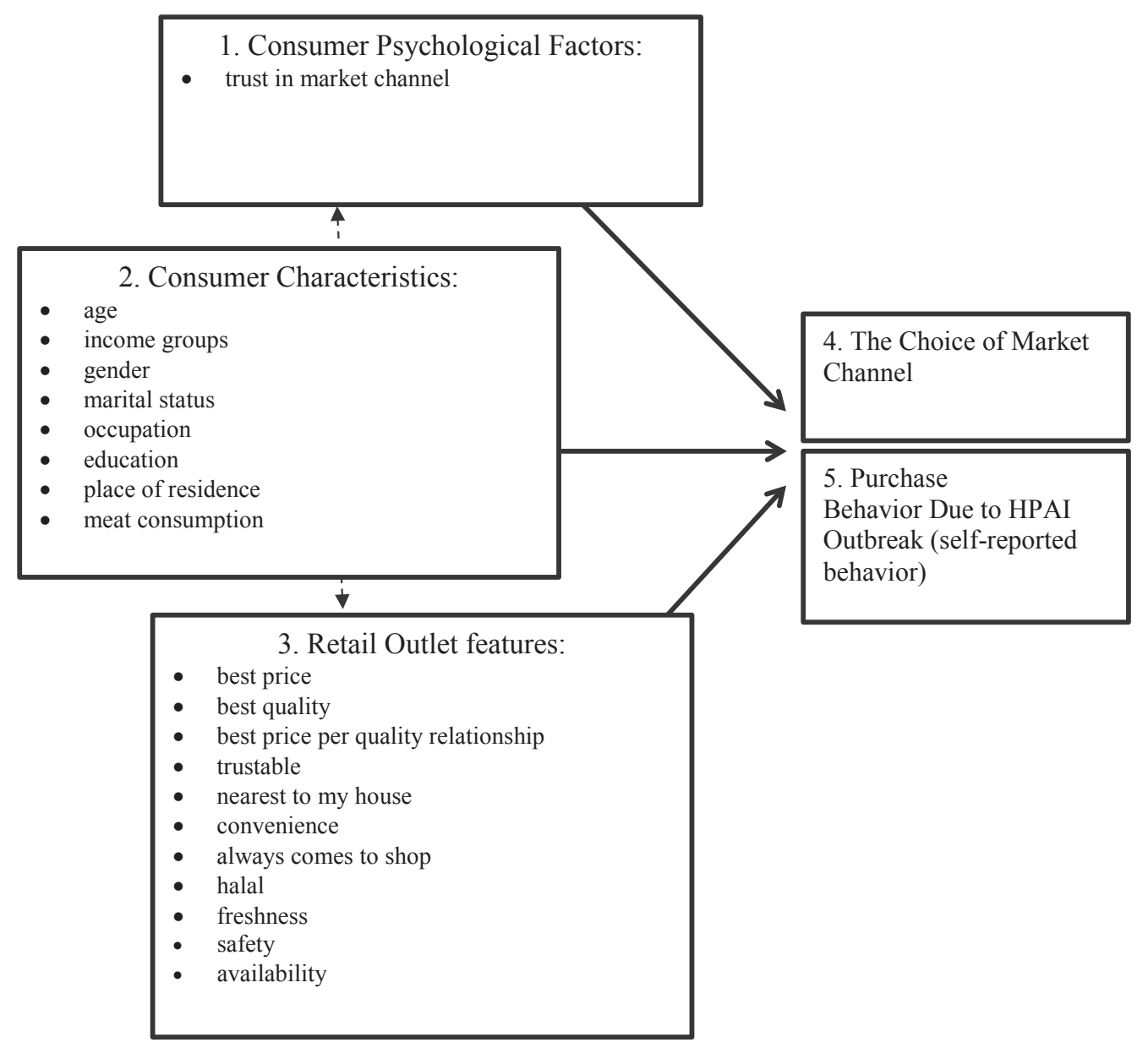

Figure 5.1 Research framework for the choice of poultry market channel and the change of purchase behavior due to HPAI outbreak.

The second part of the questionnaire consisted of a set of standard questions on consumer characteristics: age, income groups, gender, marital status, occupation, education, place of residence, and meat consumption (Florkowski et al., 1999; Iton, 2015; Verbeke et al., 2011). The variables, income groups, gender, marital status, occupation, education, and place of residence were measured with a nominal scale. The variables age and meat consumption were measured with an interval scale.

The third part of the questionnaire contained a set of closed questions on market outlet features. The following features were used: "best price" (Chamhuri and Batt, 2009; Goldman and Hino, 2005; Sinha and Banerjee, 2004), "best quality” (Figuié and Truyen, 2006), "best price/quality 
relationship" (Vukasovič, 2014), "trustable" (Chamhuri and Batt, 2013a; Chamhuri and Batt, 2013b), "convenience" (Bonne and Verbeke, 2006; Chamhuri and Batt, 2009), "halal" (Chamhuri and Batt, 2009; Chamhuri and Batt, 2013a), "freshness" (Goldman and Hino, 2005; Goldman et al., 1999; Sujiwo et al., 2018; Vanhonacker et al., 2016; Verbeke and Viaene, 2000), "safety" (Figuié and Truyen, 2006), "nearest to my house," "habit," and "availability" (Vanhonacker et al., 2016).

The fourth part of the questionnaire was aimed at the market channel where the consumer usually buys poultry meat. The following outlets were defined: wet markets, street vendors, supermarkets, hypermarkets and specialty stores (Daryanto et al., 2014). Responses were grouped into 2 market channels: traditional and modern channels.

The last part of the questionnaire contained questions on the consumers' change of poultry purchase behavior due to HPAI outbreaks. Answers could be: not changed, changed product, changed outlet, changed seller, and changed channel. The responses were grouped into 2 actions: a change of purchase behavior due to HPAI outbreaks or no change in purchase behavior.

The questionnaire was developed in English and translated into Bahasa (Indonesian Language). In order to check the validity of the translations, the questionnaire was then translated back to English by a different person and compared with the original questionnaire. Then, the questionnaires were pre-tested with 30 respondents at different market outlets. Feedback from the pre-test survey initiated minor changes in the final questionnaire.

\subsubsection{Sample size and design}

The method of non-probability sampling, also known as quota sampling, was used to select the respondents. This method is the non-probabilistic analog of stratified random sampling. It is typically used to assure that smaller groups are adequately represented in the sample. First, the quota was designed to have $60 \%$ of the respondents of the DKI Jakarta Region and $40 \%$ of the respondents from the surrounding areas. The rationale was to have more information of the higher income population in DKI Jakarta region. In addition, the surrounding area provides the information of middle and low income population. 
The second quota concerned different income groups. The definition of income groups was based on the classification of individual expenditures per capita per month per region in the 2013 National Socio-Economic Survey (Jakarta and surroundings). Assuming that the lowest number of family members is 3 , the individual expenditures were transformed into family expenditures. Also, the 8 original classes were reduced to 4 classes by combining the lower and the higher expenditure groups.

The third quota was aimed at having $30 \%$ of the respondents in the modern channel and $70 \%$ in the traditional channel. Although $20 \%$ of the poultry meat is bought in the modern channel, in order to have a sufficiently large sample to draw statistically sound conclusions, the modern channel respondents' quota was set at 30 . The quota for the traditional channel was split over the wet markets ( $40 \%$ of the respondents) and street vendors (30\% of the respondents).

Table 5.1 The stratified number of respondents per area, market type and income level.

\begin{tabular}{|c|c|c|c|c|c|c|c|}
\hline \multirow[t]{2}{*}{$\begin{array}{l}\text { Expenditure per } \\
\text { month }\end{array}$} & \multicolumn{3}{|c|}{ Jakarta } & \multicolumn{3}{|c|}{$\begin{array}{c}\text { Outside Jakarta } \\
\text { (surrounding region) }\end{array}$} & \multirow[t]{2}{*}{ Total } \\
\hline & $\begin{array}{c}\text { Wet } \\
\text { market }\end{array}$ & $\begin{array}{l}\text { Street } \\
\text { Vendor }\end{array}$ & $\begin{array}{c}\text { Modern } \\
\text { market }\end{array}$ & $\begin{array}{c}\text { Wet } \\
\text { market }\end{array}$ & $\begin{array}{l}\text { Street } \\
\text { Vendor }\end{array}$ & $\begin{array}{c}\text { Modern } \\
\text { market }\end{array}$ & \\
\hline$>137.7$ Euro & 199 & 36 & 94 & 110 & 74 & 52 & 565 \\
\hline 91.8 - 137.6 Euro & 65 & 22 & 41 & 56 & 33 & 18 & 235 \\
\hline 55.1 - 91.7 Euro & 61 & 21 & 32 & 33 & 38 & 15 & 200 \\
\hline$<55.1$ Euro & 24 & 14 & 17 & 11 & 20 & 10 & 96 \\
\hline Total & 349 & 93 & 184 & 210 & 165 & 95 & 1,096 \\
\hline
\end{tabular}

Based on Slovin's methods (Slovin, 1960) and the designed quota, using a $5 \%$ error tolerance, the data collection was aimed at 1,032 respondents. Practically, to collect data in the traditional channel, 2 wet markets and 1 area of poultry street vendors were selected in South Jakarta. For each of the areas East Jakarta, Bekasi and Bogor, 1 wet market and 1 area of street vendors were selected. In total, data in the traditional channel were collected in 5 wet markets and 4 areas with poultry street vendors. In the modern channel there are not too many outlets. Therefore, to collect data in the modern channel, the enumerators had the freedom to find respondents at every outlet in the modern channel for each of the areas South Jakarta, East Jakarta, Bekasi, and Bogor. Interviews were held with respondents who, at the time of the interview, were buying poultry meat. The final number of respondents was 1,096 with a slightly different quota composition than planned (table 5.1). 


\subsubsection{Data analysis}

Before further statistical analyses, first the variables were tested for univariate normality using chi-square test. The data were normally distributed $(\mathrm{P}=0.000)$ with a $95 \%$ significance level and therefore valid for further analysis. Because the trust variable had 7 possible responses, those responses were tested on reliability using Cronbach's alpha. The resulting Cronbach's alpha of 0.8883 indicates that the average correlation of the set of items within the construct was an accurate estimate of the average correlation of all items that pertain to the trust variable construct. Hence, we used the average of the 7 attribute values as the new trust variable value. Next, we grouped the new trust variable value as follows: low trust (1 to 3 points) and high trust (4 to 5 points). After that, we tested the trust variables for reliability using the Cronbach's alpha (0.789), and the result was regarded as reliable.

A descriptive statistical analysis was carried out to summarize the respondents' responses using cross-tabulation. Differences between the determinant factors in the different market channels and between the determinant factors and the respondents' change of behavior due to HPAI outbreaks, were statistically tested using Pearson's chi-square.

Finally, multivariable logistic regression analysis was employed to measure the association of relevant determinant factors to the respondents' choice of market channel and the change of purchasing behavior of respondents due to HPAI outbreaks. The logistic regression is a robust test predicting the probability of an event taking place (Hair et al., 1998). Before the logistic regression, Spearman's correlation coefficients between the variables were determined to check for multicollinearity. Because all correlations were smaller than 0.7 , it was concluded that multicollinearity was not present.

The general format of the multivariate logistic regression model is shown by Equation 1 as follows:

$\ln \left(\frac{v}{1-v}\right)=\beta_{0}+\beta_{1} X_{1}+\beta_{2} X_{2}+\beta_{3} X_{3}+\cdots+\beta_{p} X_{p}$

where the $\log$ of the odds of the outcomes is represented by $\ln \left(\frac{v}{1-v}\right)$ (i.e., high level or low 
level of trust, best price or not, best quality or not, best price/quality relationship or not, trustable or not, nearest to my house or not, convenience or not, always comes to shop or not, halal or not, freshness or not, safety or not, availability or not, choose to shop in the modern channel or not, and reported change of purchase behavior or not, represented by $(v)$ and $(1-v)$, respectively), estimated intercept is represented by $\beta_{0}$, and the coefficient regression of each independent variable included in the analysis is represented by $\beta_{1} \ldots \beta_{p}$.

Analyses chi-square and Pearson's chi-square were carried out with SPSS 22 (IBM Corp. New York.), analyses Cronbach's alpha, Spearman's correlation coefficients, descriptive statistics, and logistic regressions were carried out with Stata 13 (StataCorp., Texas).

\subsection{Results}

Table 5.2 provides an overview of the 11 social-demographic characteristics for respondents in the 2 different market channels, and for respondents who did and did not change their meat purchase due to HPAI outbreaks. Five social-demographic characteristics, trust, education, place of residence, meat purchase and outlet features, were significantly $(\mathrm{P}<0.05)$ associated with the choice of market channel. Consumers with a senior high school education did mostly purchase meat at the traditional channel, whereas consumers with a higher education seemed to purchase more at the modern channel. The within-class differences in the other 4 significant socio-demographic characteristics were less prominent (Table 5.2). More (nine) socialdemographic consumer characteristics were significantly $(\mathrm{P}<0.05)$ associated with the selfreported change in purchase behavior due to HPAI. These factors were type of market channel, trust, age, income, gender, marital status, place of residence, total amount of meat per purchase and outlet features. Consumers living outside of Jakarta were more likely to change their purchase behavior due to HPAI outbreaks. Likewise, consumers purchasing small amounts of meat were also more likely to change their purchase behavior due to HPAI outbreaks. The within-class differences in the other 7 significant socio-demographic were less prominent. 
Table 5.2. Descriptive statistics (counts) of the social-demographic characteristics of the respondents in relation to their choice of market channel and their change in meat purchase behavior due to HPAI outbreaks.

\begin{tabular}{|c|c|c|c|c|c|c|c|}
\hline \multirow[t]{2}{*}{ General Characteristics } & \multicolumn{3}{|c|}{ Market channel } & \multicolumn{4}{|c|}{$\begin{array}{l}\text { Changing purchase behavior due to HPAI } \\
\text { outbreaks }\end{array}$} \\
\hline & Traditional & Modern & $P$ value & No & Yes & $\begin{array}{c}\text { Don't } \\
\text { know AI }\end{array}$ & $\mathrm{P}$ value \\
\hline Market & & & & & & & 0.000 \\
\hline Traditional & - & - & - & 408 & 346 & 63 & \\
\hline Modern & & & & 101 & 172 & 6 & \\
\hline Trust toward market channel & & & 0.000 & & & & 0.022 \\
\hline High trust & 636 & 259 & & 398 & 438 & 59 & \\
\hline Low trust & 181 & 20 & & 111 & 80 & 10 & \\
\hline Age Group & & & 0.641 & & & & 0.000 \\
\hline$<25$ years old & 64 & 14 & & 21 & 49 & 8 & \\
\hline $26-30$ years old & 118 & 43 & & 66 & 86 & 9 & \\
\hline $31-35$ years old & 171 & 61 & & 117 & 100 & 15 & \\
\hline $36-40$ years old & 166 & 58 & & 114 & 90 & 20 & \\
\hline 41-45 years old & 118 & 46 & & 90 & 70 & 4 & \\
\hline$>45$ years old & 180 & 57 & & 101 & 123 & 13 & \\
\hline Income Groups per month & & & 0.844 & & & & 0.049 \\
\hline$>137.7$ Euro & 419 & 146 & & 259 & 279 & 27 & \\
\hline 91.8 - 137.6 Euro & 176 & 59 & & 110 & 109 & 16 & \\
\hline 55.1 - 91.7 Euro & 153 & 47 & & 103 & 83 & 14 & \\
\hline$<55.1$ Euro & 69 & 27 & & 37 & 47 & 12 & \\
\hline Gender & & & 0.868 & & & & 0.043 \\
\hline Male & 67 & 22 & & 30 & 52 & 7 & \\
\hline Female & 750 & 257 & & 479 & 466 & 62 & \\
\hline Marital Status & & & 0.142 & & & & 0.000 \\
\hline Married & 750 & 258 & & 483 & 465 & 60 & \\
\hline Single & 46 & 19 & & 11 & 47 & 7 & \\
\hline Divorced & 21 & 2 & & 15 & 6 & 2 & \\
\hline Occupation & & & 0.365 & & & & 0.648 \\
\hline Non Housewife & 361 & 132 & & 232 & 227 & 34 & \\
\hline Housewife & 456 & 147 & & 277 & 291 & 35 & \\
\hline Education & & & 0.018 & & & & 0.096 \\
\hline Lower Education & 171 & 42 & & 83 & 117 & 13 & \\
\hline Senior High School & 361 & 116 & & 232 & 219 & 26 & \\
\hline University & 285 & 121 & & 194 & 182 & 30 & \\
\hline Place of residence & & & 0.001 & & & & 0.001 \\
\hline DKI Jakarta & 442 & 184 & & 317 & 265 & 44 & \\
\hline $\begin{array}{l}\text { Outside Jakarta } \\
\text { (Bogor, Depok, Tangerang, } \\
\text { Bekasi) }\end{array}$ & 375 & 95 & & 192 & 253 & 25 & \\
\hline Kilogram Meat per Purchase & & & 0.007 & & & & 0.000 \\
\hline$<=1 \mathrm{~kg}$ & 461 & 183 & & 274 & 336 & 34 & \\
\hline Above $1 \mathrm{~kg}$ & 356 & 96 & & 235 & 182 & 35 & \\
\hline Outlet Features & & & 0.000 & & & & 0.000 \\
\hline Best price & 65 & 12 & & 45 & 27 & 5 & \\
\hline Best Quality & 176 & 94 & & 155 & 111 & 4 & \\
\hline Best price/quality & 16 & 42 & & 13 & 43 & 2 & \\
\hline Trustable & 57 & 14 & & 23 & 31 & 17 & \\
\hline Nearest to house & 220 & 28 & & 121 & 105 & 22 & \\
\hline Convenience & 99 & 60 & & 73 & 82 & 4 & \\
\hline Always comes to shop & 20 & 4 & & 8 & 11 & 5 & \\
\hline Halal & 11 & 5 & & 5 & 11 & 0 & \\
\hline Freshness & 141 & 8 & & 55 & 84 & 10 & \\
\hline Safety & 2 & 4 & & 4 & 2 & 0 & \\
\hline Availability & 10 & 8 & & 7 & 11 & 0 & \\
\hline
\end{tabular}

$P$-values denote the results of the chi-square test. Significance in 0.05 (bold).

HPAI, highly pathology avian influenza. 
Table 5.3. Odd ratio (OR) of the variables in the estimated logistic regression model for the consumers' choice of market channel and their purchase behavior due to HPAI outbreaks.

\begin{tabular}{|c|c|c|c|c|c|c|c|}
\hline & \multirow[t]{2}{*}{ Determinant } & \multicolumn{3}{|c|}{ Choice of Market Channel } & \multicolumn{3}{|c|}{$\begin{array}{c}\text { Changing purchase behavior due } \\
\text { to HPAI Outbreak }\end{array}$} \\
\hline & & OR & $95 \%$ CI & P value & OR & $95 \%$ CI & P value \\
\hline \multicolumn{8}{|c|}{ Consumer Psychological Factor } \\
\hline & Low Trust (reference) & 1 & & & 1 & & \\
\hline & High Trust & 5.52 & $3.24-9.41$ & 0.000 & 1.50 & $1.06-2.13$ & 0.023 \\
\hline \multicolumn{8}{|c|}{ Consumer characteristics } \\
\hline \multirow[t]{6}{*}{ Age Group } & $<25$ years old (reference) & 1 & & & 1 & & \\
\hline & 26-30 years old & 1.92 & $0.80-4.63$ & 0.146 & 0.84 & $0.41-1.73$ & 0.625 \\
\hline & $31-35$ years old & 2.06 & $0.85-4.98$ & 0.110 & 0.64 & $0.31-1.31$ & 0.220 \\
\hline & $36-40$ years old & 2.35 & $0.96-5.75$ & 0.061 & 0.62 & $0.30-1.28$ & 0.197 \\
\hline & 41-45 years old & 1.73 & $0.69-4.35$ & 0.242 & 0.53 & $0.25-1.11$ & 0.092 \\
\hline & $>45$ years old & 2.26 & $0.92-5.61$ & 0.078 & 0.89 & $0.43-1.83$ & 0.754 \\
\hline Income & $<55.1$ Euro (reference) & 1 & & & 1 & & \\
\hline Groups per & 55.1 - 91.7 Euro & 0.61 & $0.31-1.18$ & 0.141 & 0.65 & $0.37-1.15$ & 0.138 \\
\hline \multirow{2}{*}{ month } & 91.8 - 137.6 Euro & 0.59 & $0.31-1.13$ & 0.114 & 0.81 & $0.46-1.43$ & 0.471 \\
\hline & $>137.7$ Euro & 0.66 & $0.36-1.20$ & 0.175 & 0.93 & $0.55-1.57$ & 0.781 \\
\hline \multirow[t]{2}{*}{ Gender } & Male (reference) & 1 & & & 1 & & \\
\hline & Female & 0.90 & $0.48-1.71$ & 0.751 & 0.65 & $0.37-1.15$ & 0.115 \\
\hline \multirow{3}{*}{$\begin{array}{l}\text { Marital } \\
\text { Status }\end{array}$} & Married (reference) & 1 & & & 1 & & \\
\hline & Single & 2.24 & $0.95-5.24$ & 0.064 & 3.75 & $1.64-8.59$ & 0.002 \\
\hline & Divorced & 0.33 & $0.07-1.52$ & 0.154 & 0.29 & $0.11-0.81$ & 0.018 \\
\hline \multirow[t]{2}{*}{ Occupation } & $\begin{array}{l}\text { Non Housewife } \\
\text { (reference) }\end{array}$ & 1 & & & 1 & & \\
\hline & Housewife & 1.00 & $0.69-1.46$ & 0.982 & 1.34 & $0.98-1.83$ & 0.070 \\
\hline \multirow[t]{3}{*}{ Education } & Lower Education & 1 & & & 1 & & \\
\hline & Senior High School & 1.15 & $0.72-1.84$ & 0.551 & 0.70 & $0.49-1.02$ & 0.063 \\
\hline & University & 1.41 & $0.85-2.33$ & 0.190 & 0.74 & $0.49-1.12$ & 0.157 \\
\hline \multirow{2}{*}{$\begin{array}{l}\text { Place of } \\
\text { residence }\end{array}$} & DKI Jakarta (reference) & 1 & & & 1 & & \\
\hline & $\begin{array}{l}\text { Outside Jakarta } \\
\text { (Bogor, Depok, } \\
\text { Tangerang, Bekasi) }\end{array}$ & 0.62 & $0.44-0.86$ & 0.005 & 1.84 & $1.39-2.44$ & 0.000 \\
\hline Kilogram & $<=1 \mathrm{~kg}$ (reference) & 1 & & & 1 & & \\
\hline Meat per & Above $1 \mathrm{~kg}$ & 0.48 & $0.34-068$ & 0.000 & 0.43 & $0.43-0.78$ & 0.000 \\
\hline \multicolumn{8}{|c|}{ Purchase } \\
\hline \multicolumn{8}{|c|}{ Outlet features } \\
\hline & Best price (reference) & 1 & & & 1 & & \\
\hline & Best Quality & 3.49 & $1.72-7.07$ & 0.001 & 1.20 & $0.62-1.94$ & 0.752 \\
\hline & Best price/quality & 13.73 & $5.51-34.19$ & 0.000 & 5.37 & $2.37-12.19$ & 0.000 \\
\hline & Trustable & 1.05 & $0.43-2.55$ & 0.920 & 1.91 & $0.89-4.08$ & 0.097 \\
\hline & Nearest to house & 0.56 & $0.26-1.20$ & 0.134 & 0.99 & $0.55-1.78$ & 0.964 \\
\hline & Convenience & 3.98 & $1.89-8.36$ & 0.000 & 1.92 & $1.04-3.52$ & 0.037 \\
\hline & Always comes to shop & 0.73 & $0.21-2.61$ & 0.631 & 2.26 & $0.77-6.62$ & 0.136 \\
\hline & Halal & 2.43 & $0.64-9.25$ & 0.195 & 3.44 & $0.99-11.88$ & 0.050 \\
\hline & Freshness & 0.24 & $0.09-0.64$ & 0.004 & 2.30 & $1.23-4.28$ & 0.009 \\
\hline & Safety & 13.51 & $1.94-93.96$ & 0.008 & 1.23 & $0.20-7.40$ & 0.824 \\
\hline & Availability & 4.73 & $1.39-15.97$ & 0.012 & 3.18 & $1.03-9.79$ & 0.044 \\
\hline Constanta & & 0.05 & $0.01-0.19$ & 0.000 & 1.22 & $0.38-3.88$ & 0.737 \\
\hline \multicolumn{2}{|c|}{ Log likelihood } & & & -490.28001 & & & -644.94184 \\
\hline \multicolumn{2}{|c|}{ Number of obs } & & & 1096 & & & 1027 \\
\hline \multicolumn{2}{|c|}{ LR chi2(16) } & & & 262.94 & & & 133.76 \\
\hline \multicolumn{2}{|l|}{ Prob $>$ chi2 } & & & 0.0000 & & & 0.0000 \\
\hline Pseudo R2 & & & & 0.2115 & & & 0.0940 \\
\hline
\end{tabular}

$P$ values denote the significance of variable association to the choice of market channel and change purchase behavior. Value in bold = significance in 0.05

HPAI, highly pathology avian influenza. 
Table 5.3 gives the results of 2 logistic regression model estimations of the determinant factors that significantly associated with the consumers' choice of poultry market channel, and the consumers' change of purchase behavior due to HPAI. The logistic regression model of choice of poultry market channel was significant whereby $21 \%$ of the variation could be explained by the model (pseudo R2 value $=0.2115$ ). The 2 most influential among 9 significant variables that were associated with the consumers' choice of modern channel were the best price/quality relationship variable and the safety variable. The other variables that were significantly $(\mathrm{P}<0.05)$ associated with the choice of the modern channel were best quality, convenience, availability, and a high level of trust in the market channel. Three determinants were associated with the respondents' choice of the traditional channel: freshness as an outlet feature, living outside Jakarta, and purchasing more than $1 \mathrm{~kg}$ of meat.

Table 5.3 presents the significant variables that were associated with the consumers' change of purchase behavior due to HPAI. The model did explain $9 \%$ of the variation (the pseudo R2 value $=0.0940$ ). Best price/quality was the most influential variable to the consumers' change of purchase. The other significant variables associated to the consumers' change of purchase were convenience, halal, freshness, availability, a high level of trust, being single, and living outside Jakarta

\subsection{Discussion}

In this study we provided more insight in the relevant determinants of the choice for a market channel and the change in purchase behavior due to HPAI outbreaks. We focused on consumer psychological factors, consumer characteristics, and outlet features, and related those to the choice for a market channel and the change of purchase behavior due to HPAI outbreaks

The most important variables related to the choice for the modern poultry market channel were the price/quality relationship, the safety feature, and the level of consumer trust. The most important variables for the choice for the traditional poultry market channel were freshness, living outside Jakarta, and the amount per purchase. Some variables explaining the change in purchase behavior due to HPAI outbreaks were similar to those for the choice of market channel (the price/quality relationship, the level of consumer trust, living outside Jakarta, and the amount per purchase). Those results support the notion that consumers' decisions in 
purchase behavior are related to the microbiological hazard incidents (Figuié and Fournier, 2008; Yeung and Morris, 2001). If the government were to pull producers toward the modern channel by means of a change in preference of consumers, the government should take those factors into account.

The relationship between price and quality was an important factor for the consumers to choose for the modern channel, as well as for a change in purchase behavior. Also Yu et al. (2011) showed that the relationship between the perceived channel quality, price and value determines the consumers' choice of market channel, and that the intention to switch channels is related to price attributes. Therefore, a government can influence the price/quality relationship of the preferred market channel by subsidies and/or taxes. For instance, by subsidizing the modern channel the price/quality relationship of poultry sold in that channel can be improved. The other way around, by additional or increased taxes, the price quality relationship of poultry in the traditional channel can be decreased. However, in the Indonesian situation these types of measures are difficult to implement. The Indonesian poultry consumers use quality and freshness interchangeably (Chamhuri et al., 2015). In other words, freshness is a synonym for quality. Quality relies on the consumers' perceptions and judgments of the products (Chamhuri and Batt, 2015). Therefore, another option to increase the price/quality relationship is by promoting the quality aspect of the poultry in the modern channel. Such a campaign should focus on the safety of poultry in the modern channel, but should also take freshness into account, as, in our findings, it was clear that freshness was an important argument for the consumers who purchased poultry on the traditional market, a fact that was also shown in earlier research (Chamhuri et al., 2015; Daryanto et al., 2014). For Indonesian consumers, freshness is related to slaughtering on the spot or the night before sales. As long as consumers link freshness to the time between slaughtering and sales, the modern channel will have a negative image with regard to freshness. That means the government should communicate a redefinition of freshness, linking this term to the quality and the taste of poultry rather than to the time since slaughtering.

Another factor related to the purchase of poultry meat in the traditional channel was living outside Jakarta. This might be related to a higher availability of traditional outlets outside Jakarta. So by increasing the availability of modern outlets outside Jakarta, consumers may change their preference toward the modern channel. 
The amount of poultry (more than $1 \mathrm{~kg}$ ) purchased was also associated with buying in the traditional channel. This may have been related to the lower price of poultry in the traditional market compared to the modern market. This aspect might be changed by the aforementioned measures with regard to subsidies and taxes.

Finally, it was shown that the psychological factor level of trust was higher for consumers who purchased poultry meat in the modern channel, and for consumers who changed their purchase behavior after an HPAI outbreak. This can be seen as a result of the higher level of food safety in the modern channel and shows the degree of consumer confidence in the market channel (de Jonge et al., 2007; Drescher et al., 2012).

The study was done in 2013; however since that time, the poultry market and socioeconomic circumstances in western Java have not changed very much “(D. Indrawan, unpublished data).” That means the information is still relevant to the current situation in Western Java and can be used to support the Indonesia government with decisions on how to change consumers' preferences towards a modern market channel. However, this study has a few limitations. The study was designed to model the consumers' choice of poultry market channel and a change in purchase behavior due to HPAI outbreaks. Therefore, we only looked at the factors behind poultry purchase in a specific market channel, making this study rather descriptive. We did not consider the factors that motivate or demotivate consumers in the traditional channel to change to the modern channel. Furthermore, the questions with regard to a change after HPAI outbreaks did only look at a change in purchase behavior and did not check the effect of product substitution from poultry to beef or fish. These might have been a reason that the pseudo R2 of both logistic regression models was relatively low (0.2115 and 0.0940 respectively). Finally, the conceptual model we used, based upon consumer psychological factors, consumer characteristics and retail outlet features was adapted from studies in Europe and United States (Heider and Moeller, 2012; Spiggle and Sewall, 1987) and may not have been appropriate for the Indonesian situation. In future studies, other explanatory variables that are specifically related to the population under study can be added to each factor. However, the results of this study are the first of its kind and can be seen as a first indication for the Indonesian government in what direction they should implement their policies to restructure the poultry supply chain. 


\subsection{Conclusions}

This study provides information about consumers' preferences with regard to their choice of market channel. Results can be used to change the consumers' preference toward a modern market channel. This can be done by improving the price/quality relation of the poultry in the modern market channel, for instance by changing taxes and/or subsidies, as well as by advertising the food safety features of the modern market channel. Special attention should be paid to the perceived freshness that consumers associate with the traditional market channel. By changing the preference of the consumers toward the modern poultry market channel, the Indonesian government can pull producers toward this channel, thus making poultry supply more safe.

\section{Acknowledgements}

The first author is funded by an LPDP scholarship. The funder had no role in the contents of this study. The authors would like to acknowledge the Dutch-Indonesian Food Security Program: Poultry \& Dairy Sector (2013-2016) for the data support and collection. We are thankful to Ivo van der Lans, Paul Ingenbleek, Ujang Sumarwan and Idqan Fahmi for valuable input, and to Asep Rakhmat and Indhy Aidha for organizing the interviews. 


\section{Chapter 6}

\section{Willingness to pay for poultry meat attributes: \\ A discrete choice experiment in multi-market channels}

Authors: Dikky Indrawan, Accesstia Christy, Henk Hogeveen

Submitted for publication 


\begin{abstract}
This study explains Indonesian consumers' choice of attributes of poultry meat and the willingness to pay (WTP) for these attributes using a discrete choice experiment. The survey was conducted for the traditional and the modern channels and involved a sample of 440 respondents in the Greater Jakarta Area. A multinomial logistic regression analysis was used to evaluate the consumers' preference for poultry attributes. Consumers had a preference for warm poultry meat, government certification, and product information label. The WTP for warm poultry meat was the highest which indicates that freshness is very important for the consumers to ensure quality. The ordinary least square analysis indicated that the market channel had an influence on the WTP for warm and chilled poultry meat, WTP for no certification, and the WTP for poultry meat without a product information label. This study shows that understanding the WTP for poultry meat attributes enables the government to make the poultry supply safer using the price mechanism.
\end{abstract}

Keywords: poultry meat attributes; non-food safety attribute; food safety attribute; willingness to pay; discrete choice experiment 


\subsection{Introduction}

Food safety challenges include of microbial hazards, such as avian influenza, salmonella, campylobacter, listeria monocytogenes, clostridium perfringens, and E. coli O157 (Mead, 2004; Meredith et al., 2013; Yeung and Morris, 2001), and chemical hazards such as formaldehyde, aflatoxins and veterinary drugs (Fardiaz et al., 2011; Kiilholma, 2008; Sparringa, 2014). The Indonesia poultry meat industry faced a food safety challenge after the outbreak of highly pathogenic avian influenza (HPAI) H5N1 in 2005 because of a complex poultry chain structure with an interaction between traditional and modern channels where a sick poultry market exist (Indrawan et al., 2018a). Three factors can be identified as the main sources of the food safety challenge: first, the current food safety control systems in Indonesia are weak (Bahri, 2008; Hariyadi, 2008); second, some consumers prefer to buy poultry meat from traditional channel with low food safety levels (Indrawan et al., 2018a; Indrawan et al., 2018b; Muladno and Thieme, 2009); third, some consumers were taken into account price and freshness presentation when purchasing poultry (Daryanto et al., 2014; Indrawan et al., 2018a; Indrawan et al., 2018b). These reasons suggest the preferences of Indonesian consumers for poultry meat attributes are not related to food safety.

After the outbreak of avian influenza in 2005, government effort to overcome the problem by increasing controls of live birds entering the traditional channel was not successful. Since the consumers still prefer to purchase their poultry meat from the traditional channel (Muladno and Thieme, 2009). The poultry meats they buy were in the form of wholesome, which was slaughter early in the morning (Daryanto et al., 2014; Indrawan et al., 2018a). Thus, changing the consumers' preferences was suggested to increase the poultry meat quality and safety (Indrawan et al., 2018a).

Reducing the demand for poultry meat bought from unsafe market channels is one key to overcome the food safety challenge, since it will pull the market towards safer production processes. The improvement of food safety and quality is a critical factor to reduce the number of food safety incidents (Grunert, 2005; Grunert et al., 2004; Scallan et al., 2011; Scott, 2003). If the government decides to raise the food safety level of poultry meat, it is important to ensure that the consumers will recognize this. Moreover, it is important to know whether they are willing to pay for it. The actors in the poultry chain produce a high variety of poultry meat quality, following the consumers' heterogeneous poultry meat preferences (Verbeke and 
Viaene, 1999). Therefore, a new poultry meat safety standard has to match the consumers' demand for the poultry actors to produce poultry meat of a higher quality.

Consumers rely on experienced quality and credence attributes of a product as their quality cue when making buying decisions (Grunert, 2005; Grunert et al., 2004; Issanchou, 1996). These attributes can consist of non-food safety attributes (e.g. freshness, taste (sensory), environment, animal welfare) and food safety attributes (e.g. certification, product information label, country of origin). By evaluating consumers' willingness to pay (WTP) for these quality attributes, food safety policies in the multi-market channels can be developed. Studies on non-food safety attributes found that consumers rely on intrinsic cues (e.g. cut, color, fat) to evaluate a product (Grunert, 2005; Grunert et al., 2004) but the demands for intrinsic values of meat are heterogeneous and difficult to (Henchion et al., 2014). Studies on food safety attributes concluded that food safety as a credence attribute is not easily evaluated by consumers. Instead, consumers tend to rely on the intrinsic and extrinsic cues to assume food safety (Angulo and Gil, 2007; Grunert, 2005; Grunert et al., 2004). Research on non-food safety and food safety attributes in relation to WTP for poultry meat is limited. For example, studies in Indonesia, such as Indrawan et al. (2018a), Indrawan et al. (2018b) and Muladno and Thieme (2009), identified the role of the freshness attribute in the poultry demand of Indonesian consumers, but did not explore WTP for freshness as a non-food safety attribute. While the WTP for poultry meat with 'country of origin' as food safety attribute was evaluated in a 2010 meta-analysis (Cicia and Colantuoni, 2010), to the best of our knowledge, there is very limited research available on the WTP for non-food safety or food safety attributes for poultry meat in Indonesia such as Lestari et al. (2016) and Wahida et al. (2013). Therefore, the overall objective of this research is to evaluate consumer preferences and WTP for poultry meat attributes in two market channels in the Greater Jakarta area: the modern channel and the traditional channel.

This paper assesses consumer preferences and WTP for a set of poultry meat attributes, using a choice experiment in multi-market channels. Carrying out a choice experiment can provide insight into consumer acceptability of the relative utility of attributes in a product (Probst et al., 2012; Rousseau and Vranken, 2013; Van Loo et al., 2011). Such an experiment can be combined with a WTP study for poultry meat attributes. To obtain this overall objective, the following specific objectives are included: (i) to identify the attributes of poultry meat that are accepted by consumers in different market channels, and (ii) to examine the preferences and WTP for poultry identified acceptable meat attributes in different market channels. 


\subsection{Material and methods}

\subsubsection{Selection of poultry meat attributes and consumers' WTP}

As a first step in the selection of poultry meat attributes, we studied the scientific literature on consumers' preferences and WTP for non-food safety and food safety attributes to purchase meat. The consumers' preferences and WTP for meat attributes have been an ongoing focus in many consumer studies (Font-i-Furnols and Guerrero, 2014; Grunert et al., 2004; Kehagia et al., 2007). Studies on meat quality attributes indicated several intrinsic (color, fat content, marbling) and extrinsic (price, origin, quality labels) cues as the most important factors in the consumers' intention to purchase food (Chamhuri and Batt, 2013c; Font-i-Furnols and Guerrero, 2014; Grunert, 2005; Grunert et al., 2004; Henchion et al., 2014; Hoffmann, 2000; Kennedy et al., 2004; Verbeke and Viaene, 1999). Some studies examined these cues as quality attributes for poultry meat (Castellini et al., 2008; Fletcher, 2002; Samant and Seo, 2016; Verbeke and Viaene, 1999). While studying the WTP for food safety in the Indonesian poultry market, preliminary interviews with local experts identified freshness, food safety certification (FSC) and product information label as the three most important experience quality and credence attributes. Freshness is the most important non-food safety attribute in Indonesia and often refers to poultry meat quality (Chamhuri et al., 2015). Chamhuri et al. (2015), Daryanto et al. (2014), and Indrawan et al. (2018a) also acknowledge freshness as an important utility that differentiates poultry meat consumers in multi-market channels. FSC is another important food safety attribute, providing a hygiene standard to prevent and reduce unacceptable risks of microbial and chemical hazards in food production (Lestari et al., 2016; Meuwissen et al., 2003; Wahida et al., 2013). Often, FSC as a food safety attribute cannot be separated from the application of a product information label. The food safety attribute 'product information label' plays an important role as an extrinsic cue for the consumers (Ortega et al., 2011; Wahida et al., 2013).

Previous studies on non-food safety attributes showed that consumers often look at freshness as one of the most important poultry meat attributes when buying poultry meat in market outlets (Goldman and Hino, 2005; Goldman et al., 1999; Verbeke and Viaene, 2000). Different definitions of freshness have been used to examine consumers' behavior in relation to poultry meat consumption (Bett et al., 2013; Martínez Michel et al., 2011; Maynard et al., 2003). In the 
context of the Indonesian poultry meat sector, freshness can be defined in three levels: warm, chilled, and frozen (Daryanto et al., 2014; Indrawan et al., 2018a). A previous study showed that in Indonesia freshness is defined differently than in western countries (Indrawan et al., 2018b), since many of the consumers prefer to buy poultry meat in the traditional channel, where the food safety level is lower than in the modern channel (Muladno and Thieme, 2009). The reason is that consumers perceive the freshness of the warm (freshly cut) poultry meat in the traditional channel to be better than that of chilled poultry meat in the modern channel (Indrawan et al., 2018a; Indrawan et al., 2018b).

The importance of food safety attributes for consumers was studied by examining two main attributes: FSC and product information labeling. These attributes were not applied in the most of poultry market channels in Indonesia. FSC was defined by Meuwissen et al. (2003) as a certified assessment and approval by an accredited party on food safety standards. Certification is essential for the improvement of the safety of poultry meat (Souza et al., 2015) and there are many studies on FSC as a meat quality attribute (Lestari et al., 2016; Loureiro and Umberger, 2007; Ortega et al., 2011; Wahida et al., 2013; Wu et al., 2016). Since FSC provides a hygiene standard and is supported by swift internalization in the food industry, the demand for a public or private FSC has increased considerably (Meuwissen et al., 2003; Trienekens and Zuurbier, 2008). Hence, many studies examined the WTP for FSC (Lestari et al., 2016; Ortega et al., 2011; Owusu-Sekyere et al., 2014; Wahida et al., 2013; Wu et al., 2016). Other studies on FSC revealed that many consumers have less confidence in the government to guarantee food safety, due to past food safety incidents. However, private FSC provides higher levels of quality, safety, and traceability than government regulations (Albersmeier et al., 2009; Qijun and Batt, 2016; Simmons, 2010). A study on WTP for third-party FSC met with consumer approval (Ortega et al., 2011). Although many food safety systems were established in the Indonesian poultry meat chain, FSC implementation was limited because of inadequate monitoring (Bahri, 2008; Hariyadi, 2008).

As an important food safety attribute, alongside with FSC, a product information label provides information about the product on a label attached to the product package. Many food safety studies relate to product information labeling, since such a label is a cue of the meat quality (Stranieri and Banterle, 2015; Verbeke and Ward, 2006; Wahida et al., 2013) influences consumers' meat-buying preferences (Font-i-Furnols and Guerrero, 2014; Makanyeza et al., 2016). Product information labeling, when provided alone, does not increase consumers' utility 
significantly. However, this attribute will increase consumers' utility when provided together with a traceability standard (Ortega et al., 2011). Many studies show that consumers are willing to pay more for food products with a specific credence attributes label (Hu et al., 2011; Kehlbacher et al., 2012; Van Loo et al., 2011; Wahida et al., 2013). Another study proves that product information labeling is able to signal product quality from food safety certification since the consumers have more trust in certified labeling (Schleenbecker and Hamm, 2013).

\subsubsection{Design of the choice experiment for poultry meat}

The choice experiment in this study was based on Lancaster's consumer theory (Lancaster, 1966), which states that consumer choice (maximizing utility) is directed towards combinations of product attributes rather than goods. Combined with the random utility theory that describes the utility $\mathrm{U}$ of an alternative as the sum of observed and unobserved components (McFadden, 2001).

Table 6.1 Selected attributes and levels for experimental design.

\begin{tabular}{ll}
\hline Attribute & Attribute Level \\
\hline Freshness & $\begin{array}{l}\text { Warm poultry, } \\
\text { chilled poultry, } \\
\text { frozen poultry }\end{array}$ \\
& $\begin{array}{l}\text { Government, } \\
\text { private, } \\
\text { Fo-certification }\end{array}$ \\
& Yes, \\
Label & No \\
& 2.11 \\
Price: $(€ /$ kg poultry $)$ & 2.46 \\
& 2.81
\end{tabular}

Note: $1 €=14,231$ IDR

We used a randomized choice-based conjoint research design that requires respondents to choose rather than rank or rate products. The randomized choice-based conjoint research design contained four attributes that are suitable to a local situation in the Greater Jakarta area. As shown in table 6.1, the final shortlisted attributes were freshness (3 levels), food safety certification (3 levels), label (3 levels), and price (3 levels). Warm represents poultry meat that 
recently slaughtered, while chilled and frozen represent longer time process. In food safety certification, we used the provider (instead of certification items such as brand, expiry date, country of origin, slaughtered date) government and private to examine the consumer trust towards provider if the FSC applied. We used the attribute price to calculate the WTP for poultry meat attributes, while we used other attributes to examine their utility. The price attribute consisted of three levels, based on the minimum, mean, and maximum price per $\mathrm{kg}$ poultry in the period of January-September 2016, based on the broiler poultry price at the website of the Poultry Farmer Association (PINSAR, 2016). The levels for the other 3 attributes were based on scientific literature as described earlier.

Table 6.2 Example of choice set in the questionnaire for consumers who purchase per kg poultry.

\begin{tabular}{llll}
\hline & A & B & C \\
\hline Freshness & Warm & Frozen & Neither of the \\
Food safety certification & Private & Government & options \\
Product information label & No & Yes & \\
Price $(€ /$ kg poultry) & 2.46 & 2.11 & \\
\hline I would choose & & & \\
\hline
\end{tabular}

We designed the combination of attributes and levels to be balanced and orthogonal, using a full factorial design (Kuhfeld, 1997), resulting in 54 possible choice sets. Since we considered the number of choices to be too overwhelming for one respondent to answer, we used a fractional factorial design to reduce the number of choices for each respondent $(\mathrm{Wu}$ et al., 2016). The questionnaires were computer-generated by Sawtooth Software (Lighthouse Studio version 9.2.0) to obtain 13 choice sets. Respondents were randomly offered different versions of choice sets (Chrzan and Orme, 2000). Using the random option, profiles were sampled (randomly, with replacement) from the thousands of possibilities and placed into choice sets. Since overlap can and will occur in such design, no two profiles were permitted within a choice set that was identical on all attributes (Chrzan and Orme, 2000). A number of level combinations between the attributes FSC and label were excluded, potentially resulting in imbalances and dependencies in the design. Therefore, we used D-efficiency to construct an orthogonal design, so that every pair of levels occurs equally across all of the pairs of factors in each design (Kuhfeld, 2005). Depending on the answer on how poultry was bought (per kilogram or as whole chicken), prices were provided as a price per kilogram or a price for a whole chicken. 
Besides the choice set, the questionnaire contained a number of additional questions to retrieve information on socio-demographic circumstances of the respondents. Closed questions were asked about age group, educational level, gender, income group and place of residence. An open question was asked about consumers' awareness of food hazards in order to obtain information about the respondents' knowledge about the safety of poultry.

\subsubsection{Sampling and administration}

Surveys were conducted in the Greater Jakarta Area because it is the largest poultry production and consumption area in Indonesia. Based on the method of (Slovin, 1960), and taking into account a 5\% margin error with Jakarta's population of 28,019,545 in 2014 (Statistics, 2016), the target number of respondents was 400 people. The survey 's sampling method used a quota sampling model based on the consumers' income classification in the Greater Jakarta Area, and we obtained 440 respondents (Table 6.3). The sample was split over modern market and traditional market (wet market and street vendor) to determine where the respondents mainly shop for poultry meat.

Table 6.3 Quota sampling in the Greater Jakarta area.

\begin{tabular}{|c|c|c|c|c|c|c|c|c|}
\hline & \multicolumn{4}{|c|}{ Jakarta Region (57\%) } & \multicolumn{4}{|c|}{ Jakarta Surrounding Region (43\%) } \\
\hline $\begin{array}{l}\text { Expenditure } \\
\text { per month }\end{array}$ & $\begin{array}{l}\% \text { of } \\
\text { sample }\end{array}$ & $\begin{array}{l}\text { Wet } \\
\text { market }\end{array}$ & $\begin{array}{l}\text { Modern } \\
\text { market }\end{array}$ & $\begin{array}{l}\text { Street } \\
\text { vendor }\end{array}$ & $\begin{array}{l}\% \text { of } \\
\text { sample }\end{array}$ & $\begin{array}{l}\text { Wet } \\
\text { market }\end{array}$ & $\begin{array}{l}\text { Modern } \\
\text { market }\end{array}$ & $\begin{array}{l}\text { Street } \\
\text { vendor }\end{array}$ \\
\hline $\begin{array}{l}\% \text { of sample } \\
\text { based on } \\
\text { channel } \\
\text { market }\end{array}$ & & $30 \%$ & $30 \%$ & $40 \%$ & & $30 \%$ & $30 \%$ & $40 \%$ \\
\hline$>€ 189.7$ & 13 & 10 & 10 & 13 & 27 & 15 & 15 & 21 \\
\hline$€ 147.6-189.7$ & 27 & 20 & 20 & 27 & 23 & 13 & 13 & 17 \\
\hline$€ 105.4-147.6$ & 28 & 21 & 21 & 28 & 21 & 12 & 12 & 16 \\
\hline$€ 63.3-105.4$ & 21 & 16 & 16 & 21 & 17 & 10 & 10 & 13 \\
\hline$<€ 63.3$ & 11 & 8 & 8 & 11 & 12 & 7 & 7 & 9 \\
\hline Total & & 75 & 75 & 100 & & 57 & 57 & 76 \\
\hline
\end{tabular}

Note: $1 €=14,231$ IDR

The surveys were conducted by nine trained enumerators. Each question was explained in a meeting and briefing session where all enumerators could give input. In a pilot survey conducted at different locations, respondents answered the questionnaire on a tablet through an offline Sawtooth Software application (SSI Web 9.2.). There were no changes in the 
questionnaires. Finally, the survey was conducted using a tablet. Consumers were approached in traditional markets, modern markets, neighborhoods, and places where target consumers were expected to gather, such as schools.

\subsubsection{Estimation of the probability of a chosen attribute}

First, we modeled the probability of attributes using Choice-based Conjoint-Hierarchical Bayes estimation, since the method allows for heterogeneity at the respondent's level. The utility for the attributes is derived from choices of the respondents for defined poultry meat alternatives consisting of different levels of the defined attributes. A specified level of utility was associated with any poultry meat alternative $\mathrm{j}$ for any respondent $\mathrm{i}$. Utility $(\mathrm{U})$ derived from any of the poultry meat alternatives was determined by the attributes of the poultry meat (expressed in vector $Z$ ), the freshness of poultry meat, the presence of food safety certification or the product information label. The utility of a choice consists of a deterministic part and follows a predetermined distribution. Thus, the respondent has a utility function of the form:

$$
\mathrm{U}_{\mathrm{ij}}=\mathrm{V}\left(\mathrm{Z}_{\mathrm{ij}}\right)+\varepsilon\left(\mathrm{Z}_{\mathrm{ij}}\right)
$$

Consumers' choices between alternatives were a function of the probability that the utility of respondent $\mathrm{i}$ associated with a particular poultry meat product $\mathrm{j}$, is higher than those for other alternatives. The relationship between utility and attributes was assumed to be linear in the parameters and variables function. The error term $(\varepsilon)$ was assumed to be identical and distributed independently by a Weibull distribution. Therefore, the probability $\left(\mathrm{P}_{\mathrm{ij}}\right)$ of any specific poultry meat alternative $\mathrm{j}$ being chosen by respondent $\mathrm{i}$ can be stated in terms of a logistic distribution, which takes the general form (where $\mathrm{C}$ is the total number of choice alternatives):

$$
\mathrm{P}_{\mathrm{ij}}=\frac{\exp (V(Z i j))}{\sum_{i=1}^{C} \exp (V(Z i j))}
$$

For each respondent, the probability that a level of an attribute would be chosen was determined, followed by a calculation of the mean of probability for the chosen level of attributes. Based on the probabilities for each level of an attribute, for each respondent the level of an attribute with the highest probability was determined and defined as the chosen level Y 
of attribute j. Then, the relationship between the chosen level of the attributes and socioeconomic variables was examined for each attribute using multinomial logit analysis. The general equation was drawn based on the following multinomial logistic regression (MNL) function:

$$
\begin{aligned}
Y_{\mathrm{j}}= & \beta_{0}+\beta_{1} \text { (Market Channel) }+\beta_{2} \text { (Place of resident) }+\beta_{3} \text { (Age group) }+\beta_{4} \text { (Gender) } \\
& +\beta_{5} \text { (Marital Status) }+\beta_{6} \text { (Income group) }+\beta_{7} \text { (Education) }+\beta_{8} \text { (Food safety } \\
& \text { awareness })+e
\end{aligned}
$$

Where $Y_{j}$ represents the attribute levels chosen by the consumers (dependent variable), $\beta_{1}, \beta_{2}$, $\ldots$, and $\beta_{9}$ are representing regression coefficients for their respective independent variables and $\beta_{0}$ represents the fixed regression coefficient (intercept).

\subsubsection{Estimation of willingness-to-pay of the poultry meat attributes}

By calculating the ratios between the ratio of attributes utility and the ratio of price utility, the mean WTP for each attribute was estimated. Hence, the WTP for attributes is the price change associated with a change in a level of utility in a specified attribute as indicated in Van Loo et al. (2011):

$$
\text { WTP Attribute }=\frac{\frac{\partial \text { Uijt }}{\partial \text { Attributelevel }}}{\frac{\partial U \text { Uijt }}{\partial \text { Price }}}
$$

For each respondent we calculated the individual WTP Q for attribute $j$ other than price followed by the calculation of the mean of WTP. We employed ordinary least square regression analysis to estimate the association between WTP and socio-economic variables, with WTP as a dependent variable, and socio-demographic characteristics as an independent variable, as follows:

$$
\begin{aligned}
\mathrm{Q}_{\mathrm{j}}= & \left.\beta_{0}+\beta_{1} \text { (Market Channel) }+\beta_{2} \text { (Place of resident) }+\beta_{3} \text { (Age groups }\right)+\beta_{4} \\
& (\text { Gender })+\beta_{5} \text { (Marital Status) }+\beta_{6} \text { (Income group) }+\beta_{7} \text { (Education) }+\beta_{8}(\text { Food } \\
& \text { safety awareness })+e
\end{aligned}
$$


Where $Q_{j}$ represents the WTP for attributes $j$ (dependent variable) $\beta_{1}, \beta_{2}, \ldots$, and $\beta_{9}$ are representing regression coefficients for their respective independent variables and $\beta_{0}$ represents the fixed regression coefficient (intercept).

Table 6.4 Socio-demographic characteristics in modern and traditional channel.

\begin{tabular}{llcc}
\hline \multicolumn{1}{c}{ Definition } & $\begin{array}{c}\text { Modern channel } \\
(\mathrm{N}=117)\end{array}$ & $\begin{array}{c}\text { Traditional channel } \\
(\mathrm{N}=313)\end{array}$ \\
\hline Age group & 20-30 years old & 29.9 & 22.68 \\
& 31-40 years old & 36.8 & 31.95 \\
& 41-50 years old & 23.9 & 29.39 \\
& 51-60 years old & 8.5 & 13.74 \\
& More than 60 years old & 0.9 & 2.24 \\
\hline Educational & Primary & 0 & 6.71 \\
level & Junior High School & 6 & 10.86 \\
& Senior High School & 53 & 54.95 \\
& University & 41 & 27.48 \\
\hline Gender & Female & 92.3 & 97.76 \\
& Male & 7.7 & 2.24 \\
\hline Income & Less than $€ 63.3$ & 20.5 & 22.04 \\
group & $€ 63.3-105.4$ & 25.6 & 19.81 \\
& $€ 105.4-147.6$ & 20.5 & 23.64 \\
& $€ 147.6-189.7$ & 6.8 & 11.18 \\
& More than $€ 189.7$ & 26.5 & 23.32 \\
\hline Place of & Jakarta & 41 & 52.72 \\
residence & Greater Jakarta & 59 & 47.28 \\
\hline Food safety & No awareness & 20.5 & 31.9 \\
awareness & Avian Influenza & 32.5 & 29.7 \\
& Newcastle Disease & 8.5 & 6.1 \\
& Antibiotic & 0.9 & 1.6 \\
& Hormone & 0.9 & - \\
& Bacteria & 7.7 & 3.2 \\
& Formalin (Preservatives) & 3.4 & 5.8 \\
& Others & 2.6 & 4.8 \\
\hline
\end{tabular}

\subsection{Results}

An overview of the socio-demographic information of the respondents, per poultry market channel, is presented in table 6.4. The majority of the respondents was female, as expected since in most families women purchase poultry meat. The most common age of the respondents was $31-40$ years old. The educational level of the respondents showed that more than $50 \%$ of the respondents in both market channels went to senior high school. However, there were no respondents with only a primary school education in the modern channel. The comparison of 
income groups showed that the most common income of respondents in the modern channel was over $€ 190$ per month, while the most common income of respondents in the traditional channels was between $€ 105$ and $€ 148$ per month. Table 6.4 also shows that the number of respondents unaware of food safety was smaller in the modern channel than in the traditional channel (20.5\% and $31.9 \%$, respectively). In both market channels, the respondents that were aware of food safety hazards most common considered avian influenza as such $(32.5 \%$ and $29.7 \%$, respectively).

Table 6.5 Predicted relative importance of consumers' preferences of poultry meat attributes based on MNL estimates

\begin{tabular}{|c|c|c|c|}
\hline Attributes & Modern Channel & Traditional Channel & Pooled sampled \\
\hline $\begin{array}{l}\text { Freshness } \\
\text { - } \quad \text { Warm } \\
\text { - } \quad \text { Chilled } \\
\text { - }\end{array}$ & $\begin{array}{l}0.64 \\
0.27 \\
0.09\end{array}$ & $\begin{array}{l}0.63 \\
0.27 \\
0.10\end{array}$ & $\begin{array}{l}0.64 \\
0.27 \\
0.09\end{array}$ \\
\hline 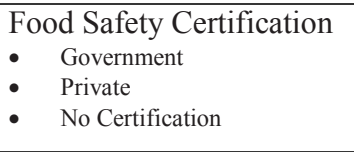 & $\begin{array}{l}0.50 \\
0.34 \\
0.16\end{array}$ & $\begin{array}{l}0.49 \\
0.35 \\
0.16\end{array}$ & $\begin{array}{l}0.49 \\
0.35 \\
0.16\end{array}$ \\
\hline $\begin{array}{l}\text { Product Information Label } \\
\text { - With label } \\
\text { - Without label }\end{array}$ & $\begin{array}{l}0.69 \\
0.31\end{array}$ & $\begin{array}{l}0.68 \\
0.32\end{array}$ & $\begin{array}{l}0.69 \\
0.31\end{array}$ \\
\hline
\end{tabular}

\subsubsection{The probability and the determinant of the chosen attributes}

The discrete choice experiment of consumers' preferences for the freshness, FSC, and label attributes in the modern and traditional channels is presented in table 6.5. The MNL analysis of the discrete choice experiment for freshness showed that the respondents in both channels preferred warm poultry meat over chilled or frozen poultry meat. In both channels, warm poultry meat has the highest relative importance for the attribute freshness in both channels is large, being the main choice of more than $60 \%$ of the respondents, while only $9 \%$ of the respondents had a preference for frozen poultry meat. The relative importance of warm poultry meat was slightly higher in the modern channel than in the traditional channel. For FSC, the relative importance showed that the respondents in both market channels preferred government certification over private certification or no certification. The relative importance of government certification in both channels was around 50\%, while the relative importance of no-certification was the smallest $(16 \%)$. There was a similar relative importance of FSC 
attribute level in both channels. Lastly, the respondents in both market channels preferred poultry meat with a product information label over poultry meat without. Respondents in the traditional channel had a slightly higher preference for poultry meat with a product information label compared to respondents in the modern channel.

Table 6.6 presents the results of the MNL models' estimation of main effects associated with the choice of freshness, FSC, and product information label attributes. The levels of frozen poultry meat, without certification and without product information label were used as the base reference. The models' statistically significant $(\mathrm{P}<0.01)$ effects explained some of the variations. In the model for freshness attribute, gender, income group, and education were statistically significantly associated with both the preference for warm or chilled poultry meat over frozen meat $(\mathrm{P}<0.01)$. The market channel was found to be significantly associated with the choice of warm poultry meat over frozen meat $(\mathrm{P}<0.01)$. The place of residence was significantly associated with a lower preference for chilled poultry meat compared to frozen meat $(\mathrm{P}<0.01)$. The food safety awareness was significantly associated with a lower preference for warm poultry meat and a higher preference for chilled poultry meat, compared to frozen poultry meat $(\mathrm{P}<0.01)$. In the model for the attribute FSC, gender was significantly associated with a lower preference for government and private certification compared to no certification $(\mathrm{P}<0.01)$. The place of residence was significantly associated with respondents' preference for government certification compared to no certification, while marital status variables were associated with a lower preference for government certification when compared to no certification $(\mathrm{P}<0.01)$. The market channel and marital status were significantly associated with a higher preference for government and private certification compared to no certification $(\mathrm{P}<0.01)$. In the model for product information attribute, the market channel was significantly associated with preference for product information label, while age group was significantly associated with preference for poultry meat without product information attribute $(\mathrm{P}<0.01)$. 


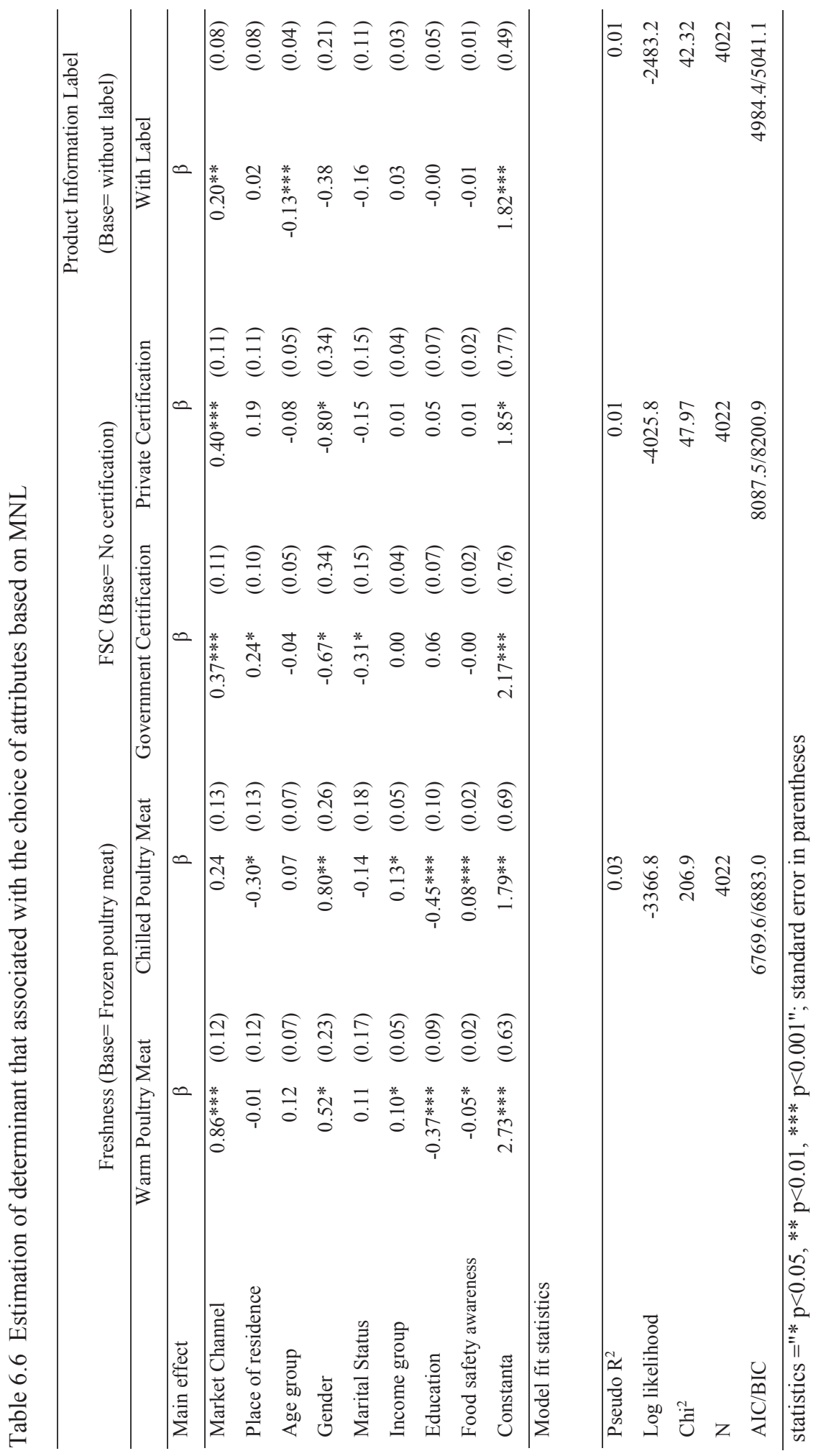




\subsubsection{Consumer WTP and its determinants for the chosen attributes}

The consumers' WTP for each of the chosen attributes is presented in table 6.7. The WTP for the freshness attribute showed that respondents in both channels had a higher WTP for warm poultry meat than for chilled or frozen poultry meat. Respondents in the traditional channel had a higher WTP for warm and frozen poultry meat compared to respondents in the modern channel. Respondents in the modern channel had a higher WTP for chilled poultry meat compared to respondents in the traditional channel. The WTP for the FSC attribute showed that the respondents in both market channels were willing to pay more for government certification over private certification or no certification. Respondents in the traditional channel had a higher WTP for government or no certification, compared to respondents in the modern channel. Respondents in the modern channel had higher WTP for private certification than those in the traditional channel. Lastly, the respondents in both market channels had a higher WTP for poultry meat with a product information label than for poultry meat without. Respondents in the modern channel had a higher WTP for poultry meat with a product information label, compared to respondents in the modern channel.

Table 6.7 Predicted consumers' WTP of poultry meat attributes $(€ / \mathrm{kg})$.

\begin{tabular}{lccc}
\hline Attributes & Modern Channel & Traditional Channel & Pooled sampled \\
\hline Freshness & & & \\
- Warm & 2.64 & 2.83 & 2.83 \\
- Chilled & 2.22 & 2.01 & 2.00 \\
- Frozen & 2.30 & 2.33 & 2.34 \\
\hline Food Safety Certification & & & \\
- Government & 2.68 & 2.73 & 2.71 \\
- Private & 2.14 & 2.05 & 2.04 \\
- No Certification & 2.29 & 2.39 & 2.38 \\
\hline Product Information Label & & & \\
- With label & 2.49 & 2.42 & 2.40 \\
- Without label & 2.25 & 2.36 & 2.35 \\
\hline
\end{tabular}

The determinants related to WTP of poultry meat attributes based on linear regression are shown in table 6.8. The statistically significant $(\mathrm{P}<0.01)$ associations in the models explained some of the most important determinants of consumers' WTP for the chosen attributes. The market channel was the most important determinant for WTP for warm and chilled poultry meat, for WTP for no certification, and for WTP for poultry meat without product information label $(\mathrm{P}<0.01)$. In the traditional market channel there was a lower WTP for warm poultry meat, for no certification, or for poultry meat without product information label, but a higher 
WTP for chilled poultry meat. Gender was the most important determinant for WTP for frozen poultry meat, and WTP for product information label $(\mathrm{P}<0.01)$. Female consumers had a lower WTP for frozen poultry meat, and for the presence of a product information label. Marital status was an important determinant and divorce status had a negative effect on consumers' WTP for government certification $(\mathrm{P}<0.01)$. Meanwhile, we could not find any significant determinant that influences WTP for private certification. 


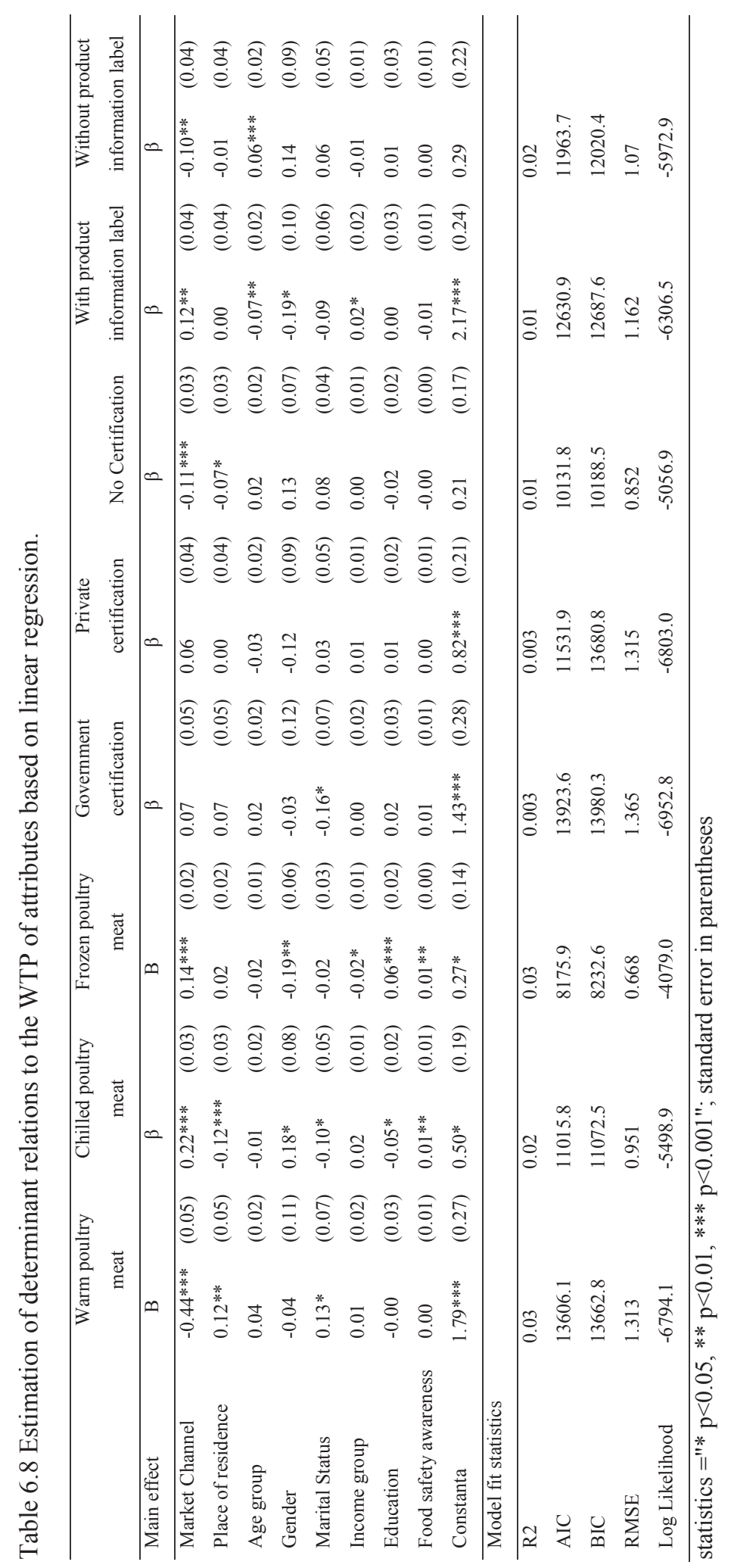




\subsection{Discussion}

In this study, we carried out a discrete choice experiment to obtain insight into preferences of Indonesian consumers for poultry meat attributes related to food safety. Although such a research setup provides many outcomes and significant relations, two main findings stand out: consumers have a high preference for warm poultry meat and have a higher trust in a governmental certification system than in a private system.

The importance of the experience quality attribute for consumers was shown by the preference and WTP for freshness level as the non-food safety attribute for poultry meat. We found that the preference and WTP for warm poultry meat were much higher compared to chilled and frozen poultry meat in both poultry market channels. For the consumers interviewed at the wet market, this might be logical, but also consumers interviewed in the modern market had a preference for warm poultry meat. This means that consumers in the modern channel, who had an experience of buying poultry meat in the traditional channel, may choose warm poultry meat if the modern channel provides this type of poultry meat. This observation supports previous work suggesting that in certain countries, consumers relate the term freshness to freshly cut (a very short time between slaughter and sales) (Chamhuri et al., 2015; Goldman and Hino, 2005; Indrawan et al., 2018b; Zhang, 2003). This brings a dilemma, because, while warm poultry is perceived as a quality cue in terms of freshness, it is generally assumed to be less safe (Indrawan et al., 2018a). The results also show that the consumers' WTP for chilled and frozen poultry meat related to food safety awareness. This may be the consequence of an ongoing government program in Indonesia aimed at increasing food safety awareness by promoting these types of meats (Sparringa, 2014). It means the government efforts may have had an effect and that this program should be continued to further increase the awareness of food safety hazards.

Since we aimed to explore the possibilities of increasing the level of food safety in poultry meat consumption, we also examined FSC and product information labels as food safety attributes for poultry meat. Although many recent studies suggest that the role of third-party certification is increasing (Albersmeier et al., 2009; Qijun and Batt, 2016; Simmons, 2010), we found that the consumers in both market channels (traditional and modern) had a higher preference for government certification. Also Wahida et al. (2013) found that government certification was more trusted by the consumers in Indonesia. In combination with FSC, 
consumers in both poultry market channels were perceiving the product information label as an important quality cue. The preference for poultry meat with a product information label was higher than for poultry meat without a product information label. This finding is in agreement with other research (Stranieri and Banterle, 2015; Verbeke and Ward, 2006; Wahida et al., 2013). It suggests that consumers require more information about the poultry meat before they actually purchase it (Font-i-Furnols and Guerrero, 2014; Makanyeza et al., 2016). However, the results may seem peculiar for consumers in the traditional market, because currently no such product information label exists in this channel. The preference may stem from increased consumer food safety awareness. Because of many incidents of food unsafety, consumers' trust in the salesperson in the traditional channel may be decreasing. Further research is needed to uncover the underlying reasons.

Finally, the consumers' WTP in two different market channels shows that consumers consider their WTP for a certain attribute for better quality based on the value for money (Chamhuri and Batt, 2013c). In the modern channel, consumers had a higher WTP for government certification, compared to the WTP for other poultry meat attributes. On the other hand, in the traditional channel, the consumers had higher WTP for warm poultry meat. This means that consumers in these two market channels evaluate quality value differently. Consumers in the modern channel rely on government certification to ensure poultry meat quality, while consumers in the traditional channel rely on their own experience. The results reinforce previous studies showing that price is an important instrument to signal consumers about the value of a product (Chamhuri et al., 2015; Cicia and Colantuoni, 2010). Therefore, prices can play a role as drivers of consumers' preferences for a certain poultry meat attribute. Hence, by utilizing the simple effect of own-price on consumer demand, the government can influence the consumers' WTP for the preferred attributes by subsidies and/or taxes in the market channels. By setting up a tax system for less safe poultry in the traditional channel, the poultry meat could become more expensive. Contrarily, by reducing taxes or increasing subsidies for poultry meat with preferable food safety attributes in the modern channel, it will be more attractive for consumers to buy safer poultry meat. This action may affect the poultry consumers' preferences and buying behavior. However, if consumers truly use price as a signal of quality, the taxed product would signal more quality to consumers, offsetting part of the own-price effect. Likewise, a subsidy would signal lower quality, offsetting part of the subsidy's own-price effect. Nevertheless, this effect will be less apparent in low-income countries, since the consumers are price sensitive and are not concerned with safety attributes 
(Röhr et al., 2005).

Some attentions should be given to the food safety awareness findings that were collected by open questions. Despite the fact that Salmonella contamination was reported as the most important food-borne pathogen causing diarrhea in Indonesia, with (probably underestimated) prevalence of 358-810 cases per 100,000 Indonesians per year (Kusumaningrum and DewantiHariyadi, 2012). The respondents' awareness of avian influenza was exceeding bacteria (campylobacter, listeria monocytogenes, clostridium perfringens, and E. coli $\mathrm{O} 157$ ). Only 3.2$7.7 \%$ of the respondents expressed awareness of bacteria as a food safety problem. It seems that Indonesian consumers are unaware of bacteria as a food safety problem, because of a less attention by national mass media compare to avian influenza outbreak.

In this study, the Pseudo R-squared values, varying from 0.03 to and 0.01 and the R-squared values, varying from 0.003 to 0.03 show a low explanatory power (values from $0.2-0.4$ are considered by some to be a very good or excellent fit). We did consider explanatory regression models using interaction terms for independent variables, but these results were inconclusive and did not provide more insight than the single effect models (data not shown). So this study does not give much of an explanation for the preference of poultry attributes or the WTP for these attributions. However, this study was primarily designed to generate in sight in the consumers' choice and their willingness to pay for poultry attributes in a specific market channel, rather than for explaining their choice. We did not consider the factors that motivate or demotivate consumers in purchasing poultry meat, such as religion and/or ethnicity, a presence of a domestic assistant and/or their role in shopping for food, and attitudinal variables such as trust in certifying body, concerns about food safety. In the future, studies combining techniques from social-psychology with knowledge about poultry purchasing behavior could be useful to

\subsection{Conclusions}

Indonesian consumers see the freshness of poultry meat as an important attribute that ensures poultry meat quality. Of the three preferred poultry meat attributes (warm poultry meat, government certification, and product information label), the WTP for warm poultry was the highest. It is also the main attribute for consumers who are buying poultry meat in the traditional channel. For those who buy in the modern channel, freshness of poultry meat is still 
very important but WTP for government certification is slightly higher than WTP for warm poultry meat. In order to have consumers direct the market to a safer production of poultry, the government can use a price setting mechanism (e.g. subsidies and/or taxes) and/or advertise and promote food safety to increase WTP for a certain attribute.

\section{Acknowledgments}

The first and second authors were funded by an LPDP scholarship. The funder had no role in the contents of this study. We are thankful to Asep Rakhmat for organizing the interviews. 
Chapter 7

General Discussion 
Since the first outbreak of highly pathogenic avian influenza (HPAI) H5N1 in Indonesia, government efforts to control the outbreak followed the general approach used in other countries as advised by FAO. The Indonesian government faced difficulties for a variety of reasons (Pramuwidyatama et al., 2018). One of the main reasons is the complex structure of the poultry supply chain (FAO, 2011). The structure of the poultry chain has an effect on the chain actors' participation in HPAI control. The poultry supply chain structure can be defined as the combination of links and interactions between actors involved in the production of poultry meat. A proper understanding of this structure will provide a clear overview for animal disease control, based on the interaction in the livestock production and marketing channels (Rich et al., 2011). This includes the response of different stakeholders to disease outbreak, which is related to how they interact with different control measures (Rich and Perry, 2011). Therefore, without proper knowledge on the structure, the efficacy of proposed control strategies to manage HPAI H5N1 may be lower than expected. One possible reason why the efforts of the Indonesian government were not always successful may have been caused by the lack of clarity in defining and targeting the most important actors in the control of HPAI. Moreover, the control measures may not have been aimed at the proper stage of the production cycle or may not have addressed the interaction between different actors.

A proper understanding of the structure of a value chain in relation to the control of a contagious disease can be gained by linking a value chain analysis with a veterinary epidemiology and with the insight of poultry consumers (Indrawan et al., 2018a). The knowledge generated in such an approach can be contextualized in the structure related to the chain governance. It can provide important input for the development of government strategies for the control of HPAI. In this way, efforts to control HPAI will better match the structure of the poultry value chain and will be more effective.

In order to gain knowledge about the relationship between the value chain structure and control of HPAI, in this research, first, we have provided a better description of the Western Java value chain in relation to introduction and transmission of HPAI. Second we studied the application of biosecurity practices at the farm level (the micro governance level), especially in relation to farm business types. Third, we investigated the consumers' behavior in relation to the market structure and their impact on HPAI control. Together, those aspects provide the opportunity to give a broad evaluation in which direction HPAI control should be planned to be effective. In this respect, HPAI control may be directed towards pushing biosecurity practices (a push 
strategy) or pulling the production by changing consumers' demand (a pull strategy) or a combination of both approaches. In this chapter, we synthesize the results of the research described in this thesis (chapter 7.1), we describe the main scientific contribution and methodological approaches (7.2), and explain the policy implications (7.3). Finally, we will provide a general conclusion.

\subsection{Synthesis of the results}

The main contribution of this thesis is an improved knowledge on how to implement a pushand-pull strategy in the poultry value chain; knowledge that can be used to design an effective strategy to control animal disease. The research took a value chain perspective in the context of chain actors' responses to animal disease control. The work described in this thesis was carried out in two goals: (i) increase knowledge on the poultry chain structure, and (ii) increase knowledge on a push-and-pull strategy to control HPAI. The work was highly interdisciplinary in nature. Different scientific perspectives (e.g. value chain, economic performance, epidemiology, biosecurity and consumer behavior) were linked to create a knowledge framework for improved HPAI control.

\subsubsection{The knowledge on the poultry chain structure}

The structure of the Western Java poultry production chain is very complex. We disentangled the structure by looking at the value chain as well as the consumers' perspective. We mapped the complexity of the value chain and complemented this map with insight of the value chain governance. The value chain analysis was based on a number of intensive workshops. Earlier published value chain analyses only looked at the poultry product flow (McLeod et al., 2009; Sudarman et al., 2010). The combination of a map of the structure of the poultry value chain with insight into chain governance as presented in this thesis, provides a clear overview of the human interactions within the value chain and their expected response to HPAI outbreaks (Chapter 2). Our findings show that the governance within the poultry value chain is an important factor driving interaction between actors and their response to HPAI risk. The value chain analysis from Chapter 2 was the base for further analyses linking the poultry value chain with the epidemiology of HPAI (Chapter 3). We analyzed the two main aspects of the epidemiology of HPAI: introduction of HPAI into a poultry production chain and transmission of HPAI between actors within a poultry production chain. To the best of our knowledge, this 
is the first analysis of its kind. We were not able to find any literature linking the epidemiology of a contagious notifiable disease to governance of an animal production chain. Regarding HPAI, many studies (e.g.de Glanville et al. (2010), Idris et al. (2010)) on HPAI epidemiology focus on contact structure but do not take governance into account.

We identified four poultry chains and grouped them based on two marketing channels: the modern and the traditional marketing channel (Chapter 2). The four poultry chains were defined based on slaughtering activities. Slaughtering in the modern channel is performed in slaughterhouses, while in the traditional channel it is performed at slaughter-points. Therefore, we named the chains according to slaughterhouse/point characteristics. The results demonstrate the existence of four different poultry value chains in Western Java: the integrator chain, the semi-automated slaughterhouse chain, the controlled slaughter-point chain and the private slaughter-point chain (Indrawan et al., 2018a). Each value chain operates under a different chain governance with coordination carried out at different levels and through different mechanisms. The integrator chain was the most coordinated chain, while the private slaughterpoint chain was the least coordinated. Each of the chains had a distinct main supplier based on FAO farm type biosecurity classification (e.g. sector 1 farms served the integrator chain). Therefore, the chain governance is affecting the level of biosecurity on farms and in chains. Our results showed that chain governance is also having an effect on the economic consequences of HPAI incidents (Indrawan et al., 2018a), confirming findings of previous research (Van Kerkhove et al., 2009; Van Steenwinkel et al., 2011; Yupiana et al., 2010) (Chapter 2). The integrator chain, the most coordinated chain, suffers the most severe economic consequences of HPAI outbreaks, compared to the other chains. These economic consequences explain why the integrator chain has the highest level of biosecurity.

Although the four defined value chains appear to operate in isolation, we found that the less coordinated chains heavily interlink between each other in the farming areas and the live birds markets (Chapter 2). Typically, these are the two chains working with slaughter-points. However, the semi-automated slaughterhouse chain also interacts with the slaughter-point chains. These interlinkages between actors across different poultry value chains do contribute to the overall risks of transmission over the Western Java poultry sector (Chapter 3). For example, while improved biosecurity in Indonesia, combined with a test-and-cull control policy, is still the government's main strategy to control HPAI H5N1 (Azhar et al., 2010; Dolberg et al., 2009; Ilham and Iqbal, 2011; Loth et al., 2011; Swayne and Suarez, 2000), our 
results indicate that the incentive mechanisms present in most of the poultry value chains encourage a low level of biosecurity on poultry farms (Chapter 4). Therefore, the existing chain governance is a constraint in managing HPAI risks. We identified four main constraints related to the role of chain governance in the poultry structure: the existence of a sick poultry market (Chapter 2 and Chapter 3), the role of sector 2 farming in HPAI spread (Chapter 2 and Chapter 3 ), the influence of traders (Chapter 2), and biosecurity practices varying across farm business types (Chapter 4).

The chain governance in the two poultry value chains in the traditional channel allow the existence of a market for sick poultry (Chapter 2). It is an important reason for the higher probability of HPAI introduction and transmission for the two chains within this channel (Chapter 3), and plays an important role in financial risk mitigation for the actors within those chains. This is associated with the incentive mechanism and penalties that may be imposed (Gramig et al., 2009; Williamson, 2002). Selling chickens affected by HPAI offers a higher financial reward than the government compensation for culling. Therefore, any poultry older than 20 days with clinical signs of disease will immediately be sold to this market. This discovery leads to the conclusion that the sick poultry market is an important reason for the endemicity of HPAI, because the test-and-cull mechanism is not applied adequately. The sick poultry market is not only accessed by sector 3 and 4 farms, it is also of interest for sector 2 farms. Although sector 2 farms operate in the modern channel, they were found to be influenced by incentives from the sick poultry market as well. For sector 2 farms, the sick poultry market became a financial mitigation in the event of an animal disease outbreak. This does have an impact on their biosecurity and the increase of risk of HPAI introduction (Paul et al., 2013; Van den Berg, 2009). Besides leading to the ineffectiveness of test-and-cull control measures, the transport of sick chickens increases the risk of transmission of HPAI. The existence of markets for sick chickens adds to the complex situation of live birds markets, already known to be an important source of transmission of HPAI (Indrawan et al., 2018a; Paul et al., 2013; Van den Berg, 2009).

The main actor driving the sick poultry market is the group of traders (Indrawan et al., 2018a). The traders govern the controlled slaughter-point chain and the private slaughter-point chain and are therefore important actors in the control of HPAI (Chapter 2). Traders established their influence and their critical intermediary role in financing transactions between farmers and poultry collectors, acting as brokers matching farmers and collectors without being physically 
involved (Chapter 2).

We found that chain governance plays a role in the application of biosecurity at the farm level (Chapter 2) and analyzed the related impact on the probability of HPAI introduction and transmission (Chapter 3). The level of biosecurity on individual Indonesian poultry farms, important for reducing the risk of introduction of contagious diseases on a farm, has been described as low (de Glanville et al., 2010; Indriani et al., 2010; McLeod et al., 2009). Results from this research support that finding (Chapter 4). In addition, the level of adoption of biosecurity, both in terms of implemented practices as in available infrastructure, was found to be low at the industrial-sized farms as well (sector 1 and 2 farms), whereas it was previously suggested that biosecurity on those farms was higher. The biosecurity practices at the farm level did not only vary between farm types (sector 1 to sector 4), but especially between farm business types (Chapter 4). Farm sectors under a company business related to the integrator chain were found to perform slightly better than other farm business types (Chapter 4). The different incentives applied within these business types were the cause of the variation (Basuno et al., 2010; Gerdoçi et al., 2018; Wacker et al., 2016). There was an association between the level of biosecurity practices at a farm and the economic consequences of HPAI incidents (Van Kerkhove et al., 2009; Van Steenwinkel et al., 2011; Yupiana et al., 2010) (Chapter 2). The farms that, without any government intervention, would face the most severe economic consequences of an outbreak had the highest level of biosecurity. The farm business models are closely related to the chain governance. This means that chain governance also plays a role in the level of biosecurity at the farm level.

In order to complete the value chain approach towards HPAI control, we also analyzed the Western Java poultry chain structure from the consumers' perspective. The modern channel is considered to sell poultry meat of better quality, with a higher level of food safety, than the traditional channel. In the traditional channel, live bird markets are a source of HPAI transmission, chickens are slaughtered at slaughter-points and sold at wet markets, which both are less hygienic (Chapter 2 and Chapter 3). By using the adapted approach of Spiggle and Sewall (1987) and Heider and Moeller (2012), we studied the determinants influencing the consumers to buy from each market channel and found several differences (Indrawan et al., 2018b) (Chapter 5). Consumers purchasing poultry meat from the modern channel were influenced by the price/quality relationship (also concluded by Yu et al. (2011)), the safety feature, and the level of consumer trust. On the other hand, consumers purchasing poultry meat 
from the traditional channel were influenced by freshness (also concluded by Chamhuri et al. (2015), Daryanto et al. (2014), Sujiwo et al. (2018)), place of residence (inside/outside Jakarta), and the amount of poultry meat per purchase. The findings indicate that the two marketing channels, the modern and traditional channel, serve different consumers with a different perception of poultry meat quality and food safety (Chapter 2, Chapter 5 and Chapter 6).

To elaborate on these findings, we employed a discrete choice experiment to explain consumers' preferences regarding features on poultry meat quality and food safety. We studied the Western Java consumers' choice of attributes of poultry meat and their willingness to pay (WTP) for these attributes. The findings confirmed that freshness as a meat quality attribute is more important than food safety attributes (Goldman and Hino, 2005; Goldman et al., 1999; Verbeke and Viaene, 1999) (Chapter 6), i.e. Western Java poultry consumers use freshness as a synonym for quality (Chamhuri et al., 2015) (Chapter 5). As a consequence, consumers' willingness to pay for freshness was found to be higher than for other poultry attributes (food safety certification and product information label), in both the traditional and modern channels (Chapter 6). A product information label was perceived as positive: consumers preferred poultry meat with a product information label over poultry meat without a product information label (finding supported by work of Stranieri and Banterle (2015) and Verbeke and Ward (2006)). Furthermore, the consumers had a higher preference for government certification than for private certification (Wahida et al., 2013).

\subsubsection{The knowledge on the push-and-pull strategy to control HPAI}

In order to control HPAI in Western Java, it is important to pay attention to the interrelations between the actors in the chain. These interactions affect the incentive mechanisms for the chain actors to improve production methods (Chapter 2, Chapter 3 and Chapter 4) and to influence consumers (Chapter 5 and Chapter 6) (Kaplinsky and Morris, 2001). Good insight in these incentive mechanisms are the cornerstone to effective control measures for HPAI. In general, two approaches can be taken to improve the quality of production. The first is to push producers to improve production and the second is to have consumers pulling the market towards better products. Control of HPAI is a quality aspect of poultry production, especially because of the link with food safety. When a government wants to improve the control of HPAI, it can do so within the current structure of the value chain. A government intervention will be more effective, if it is tailored to the structure of the value chain and the interactions between 
actors within the supply chain. When disease control is hampered too much by an existing poultry chain structure, governments may consider to restructure it. In the case of the Western Java poultry value chain, a restructured value chain would start with a shift of production and sales of poultry from the traditional channel to the modern channel. Results of the value chain analysis carried out in this thesis (Chapter 2), linked to the epidemiology of HPAI (Chapter 3), do support the idea that a restructured poultry value chain in Western Java would improve the control of HPAI. The consumer can play an important role in this shift, since a shift in purchase behavior (from the traditional to the modern market) will lead to a shift in production (a pull strategy). The results in chapter 5 and 6 show, however, that it is not easy to motivate consumers to shift from the traditional to the modern market. The diversity found in governance typology implies that there is no "one-size-fits-all" strategy for HPAI control (Indrawan et al., 2018b). Therefore, it may be recommended to combine the push and pull strategies. The push strategy, i.e. creating incentives for actors in the poultry value chain to carry out measures reducing the risk of introduction and transmission of HPAI, should be combined with measures to support consumers to pull the production of poultry towards the modern market. This research, together with other knowledge, provides some key insights in the incentive mechanisms for chain actors, including consumers, which can be used to design an effective push-and-pull strategy (Chitchumnong and Horan, 2018; Gramig et al., 2009; Rich and Perry, 2011).

In order to control HPAI, a push strategy seems to be a quick way to improve the quality of production in the poultry value chain. Pushing for improved biosecurity, for instance by a testand-cull approach in case of outbreaks on a farm, or for improved hygienic measures, seems relatively easy. However, the previous government efforts to improve biosecurity and to control live bird markets failed due to limited participation from chain actors (Azhar et al., 2010; Dolberg et al., 2009; Ilham and Iqbal, 2011; Loth et al., 2011; Swayne and Suarez, 2000) (Chapter 2). Apparently, governmental efforts were not adapted to the existing chain governance and incentive mechanisms in the Western Java poultry sector. In the existing poultry structure, incentives to trade sick chickens in a sick poultry market were facilitated by traders not even physically involved in the trade of poultry (Gramig and Horan, 2011; Gramig et al., 2009). So, the results of any effort to increase the level of biosecurity or to implement other measures in the value chain depend on the influence of incentive mechanisms, including the economic consequences of HPAI incidents under the current chain governance (Van Kerkhove et al., 2009; Van Steenwinkel et al., 2011; Yupiana et al., 2010) (Chapter 2). 
Therefore, the design and implementation of a push strategy needs to take the role of current chain governance in the poultry structure into account. This implies that the role of the chain leader should be taken into account when the government considers any intervention. A push strategy providing sufficient incentives for all critical chain actors will be able to drive the interaction between actors to participate in the control measures, and will therefore be much more effective.

In the current situation, there are little or no incentives for all the actors (including the traders) to improve their behavior regarding HPAI. Moreover, a sick poultry market is in place, creating an opposite incentive in case of an outbreak. Therefore, HPAI is not expected to be controlled, especially since we found that traders, who have large market power and are chain leaders in two of the four identified value chains, were never involved in HPAI control measures (Indrawan et al., 2018a)(Chapter 2). Any control measure aimed to reduce the number of chickens being traded will reduce the profits of traders. When a test-and-cull measure is combined with a compensation for the farmer, the trader will still have some revenues forgone and will not willingly collaborate. The removal of the sick poultry market, while creating much better incentives for farmers to comply to a test-and-cull measure, would reduce the traders' profitability even more. When not collaborating with the trader, there will be no incentives at all for them to participate in HPAI control measures, rather they will use their oligopolistic power to avoid losing any market share. Therefore, traders will need to be included, with clear economic or other incentives to cooperate (Gramig and Horan, 2011; Gramig et al., 2009; Indrawan et al., 2018a). A similar situation regarding the sick poultry market applies to the interaction of sector 2 farms in other poultry value chains.

In order to push for improved biosecurity at the farm level, the government needs to provide incentives for farmers in the controlled slaughter-point chain and the private slaughter-point chain. Interestingly, we found that a formal registration as a poultry farm business was associated with a higher level of biosecurity investment and implementation (Chapter 4). Apparently, governmental incentives were created through agricultural extension services that deliver information and/or laboratory services to farmers after formal registration did provide an incentive for the farms. The incentives should take the farms' business type into account. We expect from our results that taking poultry farm business types into account in the incentive will influence the adoption of biosecurity practices infrastructure (Basuno et al., 2010; Gerdoçi et al., 2018; Wacker et al., 2016). That way, adjusting new incentive mechanisms according to 
the farm business type will support the government's effort to control HPAI (Barnes et al., 2015; Gramig and Horan, 2011).

Besides pushing measures to control HPAI in the poultry value chain, the government can also motivate consumers to play a role in changing the poultry value chain (Chapter 2, Chapter 5 and Chapter 6). One way to control HPAI is to pull the market channels towards a specific chain structure. Based on the consumer studies in this thesis, additional insight can be provided in consumer behavior regarding poultry meat quality and food safety in relation to the existing market channels (Chapter 5 and chapter 6). Although a lot of research into consumers' behavior exists regarding food safety (e.g. Röhr et al. (2005) and Grunert (2005)), so far only one paper dealt with the response of consumers to the HPAI outbreak (Muladno and Thieme, 2009).

Our research shows that around 80 percent of consumers purchase poultry meat in the traditional channel (Indrawan et al., 2018a) (Chapter 2). Consumers are mainly influenced by freshness as the key determinant factor for purchase (Indrawan et al., 2018b) (Chapter 5). Moreover, the role of freshness as a meat quality attribute is more important than food safety attributes (Chapter 6). The Western Java poultry consumers see warm chicken (i.e., freshly slaughtered chicken) as a sign of freshness, perceived as a synonym for quality (Chamhuri et al., 2015). Per definition, the freshness of warm chicken is higher than of cooled or frozen chicken. Thus, consumers' willingness to pay for freshness was found to be higher than for other food attributes (Chapter 6). Therefore, without changing the perception of freshness, it will be difficult to change the consumers' behavior and influence their choice for market channel.

Consumer perceived freshness is a key driver to purchase poultry on the traditional market (Chamhuri et al., 2015; Daryanto et al., 2014; Indrawan et al., 2018b), and freshness was defined related to slaughtering on the spot or the night before sales (Indrawan et al., 2018b; Zhang, 2003) (Chapter 5 and Chapter 6). At the same time, this practice is less hygienic and carries greater risk of contamination and growth of pathogens. Moreover, chickens from the sick poultry market, providing less safe poultry meat, are also sold through this channel (Chapter 2 and Chapter 3). Because of the clear trade-offs between freshness and food safety, a redefinition of freshness is required in order to promote safer poultry meat. So, the success of a pull strategy relies on the consumers' perception and judgment of the products (Chamhuri and Batt, 2015), and on their trust in food chain actors to provide safety in their food product 
in the market channels (Arnot et al., 2016; de Jonge et al., 2007; de Jonge et al., 2008; Drescher et al., 2012), rather than on objective criteria.

In order to be able to pull changes in the value chain, the preference of consumers needs to be changed or overcome. The preference of consumers for warm chicken can be reduced by means of a pricing mechanism: the Western Java consumers were found to associate price with quality (Indrawan et al., 2018b) (Chapter 5). The price difference in the modern market should be large enough to overcome the consumers' willingness to accept meat that is perceived as less fresh (Chapter 6). Price level differences can be created via subsidy or tax mechanisms. Another option to change the behavior of consumers is to promote food safety (Chapter 5 and Chapter 6) and/or a new way of defining freshness. Such an effort should change the consumers' preference towards poultry meat quality and food safety. Then, the changing consumer demand of will pull an upgrade or an improvement of the production chain.

\subsection{Methodological approaches}

The main scientific contribution of this thesis is to link institutional economics with veterinary epidemiology. Highly contagious animal diseases, such as HPAI, do have a huge impact on farm incomes, food security and a country's economy. In many countries, with more complex governance structures, highly contagious animal diseases are endemic. Although socioeconomic work on the control of contagious diseases has been carried out (e.g., Dijkhuizen et al. (1995) and King et al. (2007)), it was mostly done in Western countries and aimed at cost minimization, assuming the measures to be feasible. Because of the low level of compliance, such an approach is not useful in countries such as Indonesia. Measures should be evaluated for their efficacy, both in terms of epidemiology and in terms of adoption by actors in the value chain. Combining a value chain analysis with epidemiological knowledge was novel (Chapter 3). The use of a value chain map combined with an in-depth assessment of governance structures through different typologies of transactional dynamics and transaction cost economics, a quantitative estimate of market power, and the probability of HPAI introduction and transmission can be added to the knowledge base on the interactions in the poultry structure. This approach differs considerably from previous HPAI studies based on poultry value chain (Idris et al., 2010; Loth et al., 2011; Sudarman et al., 2010; Sumiarto and Arifin, 2008; Willyanto et al., 2010). 
Using this novel approach, we obtained a detailed understanding of the structure of the poultry sector and were able to untangle the complexity of control of HPAI in Western Java. In our analysis, we used the value chain as a basis for risk assessment of the probability of an unwanted event and its ensuing consequences (Costard et al., 2014). The probability of HPAI introduction and transmission was addressed in relation with the relative importance of the different actors in the poultry value chains. Therefore our work combines a farm level (microgovernance) assessment for biosecurity practices, complemented (Chapter 4) with novel knowledge of the incentive mechanisms that play a role in the prevention of animal diseases in the poultry value chain (Barnes et al., 2015; Basuno et al., 2010; Gerdoçi et al., 2018; Gramig and Horan, 2011; Wacker et al., 2016). In order to combine the value chain information with epidemiological information, we used a qualitative assessment to measure risk in the context of HPAI. This assessment method was adapted from similar studies by the EFSA (2006) and Kasemsuwan et al. (2009).

The thesis made use of a wide range of methodological approaches for collecting data. We mapped the poultry value chains and assessed governance, economic performance of actors and epidemiological relationships between actors in workshops, site visits and in-depth interviews (Chapter 2 and Chapter 3). These qualitative approaches were used, partly to overcome our limited sampling frame and resources, given the complexity of value chains. On the other hand, qualitative approaches, when carried out in a systematic manner, may yield a much better understanding of the structure of the value chain, especially in an exploratory phase. For instance, in order to fully quantify the epidemiological relations between actors in the value chain, many years of data collection and a huge number of samples taken during HPAI outbreaks would be required. For example, in the quantitative research of Indriani et al. (2010), 83 live birds markets were sampled to establish the risk of avian influenza transmission from poultry to humans. The relatively small number of 26 semi-structured interviews with key informants did reveal a good overview of the risks for transmission and introduction. As a result, this study provides information on the most important epidemiological pathways in the poultry value chain and can be used to start quantitative epidemiological research in those pathways. Surveys in four important poultry production regions were conducted to collect data on existing biosecurity measures. In order to obtain a good overview, we chose a stratified data collection approach. Besides questionnaires, on-farm measurements provided insight in available biosecurity measures (Chapter 4 ). Surveys were also conducted to collect information on consumers. In chapter 5 and 6, we used the non-probability sampling method, also known 
as quota sampling, to select respondents. The sample was split based on market channels, to determine where the respondents mainly shop for poultry meat. This method assures that smaller groups (in this case the modern channel) are adequately represented in the sample. The consumer study aimed at evaluating consumers' behavior after HPAI outbreaks (Chapter 5) used Spiggle and Sewall's (1987) and Heider and Moeller's (2012) research framework for consumers' choice of market channel. Moreover, the study added an additional factor to that framework, i.e. the consumers' perceived risk in the situation of food unsafety (Yeung and Morris, 2001). A discrete choice experiment was used to explain the Western Java consumers' preferences for selected poultry meat attributes and their willingness to pay (WTP) for those attributes (Chapter 6).

Although intrinsically not a methodology, this thesis did take a novel approach to socioeconomic research supporting decisions on disease control. It combined studies supporting decisions for a push strategy as well as studies supporting decisions for a pull strategy. Doing so, we can evaluate the direction of governmental interventions in a holistic way, being able to combine both push and pull approach studies. This approach enabled us to provide knowledge and recommendations to set up an effective push-and-pull strategy for animal disease control, as mentioned by Rich et al. (2011).

\subsection{Implication for policy making}

The current approach regarding HPAI control in Indonesia is limited to farms and live bird markets. It is aimed at preventing the spread of HPAI without looking at the interaction between actors in the value chain (Chapter 2). As mentioned above, this approach is not effective in controlling HPAI sufficiently. When discussing policy making options, we should take into account that Indonesia is considered to be a low-resource country. For this reason, designing an intervention strategy for controlling HPAI in Indonesia is a difficult task and should be performed in such a way as to maximize the reduction HPAI, given the available budget, rather than aiming at complete eradication of HPAI.

Our results revealed that the main task to be undertaken by the government is the removal of the sick poultry market. The sick poultry market hampers effective control of HPAI in multiple ways. The first is that is brings an incentive for flawed behavior in case of an HPAI outbreak, by providing a market for chickens affected by HPAI. Therefore, test-and-cull measures are 
not and will not be effective, unless the payment for farmers will exceed the payment on the sick poultry market, making test and cull very expensive. The existence of the sick poultry market mitigates the financial consequences of an HPAI outbreak for farmers. Animals infected with HPAI still have value and economic incentives for improved biosecurity are therefore low. During transport, the probability of transmission of HPAI by sick chickens will be much higher. So the sick poultry market not only has a negative effect on biosecurity and a proper reaction during an outbreak, it even increases the HPAI problem.

When designing and performing measures to remove the sick poultry market, the government should involve the chain actors. It is preferable if chain actors, especially leaders (i.e., traders) join the government's efforts voluntarily, eventually encouraged by incentive mechanisms. A part of the available budget might be dedicated to incentives. The main attention of pushing a removal of the sick poultry market should be aimed at the traditional channel. The strategy should engage the traders (who were left out from previous control programs) by paying attention to their incentives to preserve the sick poultry market (Chapter 2 and Chapter 3). A potential direction to provide the traders with an incentive to join efforts to remove the sick poultry market is to upgrade their role from informal to formal commercial agents, similar to financial institutions or collecting farms (Indrawan et al., 2018a) (Chapter 2). As formal commercial agents, the traders will become more involved to stimulate efficient and effective poultry meat production. The coordination between the traders and farmers, collecting farms, and transporters is expected to change from on-the-spot transactions to contractual, long-term agreements (Chapter 2), thus improving coordination in the controlled slaughter-point chain as well as in the private slaughter-point chain. A pull approach towards a removal of the sick poultry market might take the form of an advertisement campaign, making consumers aware that a part of the poultry they buy is sick.

As described before, all Western Java poultry farms could improve their biosecurity considerably. A removal of the sick poultry market may modify the incentives for biosecurity improvement, but besides that, additional initiatives should be taken to push poultry farmers (including sector 1 farms) towards improved biosecurity. As proposed in the previous paragraph, improving chain coordination in the slaughter-point chain and the private slaughterpoint chain also helps to bring incentives to poultry farmers for biosecurity improvement. Generally, when looking at incentives for farmers for biosecurity improvement, the farm business type should be taken into account. Moreover, proper cost-benefit analyses of 
improved biosecurity need to be made. A positive aspect of biosecurity is that it does not only reduce the risk of introduction and transmission of HPAI, but also of other, contagious, poultry diseases. So, the benefits of improved biosecurity are bigger than just a reduction in the damage of HPAI. A final issue regarding measures to push the production into a specific direction is the enforcement of regulations. When implementing novel regulations, they should be designed in such a way that they are easily enforced. When moving beyond voluntary changes in behavior, regulation enforcement is crucial.

A pull strategy, as the other possible direction of government intervention, will focus on consumers. It should create incentives to shift the consumers away from buying poultry meat in the traditional channel. A classical method to move consumers in a preferred direction is the adoption of economic incentives. By differentiating taxes and/or subsidies between the two channels, consumers' preferences may shift towards another channel (Indrawan et al., 2018b). Another method to change consumers' preferences is to run campaigns, such as education and advertisement of healthy poultry meat (Chapter 5 and Chapter 6). Changing taxes and/or subsidies, the government influences the price/quality relationship for poultry meat. For instance, by subsidizing the modern channel, the consumers may buy more poultry meat from this channel. On the other hand, by additional or increased taxes in the traditional channel, the consumers may buy less in this channel. In order to do so, a proper tax or subsidy system should be implemented and, for subsidies to be effective, the market should function properly. If a tax or a subsidy has no visible effect on the consumer price, it will not be effective. Financial incentives may be combined with health campaigns to change the consumers' preference towards the modern market. With what we have learned in our work, we now know that such campaigns should be aimed at reducing the trade-off between food safety and freshness, meaning that the government should either communicate a redefinition of freshness, or the importance of safe chicken, or both. In order for the level of food safety to be trustworthy, campaigns should be combined with food safety certification (Chapter 6). By supporting the promotion of freshness and food safety features of poultry meat at the modern channel with financial incentives, Western Java consumers might very well start to prefer the modern channel, increasing the probability of pulling the poultry supply chain to a safer production. As a side note, we expect that a pull strategy is implemented for the long run, as it will not be effective in the short run. To make progress in the short run, the focus should be on the push strategy. 
Because of the cost involved with the above measures, the evaluation of the cost-effectiveness of single or combinations of measures can be linked to the available (long term) budgets, so that the most cost-effective measure can be implemented. Distribution of costs and benefits over actors in the value chain (including the government) should be taken into account.

\subsection{Future research}

In our work, we have generated an extensive body of knowledge that can is valuable for the design of future control measures for HPAI in Indonesia. However, some aspects remain unclear. We have mainly worked towards a better understanding of the poultry chain structure and were able to make conclusions on general incentive mechanisms. However, we did not study specific push or pull incentives nor how these incentives might affect the actors' motivation to change their behavior. For instance, we were only able to identify generic incentives for traders to become commercial agents, or incentives for farmers to implement better biosecurity measures. We did not study any specific measures. Given the expected effectiveness (also in time), future research should focus on the implementation of specific push strategies by the government, rather than on pull strategies.

First, it is essential to help plan, implement and evaluate incentive mechanisms for the chain actors in the poultry chain structure. In a first step, based on utility theory, the economic impact of proposed measures on the involved actors should be studied, exploring the relation between chain actors, their transaction costs, and the costs of their efforts to control HPAI, and relating that to the benefits of a reduced risk of HPAI as well as of other contagious diseases. Simulation modeling is a good basis for utility-driven cost-benefit evaluation. For instance, the economic effects of the removal of the sick poultry market should be evaluated for all actors involved. In a next step, the economic effects of a proposed measure should be studied in combination with other (tangible and intangible) factors that motivate actors to behave in a certain way. These studies can be based on social-psychological theory, such as the Theory of Planned Behavior (Ajzen, 1991), which has been used in other food safety research, including Verbeke and Viaene (1999), Verbeke and Vackier (2005), Lobb et al. (2007), and Mazzocchi et al. (2008).

To understand the interaction of actors within the different value chains, and to quantify these interactions, a Principal Agent approach (Laffont and Martimort, 2009) can be taken. In this approach, the (economic) dependencies of actors within a chain can be quantified. Principal 
Agent Theory has been used before in the animal production domain, for instance by King et al. (2007), who developed an incentive system for food quality control for Salmonella, by Resende-Filho and Buhr (2008), who evaluated the economic value of a traceability system, and by Yunxian et al. (2010), who studied retailers' order contracts in a perishable product value chain.

In order to evaluate the overall effect of implementing incentives for the full value chain, the insights of intangible incentives for individual actors should be taken into account. An evaluation can be based on game theory (e.g., Delabouglise and Boni (2018) and Manfredi and D'Onofrio (2013)). Although there are no known examples of applying game theory in the control of animal diseases, some work on epidemiological game-theoretic models have been published for control of disease in humans, for instance to control influenza (Galvani et al., 2007). Another full value chain approach can be to combine epidemiological knowledge with behavioral knowledge in an agent-based model, as recently for Bluetongue virus in the Netherlands (Sok and Fischer, 2018). In these modeling approaches, different types of incentive systems influencing poultry actors' decisions and consequences in the occurrence of HPAI can be simulated. The effects of incentive systems for farmers (Chapters 2 and 4) and traders (Chapter 2) can be studied separately, or in combination to find interactions between these systems. Simulations can also model the effect of budget constraints, highly relevant in low and middle-income countries.

\subsection{Conclusions}

The most important conclusions of this thesis are the following:

- Poultry production in Western Java is organized in a highly complex structure. Four different value chains can be distinguished: the integrator chain, the semi-automated slaughter chain, the controlled slaughter-point chain, and the private slaughter-point chain. This complex structure is responsible for the existence of a market for sick poultry that has a very negative influence on HPAI control.

- Traders need to be involved in the design and implementation of HPAI control measures, since they are the informal chain leaders in the controlled slaughter-point and the private slaughter-point chains. 
- A combination of a value chain analysis with expertise-based estimates for HPAI introduction and transmission did identify critical actors in the epidemiology of HPAI. The method can easily be applied to study the structure of endemic contagious disease problems in developing countries having inadequate resources for extensive epidemiological research.

- The main reason for consumers in Western Java to have a preference for the less safe, wet poultry markets, is their perception of freshness.

- A push strategy, as an incentive mechanism, should be designed in such a way that it pays attention to the interactions between actors in a value chain and their impact on introduction and transmission of disease.

- A pull strategy as an incentive mechanism for consumers forcing producers to improve their production environment into higher levels of biosecurity is expected to be less effective than a push strategy targeting producers. 
References 
Ajewole, O. C., and A. A. Akinwumi. 2014. Awareness and Practice of Biosecurity Measures in Small Scale Poultry Production in Ekiti State, Nigeria. Journal of Agricultural and Veterinary Science 7:24-29.

Ajzen, I. 1991. The theory of planned behavior. Organizational behavior and human decision processes 50:179-211.

Albersmeier, F., H. Schulze, G. Jahn, and A. Spiller. 2009. The reliability of third-party certification in the food chain: From checklists to risk-oriented auditing. Food Control 20:927935. doi 10.1016/j.foodcont.2009.01.010

Angulo, A. M., and J. M. Gil. 2007. Risk perception and consumer willingness to pay for certified beef in Spain. Food Quality and Preference 18:1106-1117. doi 10.1016/j.foodqual.2007.05.008

Antoine-Moussiaux, N., M. Peyre, P. Bonnet, C. Bebay, M. Bengoumi, and A. Tripodi. 2017. The Value Chain Approach in One Health: Conceptual Framing and Focus on Present Applications and Challenges. Frontiers in Veterinary Science 4. doi 10.3389/fvets.2017.00206

Arnot, C., Y. Vizzier-Thaxton, and C. G. Scanes. 2016. Values, trust and science - building trust in today's food system in an era of radical transparency. Poultry Science 95:2219-2224.

Azhar, M., A. S. Lubis, E. S. Siregar, R. G. Alders, E. Brum, J. McGrane, I. Morgan, and P. Roeder. 2010. Participatory disease surveillance and response in Indonesia: strengthening veterinary services and empowering communities to prevent and control highly pathogenic avian influenza. Avian diseases 54:749-753. doi 10.1637/8713-031809-Reg.1

Bahri, S. 2008. Beberapa aspek keamanan pangan asal ternak di Indonesia. Pengembangan Inovasi Pertanian 1:225-242.

Barnes, A. P., A. P. Moxey, B. Vosough Ahmadi, and F. A. Borthwick. 2015. The effect of animal health compensation on 'positive' behaviours towards exotic disease reporting and implementing biosecurity: A review, a synthesis and a research agenda. Preventive Veterinary Medicine 122:42-52. doi 10.1016/j.prevetmed.2015.09.003

Basuno, E., Y. Yusdja, and N. Ilham. 2010. Socio-economic Impacts of Avian Influenza Outbreaks on Small-scale Producers in Indonesia. Transboundary and Emerging Diseases 57:7-10.

Bett, H. K., K. J. Peters, U. M. Nwankwo, and W. Bokelmann. 2013. Estimating consumer preferences and willingness to pay for the underutilised indigenous chicken products. Food Policy 41:218-225. doi 10.1016/j.foodpol.2013.05.012

Birhanu, H., A. Tehetna, H. Yohannes, and T. Awot. 2015. Assessment of Bio-Security Condition in Small Scale Poultry Production System in and Around Mekelle, Ethiopia. Eur. J. Biol. Sci 7:99-102.

Boni, M. F., A. P. Galvani, A. L. Wickelgren, and A. Malani. 2013. Economic epidemiology of avian influenza on smallholder poultry farms. Theoretical Population Biology 90:135-144. doi $10.1016 /$ j.tpb.2013.10.001

Bonne, K., and W. Verbeke. 2006. Muslim consumer's motivations towards meat consumption in Belgium: qualitative exploratory insights from means-end chain analysis. Anthropology of food. 
Cardona, C. J. 2012. Poultry biosecurity evaluation and indicators in XXIV World poultry congress, Salvador,Bahia, Brazil.

Castellini, C., C. Berri, E. Le Bihan-Duval, and G. Martino. 2008. Qualitative attributes and consumer perception of organic and free-range poultry meat. World's Poultry Science Journal 64:500-512.

Chamhuri, N., and P. J. Batt. 2009. Factors influencing consumers' choice of retail stores for fresh meat in Malaysia. Acta Horticulturae 831:237-245.

Chamhuri, N., and P. J. Batt. 2013a. Exploring the factors influencing consumers' choice of retail store when purchasing fresh meat in Malaysia. International Food and Agribusiness Management Review 16:99-122.

Chamhuri, N., and P. J. Batt. 2013b. Segmentation of Malaysian shoppers by store choice behaviour in their purchase of fresh meat and fresh produce. Journal of Retailing and Consumer Services 20:516-528.

Chamhuri, N., and P. J. Batt. 2013c. Understanding the Relationship Between Perceived Quality Cues and Quality Attributes in the Purchase of Meat in Malaysia. Journal of International Food \& Agribusiness Marketing 25:187-208. doi $10.1080 / 08974438.2013 .723999$

Chamhuri, N., and P. J. Batt. 2015. Consumer perceptions of food quality in Malaysia. British Food Journal 117:1168-1187.

Chamhuri, N., Y. Kusumawaty, and P. J. Batt. 2015. Consumers' purchasing behaviour for fresh meat from modern retail stores and traditional markets in Malaysia and Indonesia. Pages 72-102 in Islamic Perspectives on Marketing and Consumer Behavior: Planning, Implementation, and ControlIGI Global.

Chitchumnong, P., and R. D. Horan. 2018. Managing Disease Risks from Trade: Strategic Behavior with Many Choices and Price Effects. EcoHealth:.1-15.

Chrzan, K., and B. Orme. 2000. An overview and comparison of design strategies for choicebased conjoint analysis. Sawtooth software research paper series 98382.

Cicia, G., and F. Colantuoni. 2010. Willingness to pay for traceable meat attributes: a metaanalysis. International Journal on Food System Dynamics 1:252-263.

Costard, S., G. Fournié, and D. U. Pfeiffer. 2014. Using Risk Assessment as Part of a Systems Approach to the Control and Prevention of HPAIV H5N1. EcoHealth 11:36-43. doi 10.1007/s10393-014-0907-1

Daems, R., G. Del Giudice, and R. Rappuoli. 2005. Anticipating crisis: towards a pandemic flu vaccination strategy through alignment of public health and industrial policy Vaccine 23(50):5732-5742.

Daryanto, A., D. de Boer, D. Indrawan, F. Leenstra, H. Mudde, I. Fahmi, and P. van Horne. 2014. Socio-economic analysis of the slaughtering systems in the poultry meat sector in Greater Jakarta Area. 
de Glanville, W., S. Idris, S. Costard, F. Unger, and D. Pfeiffer. 2010. A quantitative risk assessment for the onward transmission of highly pathogenic avian influenza H5N1 from an infected small-scale broiler farm in Bogor, West Java, Indonesia.

de Jonge, J., H. Van Trijp, R. Jan Renes, and L. Frewer. 2007. Understanding consumer confidence in the safety of food: Its two-dimensional structure and determinants. Risk analysis 27:729-740.

de Jonge, J., J. Van Trijp, I. A. van der Lans, R. J. Renes, and L. J. Frewer. 2008. How trust in institutions and organizations builds general consumer confidence in the safety of food: A decomposition of effects. Appetite 51:311-317.

Delabouglise, A., and M. F. Boni. 2018. Game theory of vaccination and depopulation for managing avian influenza on poultry farms. bioRxiv:348813. doi 10.1101/348813

Desvaux, S., C. O. Nguyen, D. T. Vu, C. Henriquez, V. D. Ky, F. Roger, S. Fenwick, and F. Goutard. 2016. Risk of Introduction in Northern Vietnam of HPAI Viruses from China: Description, Patterns and Drivers of Illegal Poultry Trade. Transboundary and Emerging Diseases 63:389-397. doi doi:10.1111/tbed.12279

Di Stefano, G., A. Gambardella, and G. Verona. 2012. Technology push and demand pull perspectives in innovation studies: Current findings and future research directions. Research Policy 41:1283-1295.

Dijkhuizen, A. A., R. B. M. Huirne, and A. W. Jalvingh. 1995. Economic analysis of animal diseases and their control. Preventive Veterinary Medicine 25:135-149. doi 10.1016/01675877(95)00535-8

Direktorat Jenderal Peternakan. 2015. Stastistik Peternakan dan Kesehatan Hewan 2015. Ministry of Agriculture Republic of Indonesia, http://ditjennak.pertanian.go.id

Direktorat Jenderal Peternakan dan Kesehatan Hewan. 2017. Livestock and Animal Health Statistic. M. o. Agriculture ed., Jakarta.

Dolberg, F., E. G. Bleich, and A. McLeod. 2009. Impact of avian influenza in the poultry sectors of five South-East Asian countries. Village chickens, poverty alleviation and the sustainable control of newcastle disease 30:147.

Dorea, F., R. Berghaus, C. Hofacre, and D. Cole. 2010. Survey of biosecurity protocols and practices adopted by growers on commercial poultry farms in Georgia, US A. Avian diseases 54:1007-1015.

Dougherty, C. 2011. Introduction to econometrics. Oxford University Press.

Drescher, L. S., J. de Jonge, E. Goddard, and T. Herzfeld. 2012. Consumer's stated trust in the food industry and meat purchases. Agriculture and Human Values 29:507-517.

Durr, P. A., M. H. Wibowo, S. Tarigan, S. Artanto, M. N. Rosyid, and J. Ignjatovic. 2016. Defining "Sector 3" Poultry Layer Farms in Relation to H5N1-HPAI-An Example from Java, Indonesia. Avian diseases 60:183-190.

Eagles, D., E. Siregar, D. Dung, J. Weaver, F. Wong, and P. Daniels. 2009. H5N1 highly pathogenic avian influenza in Southeast Asia. Revue scientifique et technique 28:341. 
European Food Safety Authority. 2006. Statement on migratory birds and their possible role in the spread of highly pathogenic avian influenza by the Scientific Panel on Animal Health an Welfare (AHAW). EFSA Journal 4:357a.

Fardiaz, D., R. Bhat, and S. Sareen. 2011. Guidelines for risk categorization of food and food establishments applicable to ASEAN countries. RAP Publication (FAO) eng no. 2011/22.

Fasina, F. O., A. Ali, J. Yilma, O. Thieme, and P. Ankers. 2012. The cost-benefit of biosecurity measures on infectious diseases in the Egyptian household poultry. Preventive veterinary medicine 103:178-191.

Figuié, M., and T. Fournier. 2008. Avian Influenza in Vietnam: Chicken-Hearted Consumers? Risk analysis 28:441-451.

Figuié, M., and N. D. Truyen. 2006. Poor consumers' access to supermarkets in Hanoi. Pages 102-141CIRAD/ADB.

Fletcher, D. 2002. Poultry meat quality. World's Poultry Science Journal 58:131-145.

Florkowski, W. J., Z. You, and C. L. Huang. 1999. Consumer selection of retail outlets in buying pecans. Journal of Food Distribution Research 30:34-43.

Font-i-Furnols, M., and L. Guerrero. 2014. Consumer preference, behavior and perception about meat and meat products: An overview. Meat Science 98:361-371. doi 10.1016/j.meatsci.2014.06.025

Food and Agriculture Organization. 2011. Approaches to controlling, preventing and eliminating H5N1 highly pathogenic avian influenza in endemic countries. FAO.

Food and Agriculture Organization of the United Nation. 2007. The importance on biosecurity in reducing HPAI risks on farms and in markets in International Ministrial Conference on Avian and Pandemic influenza, New Delhi.

Food and Agriculture Organization of the United Nation. 2011. Approaches to controlling, preventing and eliminating $\mathrm{H} 5 \mathrm{~N} 1$ highly pathogenic avian influenza in endemic countries. FAO.

Food and Agriculture Organization of the United Nations. 2006. Highly Pathogenic Avian Influenza in Africa. A Strategy and Proposed Programme to Limit Spread and Build Capacity for Epizootic Disease Control for Epizootic Disease Control in ECTAD Report. FAO, Rome.

Forster, P. 2014. Ten years on: Generating innovative responses to avian influenza. EcoHealth $11: 15-21$.

Galvani, A. P., T. C. Reluga, and G. B. Chapman. 2007. Long-standing influenza vaccination policy is in accord with individual self-interest but not with the utilitarian optimum. Proceedings of the National Academy of Sciences 104:5692-5697. doi 10.1073/pnas.0606774104

Gerdoçi, B., G. Bortoluzzi, and S. Dibra. 2018. Business model design and firm performance: Evidence of interactive effects from a developing economy. European Journal of Innovation Management 21:315-333. 
Gereffi, G., J. Humphrey, and T. Sturgeon. 2005. The governance of global value chains. Review of international political economy 12:78-104. doi 10.1080/09692290500049805

Gilbert, M., and D. U. Pfeiffer. 2012. Risk factor modelling of the spatio-temporal patterns of highly pathogenic avian influenza (HPAIV) H5N1: A review. Spatial and Spatio-temporal Epidemiology 3:173-183. doi 10.1016/j.sste.2012.01.002

Goldman, A., and H. Hino. 2005. Supermarkets vs. traditional retail stores: diagnosing the barriers to supermarkets' market share growth in an ethnic minority community. Journal of Retailing and Consumer Services 12:273-284.

Goldman, A., R. Krider, and S. Ramaswami. 1999. The persistent competitive advantage of traditional food retailers in Asia: wet markets' continued dominance in Hong Kong. Journal of Macromarketing 19:126-139.

Gramig, B. M., and R. D. Horan. 2011. Jointly determined livestock disease dynamics and decentralised economic behaviour. Australian Journal of Agricultural and Resource Economics 55:393-410. doi 10.1111/j.1467-8489.2011.00543.x

Gramig, B. M., R. D. Horan, and C. A. Wolf. 2009. Livestock disease indemnity design when moral hazard is followed by adverse selection. American Journal of Agricultural Economics 91:627-641. doi 10.1111/j.1467-8276.2009.01256.x

Grunert, K. G. 2005. Food quality and safety: consumer perception and demand. European Review of Agricultural Economics 32:369-391.

Grunert, K. G., L. Bredahl, and K. Brunsø. 2004. Consumer perception of meat quality and implications for product development in the meat sector - a review. Meat Science 66:259-272. doi 10.1016/S0309-1740(03)00130-X

Hair, J. F., W. C. Black, B. J. Babin, R. E. Anderson, and R. L. Tatham. 1998. Multivariate data analysis. Prentice hall Upper Saddle River, NJ.

Hariyadi, P. 2008. Double challenges; Food safety problems in Indonesia(in bahasa). Jurnal Pangan 17:17-27.

Heider, R., and S. Moeller. 2012. Outlet patronage in on-the-go consumption: An analysis of patronage preference drivers for convenience outlets versus traditional retail outlets. Journal of retailing and consumer services 19:313-324.

Henchion, M., M. McCarthy, V. C. Resconi, and D. Troy. 2014. Meat consumption: Trends and quality matters. Meat Science 98:561-568. doi 10.1016/j.meatsci.2014.06.007

Henning, J., D. U. Pfeiffer, M. Stevenson, D. Yulianto, W. Priyono, and J. Meers. 2016. Who is spreading avian influenza in the moving duck flock farming network of Indonesia? PLOS ONE 11:e0152123.

Hernandez-Jover, M., K. Schemann, I. East, and J.-A. Toribio. 2015. Evaluating the risk of avian influenza introduction and spread among poultry exhibition flocks in Australia. Preventive veterinary medicine 118:128-141.

Hoffmann, R. 2000. Country of origin-a consumer perception perspective of fresh meat. British Food Journal 102:211-229. 
Honhold, N., A. McLeod, S. Sarkar, and P. Harris. 2008. Biosecurity for Highly Pathogenic Avian Influenza. Rome: FAO.

Horbach, J., C. Rammer, and K. Rennings. 2012. Determinants of eco-innovations by type of environmental impact - The role of regulatory push/pull, technology push and market pull. Ecological economics 78:112-122.

Horimoto, T., and Y. Kawaoka. 2001. Pandemic threat posed by avian influenza A viruses. Clinical microbiology reviews 14:129-149.

Hu, W., M. T. Batte, T. Woods, and S. Ernst. 2011. Consumer preferences for local production and other value-added label claims for a processed food product. European Review of Agricultural Economics 39:489-510.

Idris, S., M. F. Palupi, E. Sudiana, F. Unger, S. Costard, and D. Pfeiffer. 2010. Qualitative risk assessment of HPAI H5N1 transmission between small-scale commercial broiler chicken farms in Bogor, Indonesia. Pages 64 IFPRI, Washington DC

Ilham, N., and M. Iqbal. 2011. Factors determining farmers' decision on highly pathogenic Avian Influenza vaccination at the small poultry farms in Western Java. Media Peternakan $34: 219$.

Indrawan, D., K. M. Rich, P. van Horne, A. Daryanto, and H. Hogeveen. 2018a. Linking supply chain governance and biosecurity in the context of HPAI control in Western Java: A value chain perspective. Frontiers in veterinary science 5. doi 10.3389/fvets.2018.00094

Indrawan, D., G. Tacken, and H. Hogeveen. 2018b. What drives the choice of poultry market channel and the change of purchase behavior due to highly pathogenic avian influenza outbreaks? Poultry science. doi 10.3382/ps/pey222

Indriani, R., G. Samaan, A. Gultom, L. Loth, S. Indryani, R. Adjid, N. L. P. I. Dharmayanti, J. Weaver, E. Mumford, K. Lokuge, P. M. Kelly, and Darminto. 2010. Environmental Sampling for Avian Influenza Virus A (H5N1) in Live-Bird Markets, Indonesia. Emerging Infectious Diseases 16:1889-1895. doi 10.3201/eid1612.100402

Irvine, R. M. 2015. A conceptual study of value chain analysis as a tool for assessing a veterinary surveillance system for poultry in Great Britain. Agricultural Systems 135:143-158.

Issanchou, S. 1996. Consumer expectations and perceptions of meat and meat product quality. Meat Science 43:5-19.

Iton, C. A. 2015. Factors influencing retail outlet choice of women purchasing fresh fruits in Trinidad and Tobago. American Journal of Business and Management 4:38-48.

Kaplinsky, R. 1998. Globalisation, industrialisation and sustainable growth: the pursuit of the nth rent. Institute of Development Studies.

Kaplinsky, R., and M. Morris. 2001. A handbook for value chain research. IDRC, Ottawa.

Kasemsuwan, S., C. Poolkhet, T. Patanasatienkul, N. Buameetoop, M. Watanakul, K. Chanachai, K. Wongsathapornchai, R. Métras, C. Marcé, and A. Prakarnkamanant. 2009. Qualitative risk assessment of the risk of introduction and transmission of H5N1 HPAI virus for 1-km buffer zones surrounding compartmentalised poultry farms in Thailand. The Pro-poor HPAI Risk Reduction Project Report 9. 
Kehagia, O., M. Linardakis, and G. Chryssochoidis. 2007. Beef traceability: are Greek consumers willing to pay? EuroMed Journal of Business 2:173-190.

Kehlbacher, A., R. Bennett, and K. Balcombe. 2012. Measuring the consumer benefits of improving farm animal welfare to inform welfare labelling. Food Policy 37:627-633. doi 10.1016/j.foodpol.2012.07.002

Kelly, L., R. Kosmider, P. Gale, and E. L. Snary. 2018. Qualitative import risk assessment: A proposed method for estimating the aggregated probability of entry of infection. Microbial Risk Analysis. doi 10.1016/j.mran.2018.03.001

Kennedy, O. B., B. Stewart-Knox, P. Mitchell, and D. Thurnham. 2004. Consumer perceptions of poultry meat: a qualitative analysis. Nutrition \& Food Science 34:122-129.

Kiilholma, J. 2008. Food-safety concerns in the poultry sector of developing countries in the International Conference Poultry in the Twenty-first Century: avian influenza and beyond. FAO, Rome, Bangkok.

King, R. P., G. B. Backus, and M. A. Van Der Gaag. 2007. Incentive systems for food quality control with repeated deliveries: Salmonella control in pork production. European Review of Agricultural Economics 34:81-104.

Krystallis, A., and I. S. Arvanitoyannis. 2006. Investigating the concept of meat quality from the consumers' perspective: The case of Greece. Meat Science 72:164-176.

Krystallis, A., G. Chryssochoidis, and J. Scholderer. 2007. Consumer-perceived quality in 'traditional'food chains: The case of the Greek meat supply chain. Appetite 48:54-68.

Kuhfeld, W. F. 1997. Efficient experimental designs using computerized searches. Research Paper Series, SAS Institute, Inc.

Kuhfeld, W. F. 2005. Marketing research methods in SAS. Experimental Design, Choice, Conjoint, and Graphical Techniques. Cary, NC, SAS-Institute TS-722.

Kurscheid, J., J. Millar, M. Abdurrahman, I. G. A. A. Ambarawati, W. Suadnya, R. P. Yusuf, S. Fenwick, and J.-A. L. M. L. Toribio. 2015. Knowledge and Perceptions of Highly Pathogenic Avian Influenza (HPAI) among Poultry Traders in Live Bird Markets in Bali and Lombok, Indonesia. PLOS ONE 10:e0139917.

Kusumaningrum, H., and R. Dewanti-Hariyadi. 2012. Multidrug resistance among different serotypes of Salmonella isolates from fresh products in Indonesia.

Laffont, J.-J., and D. Martimort. 2009. The theory of incentives: the principal-agent model. Princeton university press.

Lancaster, K. J. 1966. A New Approach to Consumer Theory. Journal of Political Economy 74:132-157. doi 10.1086/259131

Lestari, V. S., A. Natsir, H. Karim, and I. Patrick. 2016. Factors Affecting Consumers' Willingness to Pay for Chicken Meat from Biosecure Farms. World Academy of Science, Engineering and Technology, International Journal of Social, Behavioral, Educational, Economic, Business and Industrial Engineering 10:2062-2066. 
Liu, D., and S. Stelzer-Braid. 2014. 3 Avian Influenza Virus (Highly Pathogenic). Manual of Security Sensitive Microbes and Toxins 1960:21.

Lobb, A., M. Mazzocchi, and W. Traill. 2007. Modelling risk perception and trust in food safety information within the theory of planned behaviour. Food Quality and Preference 18:384-395.

Loth, L., M. Gilbert, J. Wu, C. Czarnecki, M. Hidayat, and X. Xiao. 2011. Identifying risk factors of highly pathogenic avian influenza (H5N1 subtype) in Indonesia. Preventive veterinary medicine 102:50-58.

Loureiro, M. L., and W. J. Umberger. 2007. A choice experiment model for beef: What US consumer responses tell us about relative preferences for food safety, country-of-origin labeling and traceability. Food policy 32:496-514.

Makanyeza, C., R. Macheyo, and F. du Toit. 2016. Perceived product necessity, perceived value, customer satisfaction and affective attitude: an integrative model. Journal of African Business 17:69-86. doi 10.1080/15228916.2016.1112709

Manfredi, P., and A. D'Onofrio. 2013. Modeling the interplay between human behavior and the spread of infectious diseases. Springer Science \& Business Media.

Martin, V., X. Zhou, E. Marshall, B. Jia, G. Fusheng, M. A. FrancoDixon, N. DeHaan, D. U. Pfeiffer, R. J. S. Magalhães, and M. Gilbert. 2011. Risk-based surveillance for avian influenza control along poultry market chains in South China: the value of social network analysis. Preventive veterinary medicine 102:196-205. doi 10.1016/j.prevetmed.2011.07.007

Martindah, E., N. Ilham, and E. Basuno. 2014. Biosecurity level of poultry production cluster (PPC) in West Java, Indonesia. Int. J. Poult. Sci 13:408-415.

Martínez Michel, L., S. Anders, and W. V. Wismer. 2011. Consumer Preferences and willingness to pay for value-added chicken product attributes. Journal of food science 76.

Maynard, L. J., K. H. Burdine, and A. L. Meyer. 2003. Market potential for locally produced meat products. Journal of Food Distribution Research 34:26-37.

Mazzocchi, M., A. Lobb, W. Bruce Traill, and A. Cavicchi. 2008. Food scares and trust: a European study. Journal of agricultural economics 59:2-24.

McFadden, D. 2001. Economic choices. American economic review 91:351-378.

McLeod, A., M. Kobayashi, J. Gilman, A. Siagian, and M. Young. 2009. The use of poultry value chain mapping in developing HPAI control programmes. World's Poultry Science Journal 65:217-224. doi 10.1017/s0043933909000166

Mead, G. 2004. Microbiological quality of poultry meat: a review. Revista Brasileira de Ciência Avícola 6:135-142.

Meredith, H., D. Walsh, D. A. McDowell, and D. J. Bolton. 2013. An investigation of the immediate and storage effects of chemical treatments on Campylobacter and sensory characteristics of poultry meat. International Journal of Food Microbiology 166:309-315. doi 10.1016/j.ijfoodmicro.2013.07.005 
Meuwissen, M. P., A. G. Velthuis, H. Hogeveen, and R. B. Huirne. 2003. Traceability and certification in meat supply chains. Journal of Agribusiness 21:167-182.

Ministry of Health 2018. Avian Influenza cases per province. https://data.go.id/dataset/kasusflu-burung-per-provinsi. Accessed 2 July 2018.

Muladno, M., and O. Thieme. 2009. Consumer Preferences for Poultry in IndonesiaGCP/RAS/228/GERWorking paper.

Negro-Calduch, E., S. Elfadaly, M. Tibbo, P. Ankers, and E. Bailey. 2013. Assessment of biosecurity practices of small-scale broiler producers in central Egypt. Preventive veterinary medicine 110:253-262.

Nemet, G. F. 2009. Demand-pull, technology-push, and government-led incentives for nonincremental technical change. Research Policy 38:700-709.

Office International des Epizooties. 2006. Bird Flu Avian Influenza from Africa to Asia.

Onkundi, D., B. Bett, S. Costard, A. Omore, and C. Zepeda. 2010. Qualitative release and exposure assessment on the risk of HPAI transmission between sector 4 farms and between sector 3 and sector 4 farms in Kenya.

Ortega, D. L., H. H. Wang, L. Wu, and N. J. Olynk. 2011. Modeling heterogeneity in consumer preferences for select food safety attributes in China. Food Policy 36:318-324. doi 10.1016/j.foodpol.2010.11.030

Owusu-Sekyere, E., V. Owusu, and H. Jordaan. 2014. Consumer preferences and willingness to pay for beef food safety assurance labels in the Kumasi Metropolis and Sunyani Municipality of Ghana. Food Control 46:152-159. doi 10.1016/j.foodcont.2014.05.019

Paul, M., V. Baritaux, S. Wongnarkpet, C. Poolkhet, W. Thanapongtharm, F. Roger, P. Bonnet, and C. Ducrot. 2013. Practices associated with highly pathogenic avian influenza spread in traditional poultry marketing chains: social and economic perspectives. Acta tropica 126:4353.

Pechey, R., and P. Monsivais. 2015. Supermarket choice, shopping behavior, socioeconomic status, and food purchases. American journal of preventive medicine 49:868-877.

Peiris, J. M., M. D. De Jong, and Y. Guan. 2007. Avian influenza virus (H5N1): a threat to human health. Clinical microbiology reviews 20:243-267.

PINSAR 2016. Info Harga. Accessed 10 October 2016.

Poetri, O., A. Bouma, I. Claassen, G. Koch, R. Soejoedono, A. Stegeman, and M. van Boven. 2011. A single vaccination of commercial broilers does not reduce transmission of H5N1 highly pathogenic avian influenza. Veterinary research 42:74.

Pramuwidyatama, M. G., H. Hogeveen, and H. W. Saatkamp. 2018. A systematic evaluation of measures against Highly Pathogenic Avian Influenza (HPAI) H5N1 in West Java Province, Indonesia. Manuscript submitted for publication.

Probst, L., E. Houedjofonon, H. M. Ayerakwa, and R. Haas. 2012. Will they buy it? The potential for marketing organic vegetables in the food vending sector to strengthen vegetable 
safety: A choice experiment study in three West African cities. Food Policy 37:296-308. doi 10.1016/j.foodpol.2012.02.014

Qijun, J., and P. J. Batt. 2016. Barriers and benefits to the adoption of a third party certified food safety management system in the food processing sector in Shanghai, China. Food Control 62:89-96. doi 10.1016/j.foodcont.2015.10.020

Remme, J. H., E. Blas, L. Chitsulo, P. M. Desjeux, H. D. Engers, T. P. Kanyok, J. F. K. Kayondo, D. W. Kioy, V. Kumaraswami, J. K. Lazdins, and P. P. Nunn. 2002. Strategic emphases for tropical diseases research: a TDR perspective. Trends in parasitology 18(10):421426.

Resende-Filho, M. A., and B. L. Buhr. 2008. A principal-agent model for evaluating the economic value of a traceability system: A case study with injection-site lesion control in fed cattle. American Journal of Agricultural Economics 90:1091-1102.

Rich, K. M., and B. D. Perry. 2011. The economic and poverty impacts of animal diseases in developing countries: new roles, new demands for economics and epidemiology. Preventive veterinary medicine 101:133-147. doi 10.1016/j.prevetmed.2010.08.002

Rich, K. M., R. B. Ross, A. D. Baker, and A. Negassa. 2011. Quantifying value chain analysis in the context of livestock systems in developing countries. Food Policy 36:214-222. doi 10.1016/j.foodpol.2010.11.018

Rich, K. M., and F. Wanyoike. 2010. An assessment of the regional and national socioeconomic impacts of the 2007 Rift Valley fever outbreak in Kenya. The American journal of tropical medicine and hygiene 83:52-57. doi 10.4269/ajtmh.2010.09-0291

Roche, S. E., N. Cogger, M. G. Garner, A. A. G. Putra, and J.-A. L. Toribio. 2014. Assessing the risk of highly pathogenic avian influenza H5N1 transmission through poultry movements in Bali, Indonesia. Preventive veterinary medicine 113:599-607.

Röhr, A., K. Lüddecke, S. Drusch, M. J. Müller, and R. v. Alvensleben. 2005. Food quality and safety-consumer perception and public health concern. Food Control 16:649-655. doi 10.1016/j.foodcont.2004.06.001

Rousseau, S., and L. Vranken. 2013. Green market expansion by reducing information asymmetries: Evidence for labeled organic food products. Food Policy 40:31-43. doi 10.1016/j.foodpol.2013.01.006

Rushton, J., R. Viscarra, E. G. Bleich, and A. McLeod. 2005. Impact of avian influenza outbreaks in the poultry sectors of five South East Asian countries (Cambodia, Indonesia, Lao PDR, Thailand, Viet Nam) outbreak costs, responses and potential long term control. World's Poultry Science Journal 61:491-514.

Samaan, G., A. Gultom, R. Indriani, K. Lokuge, and P. M. Kelly. 2011. Critical control points for avian influenza A H5N1 in live bird markets in low resource settings. Preventive veterinary medicine 100:71-78.

Samant, S. S., and H.-S. Seo. 2016. Quality perception and acceptability of chicken breast meat labeled with sustainability claims vary as a function of consumers' label-understanding level. Food Quality and Preference 49:151-160. doi 10.1016/j.foodqual.2015.12.004 
Santhia, K., A. Ramy, P. Jayaningsih, G. Samaan, A. A. G. Putra, N. Dibia, C. Sulaimin, G. Joni, C. Y. Leung, and J. S. Malik Peiris. 2009. Avian influenza A H5N1 infections in Bali Province, Indonesia: a behavioral, virological and seroepidemiological study. Influenza and other respiratory viruses 3:81-89. doi 10.1111/j.1750-2659.2009.00069.x

Scallan, E., R. M. Hoekstra, F. J. Angulo, R. V. Tauxe, M.-A. Widdowson, S. L. Roy, J. L. Jones, and P. M. Griffin. 2011. Foodborne illness acquired in the United States-major pathogens. Emerging infectious diseases 17:7.

Schleenbecker, R., and U. Hamm. 2013. Consumers' perception of organic product characteristics. A review. Appetite 71:420-429. doi 10.1016/j.appet.2013.08.020

Scott, E. 2003. Food Safety and Foodborne Disease in the 21st Century. Canadian Journal of Infectious Diseases and Medical Microbiology 14:277-280.

Scudamore, J., and D. Harris. 2002. Control of foot and mouth disease: lessons from the experience of the outbreak in Great Britain in 2001. Revue scientifique et technique-Office international des épizooties 21:699-707.

Sedyaningsih, E. R., S. Isfandari, V. Setiawaty, L. Rifati, S. Harun, W. Purba, S. Imari, S. Giriputra, P. J. Blair, and S. D. Putnam. 2007. Epidemiology of cases of H5N1 virus infection in Indonesia, July 2005-June 2006. The Journal of infectious diseases 196:522-527.

Sedyaningsih, E. R., S. Isfandari, T. Soendoro, and S. F. Supari. 2008. Towards mutual trust, transparency and equity in virus sharing mechanism: the avian influenza case of Indonesia. Annals Academy of Medicine Singapore 37:482.

Simmons, H. 2010. National and International Food Safety Certification Schemes. Pages 85101 in Fish Canning HandbookWiley-Blackwell.

Sims, L., J. Domenech, C. Benigno, S. Kahn, A. Kamata, J. Lubroth, V. Martin, and P. Roeder. 2005. Origin and evolution of highly pathogenic H5N1 avian influenza in Asia. The Veterinary Record 157:159.

Sinha, P. K., and A. Banerjee. 2004. Store choice behaviour in an evolving market. International Journal of Retail \& Distribution Management 32:482-494.

Slovin, E. 1960. Slovin's formula for sampling technique. Retrieved on February 13:2013.

Sofos, J. N. 2008. Challenges to meat safety in the 21st century. Meat science 78:3-13.

Sok, J., and E. A. J. Fischer. 2018. Farmers' heterogeneous motives, voluntary vaccination and disease spread: an agent-based model. Manuscript submitted for publication.

Solgaard, H. S., and T. Hansen. 2003. A hierarchical Bayes model of choice between supermarket formats. Journal of retailing and Consumer Services 10:169-180.

Souza, A. P. O., E. C. d. O. Sans, B. R. Müller, and C. F. M. Molento. 2015. Broiler chicken welfare assessment in GLOBALGAP ${ }^{\circledR}$ certified and non-certified farms in Brazil. Animal Welfare 24:45-54.

Sparringa, R. 2014. Food safety for animal based product in Indonesia (in bahasa). JITV 19. 
Spiggle, S., and M. A. Sewall. 1987. A choice sets model of retail selection. The Journal of Marketing:97-111.

Ssematimba, A., T. J. Hagenaars, J. J. de Wit, F. Ruiterkamp, T. H. Fabri, J. A. Stegeman, and M. C. M. de Jong. 2013. Avian influenza transmission risks: Analysis of biosecurity measures and contact structure in Dutch poultry farming. Preventive Veterinary Medicine 109:106-115. doi 10.1016/j.prevetmed.2012.09.001

Statistics. 2013. Number of household farmers based on region and types of livestockBPS, Jakarta.

Statistics. 2014. Agricultural Census 2013BPS, Jakarta.

Statistics. 2016. Statistical Yearbook of Indonesia 2016

Statistics 2018. Dynamic Table of Animal Husbandry https://www.bps.go.id/site/pilihdata.html. Accessed 17 July 2018.

Stranieri, S., and A. Banterle. 2015. Consumer interest in meat labelled attributes: Who cares? THE INTERNATIONAL FOOD AND AGRIBUSINESS MANAGEMENT REVIEW 18:2138 .

Sudarman, A., K. Rich, T. Randolph, and F. Unger. 2010. Poultry value chains and HPAI in Indonesia: The case of BogorInternational Food Policy Research Institute (IFPRI), Washington, DC.

Sujiwo, J., D. Kim, and A. Jang. 2018. Relation among quality traits of chicken breast meat during cold storage: correlations between freshness traits and torrymeter values. Poultry Science:pey138-pey138. doi 10.3382/ps/pey138

Sumiarto, B., and B. Arifin. 2008. Overview on Poultry Sector and HPAI Situation for Indonesia with Special Emphasis on the Island of Java-Background Paper. Manuscript submitted for publication, Royal Veterinary College. Retrieved from http://www. ifpri. org/publication/overview-poultry-sector-and-hpai-situationindonesia-special-emphasisisland-java.

Swayne, D., and D. Suarez. 2000. Highly pathogenic avian influenza. Revue scientifique et technique-office international des epizooties 19:463-475.

Tollis, M., and L. D. Trani. 2002. Recent developments in avian influenza research: epidemiology and immunoprophylaxis. The Veterinary Journal 164:202-215.

Trienekens, J., and P. Zuurbier. 2008. Quality and safety standards in the food industry, developments and challenges. International Journal of Production Economics 113:107-122. doi 10.1016/j.ijpe.2007.02.050

United States Agency for International Development. 2013. Indonesia's Poultry Value Chain: Costs, Margins, Prices, and Other Issues

Van den Berg, T. 2009. The role of the legal and illegal trade of live birds and avian products in the spread of avian influenza. Revue scientifique et technique 28:93.

Van Kerkhove, M. D., S. Vong, J. Guitian, D. Holl, P. Mangtani, S. San, and A. C. Ghani. 2009. Poultry movement networks in Cambodia: Implications for surveillance and control of 
highly pathogenic avian influenza (HPAI/H5N1). Vaccine 27:6345-6352. doi 10.1016/j.vaccine.2009.05.004

Van Kleef, E., J. Houghton, A. Krystallis, U. Pfenning, G. Rowe, H. Van Dijk, I. Van der Lans, and L. J. Frewer. 2007. Consumer evaluations of food risk management quality in Europe. Risk Analysis 27:1565-1580.

Van Loo, E. J., V. Caputo, R. M. Nayga, J.-F. Meullenet, and S. C. Ricke. 2011. Consumers' willingness to pay for organic chicken breast: Evidence from choice experiment. Food Quality and Preference 22:603-613. doi 10.1016/j.foodqual.2011.02.003

Van Steenwinkel, S., S. Ribbens, E. Ducheyne, E. Goossens, and J. Dewulf. 2011. Assessing biosecurity practices, movements and densities of poultry sites across Belgium, resulting in different farm risk-groups for infectious disease introduction and spread. Preventive veterinary medicine 98:259-270. doi 10.1016/j.prevetmed.2010.12.004

Vanhonacker, F., F. A. M. Tuyttens, and W. Verbeke. 2016. Belgian citizens' and broiler producers' perceptions of broiler chicken welfare in Belgium versus Brazil. Poultry Science 95:1555-1563.

Verbeke, W., F. J. A. Pérez-Cueto, and K. G. Grunert. 2011. To eat or not to eat pork, how frequently and how varied? Insights from the quantitative Q-PorkChains consumer survey in four European countries. Meat Science 88:619-626. doi 10.1016/j.meatsci.2011.02.016

Verbeke, W., and I. Vackier. 2005. Individual determinants of fish consumption: application of the theory of planned behaviour. Appetite 44:67-82.

Verbeke, W., and J. Viaene. 1999. Beliefs, attitude and behaviour towards fresh meat consumption in Belgium: empirical evidence from a consumer survey. Food Quality and Preference 10:437-445. doi 10.1016/S0950-3293(99)00031-2

Verbeke, W., and R. W. Ward. 2006. Consumer interest in information cues denoting quality, traceability and origin: An application of ordered probit models to beef labels. Food Quality and Preference 17:453-467. doi 10.1016/j.foodqual.2005.05.010

Verbeke, W. A., and J. Viaene. 2000. Ethical challenges for livestock production: Meeting consumer concerns about meat safety and animalwelfare. Journal of Agricultural and Environmental Ethics 12:141-151.

Vukasovič, T. 2014. European $\mathrm{m}$ eat $\mathrm{m}$ arket trends and consum er preference for poultry $\mathrm{m}$ eat in buying decision making process. World's Poultry Science Journal 70:289-302.

Wacker, J. G., C. Yang, and C. Sheu. 2016. A transaction cost economics model for estimating performance effectiveness of relational and contractual governance: Theory and statistical results. International Journal of Operations \& Production Management 36:1551-1575.

Wahida, H. Toiba, W. J. Umberger, and N. Minot. 2013. Indonesian Consumers' Willingness To Pay For High-Value Agricultural Products in IV International Symposium on Improving the Performance of Supply Chains in the Transitional Economies. Acta Horticulturae.

Wibawa, H., D. Karo-Karo, E. S. Pribadi, A. Bouma, R. Bodewes, H. Vernooij, A. Sugama, D. H. Muljono, G. Koch, and F. S. T. Rasa. 2018. Exploring contacts facilitating transmission of influenza A (H5N1) virus between poultry farms in West Java, Indonesia: A major role for backyard farms? Preventive Veterinary Medicine 156:8-15. 
Wieland, B., S. Dhollander, M. Salman, and F. Koenen. 2011. Qualitative risk assessment in a data-scarce environment: A model to assess the impact of control measures on spread of African Swine Fever. Preventive Veterinary Medicine 99:4-14. doi 10.1016/j.prevetmed.2011.01.001

Williamson, O. E. 1989. Transaction cost economics. Handbook of industrial organization $1: 135-182$.

Williamson, O. E. 2002. The theory of the firm as governance structure: from choice to contract. Journal of economic perspectives 16:171-195.

Willyanto, I., B. Bett, F. Unger, and T. Randolph. 2010. Alignment of poultry sector actors with avian influenza control in Indonesia. International Food Policy Research Institute (IFPRI), Washington, DC.

World Health Organization 2013. Cumulative Number of Confirmed Human Cases of Avian Influenza $\mathrm{A} /(\mathrm{H} 5 \mathrm{~N} 1)$ Reported to World Health Organization (2003-2013). http://www.who.int/influenza/humananimalinterface/ENGIP20130705CumulativeNumberH5 N1cases2.pdf15 May 2016.

Wu, L., H. Wang, D. Zhu, W. Hu, and S. Wang. 2016. Chinese consumers' willingness to pay for pork traceability information - the case of Wuxi. Agricultural economics 47:71-79.

Yeung, R. M., and J. Morris. 2001. Food safety risk: Consumer perception and purchase behaviour. British Food Journal 103:170-187.

Yu, U.-J., L. S. Niehm, and D. W. Russell. 2011. Exploring perceived channel price, quality, and value as antecedents of channel choice and usage in multichannel shopping. Journal of Marketing Channels 18:79-102.

Yunxian, H., G. Honglian, and F. Qiang. 2010. A principal-agent model on retailer's order contract in perishable product supply chain in 7th International Conference on Service Systems and Service Management (ICSSSM). IEEE, Tokyo, Japan.

Yupiana, Y., S. J. de Vlas, N. M. Adnan, and J. H. Richardus. 2010. Risk factors of poultry outbreaks and human cases of H5N1 avian influenza virus infection in West Java Province, Indonesia. International Journal of Infectious Diseases 14:e800-e805.

Zhang, X. 2003. The dynamics of Chinese consumers: a case of Shanghai food consumption. Journal of International Food \& Agribusiness Marketing 14:47-66. 
References 


\section{Summary}

HPAI H5N1 is considered endemic in Indonesian poultry and poses a major challenge to animal and human health authorities. Although the Indonesian government formulated policies to manage the threats and consequences of HPAI, this approach was not holistic due to limited resources and little experience in handling zoonotic diseases. The complex structure of the Indonesian poultry meat value chain is an important reason for the limited efficacy of HPAI control in Indonesia so far. The implementation of ineffective control measures suggests that the government failed to understand the relation between the governance within the complex poultry supply chain and HPAI introduction and transmission. The effect of possible intervention strategies should be studied in relation to integrated knowledge on HPAI transmission through the value chain in combination with knowledge on the behavior of the chain actors. Existing value chain analyses do not provide sufficient insights in human behavior related to HPAI introduction and transmission. While future knowledge about control of HPAI should be developed in light of this value chain insight. The insight will support governmental efforts to mitigate HPAI can push and/or pull the supply chain towards better management.

The overall objective of this research is to improve our understanding of how to implement a push-and-pull strategy in the poultry supply chain to control HPAI infection in Western Java. More specifically, this study investigates the poultry value chain in Western Java in relation to consumers' behavior and governance of the value chain. Specific objectives of this thesis are:

1. To assess the complexity of poultry value chain structures and their influence on HPAI control in Western Java, paying particular attention to the relationship between value chain structures, actors, governance, and economic performance;

2. To assess the probability of HPAI introduction and transmission throughout the poultry value chain;

3. To assess how micro governance of the farms and other factors influence biosecurity procedures on broiler farms in Western Java;

4. To assess the factors that influence the consumers' choice of poultry market channels and consumers' demand after the HPAI outbreak;

5. To evaluate consumers' preferences and willingness to pay for poultry meat attributes;

Chapter 2 attempted to understand the limited effectiveness of HPAI control measures, it is 
important to map the complex structure of the poultry sector. The governance of the poultry value chain in particular, could play a pivotal role, yet there is limited information on the different chain governance structures and their impacts on HPAI control. This chapter uses value chain analysis (VCA), focusing on an in-depth assessment of governance structures as well as transaction cost economics and quantitative estimates of the market power of different chain actors, to establish a theoretical framework to examine biosecurity and HPAI control in the Western Java poultry chain. During the research, semi-structured interviews were conducted with key value-chain stakeholders, and the economic performance of identified actors was estimated. Results indicated the co-existence of four different poultry value chains in West Java: the integrator chain, the semi-automated slaughterhouse chain, the controlled slaughter-point chain, and the private slaughter-point chain. The integrator chain was characterized by the highest levels of coordination and a tight, hierarchical governance. In contrast, the other three types of value chains were less coordinated. The market power of the different actors within the four value chains also differed. In more integrated chains, slaughterhouses held considerable market power, while in more informal value chains, market power was in the hands of traders. The economic effects of HPAI and biosecurity measures also varied for the identified actors in the different value chains. Implementation of biosecurity and HPAI control measures was strongly related to the governance structure of the chain, with interactions between different chains and governance structures accentuating the risk of HPAI. Our findings highlight that a proper understanding of the chain governance structure is vital to improve the effectiveness of HPAI control measures, by making the interventions more specific and fit-for-purpose given the incentive structures present in different chains.

Chapter 3 describes that in Indonesia, several poultry value chains exist in conjunction with each other. The introduction and transmission routes of highly pathogenic avian influenza (HPAI) may differ between these different poultry chains. Consequently, critical areas for control may differ between the poultry value chains and the actors within these chains. However, there is no estimation of the relative importance of the different actors in the Indonesian poultry value chains regarding the probability of HPAI introduction and transmission. To fill this gap, a qualitative risk assessment of HPAI introduction and transmission was employed and linked with a previously established value chain map of poultry production in Western Java. Introduction and transmission probability estimates were determined through expert knowledge elicitation. Results indicated variable HPAI introduction and transmission risks in the different value chains in West Java, ranging from low to very 
high. Critical actors were all farming sectors, private collecting farms, traditional outlets, and semi-automated slaughterhouses. Linking value chain with an expertise-based estimation for introduction and transmission is an efficient and systematic way to identify opportunities for control measures for developing countries.

Chapter 4 addresses biosecurity practices across different farm business types to prevent the introduction and reduce the spread of infectious diseases, including Highly Pathogenic Avian Influenza (HPAI). HPAI is currently endemic in Indonesia. Although there is anecdotal evidence about the level of biosecurity on Indonesian broiler farmers, a formal evidence is lacking, as well as knowledge about determinants of low levels of biosecurity. This paper has two main objectives: 1) to assess the adoption levels of biosecurity management across different farm business types, and (2) to analyze the determining factors, with a special reference to farm business type, for the adoption of biosecurity practices and the availability of biosecurity infrastructure in West Java poultry farms. A multi-stage sampling procedure was applied to collect data from approximately 400 broiler farmers in four districts in West Java province, namely Ciamis, Tasikmalaya, Subang and Sukabumi. Data were collected by interviewing farmers and directly observing the farms. The Biosecurity Control Score (BCS), consisting of 16 practice indicators, and Farm Infrastructures for Biosecurity (FIB) consisting of 16 biosecurity facilities were used to measure adoption levels of biosecurity. Determinants of biosecurity adoption were analyzed via tobit regression analysis. The results show that biosecurity practices across various business types of broiler producers in West Java are limited. The poorest biosecurity adoption was found for traffic control practices and facilities. The results of this study suggest that business types play a significant role in biosecurity practices; a makloon farm (farming for fee) tends to have a lower adoption than other business types due to lack of incentives. Consequently, policy makers should take farm business type into consideration when developing incentives for improved biosecurity.

Chapter 5 reviews Indonesian consumers' choice of market channels to purchase poultry, and consumer concern of food scares and food safety in their consumption due to Highly Pathology Avian Influenza (HPAI) outbreak. The survey was conducted for the traditional and the modern channels and involves a sample of 1096 respondents in the Greater Jakarta Area. The logistic regression analysis reports the model proved that the substantial findings in the choice for the modern poultry market channel are the price/quality relationship, the safety feature, and the level of consumer trust. Some variables explaining the change in purchase behavior due to 
HPAI outbreaks are similar to the results of the choice of market channel. This study shows that the developed assessment can be used by the government to make the poultry supply more safe.

Chapter 6 explains Indonesian consumers' choice of attributes of poultry meat and the willingness to pay (WTP) for these attributes using a discrete choice experiment. The survey was conducted for the traditional and the modern channels and involved a sample of 440 respondents in the Greater Jakarta Area. A multinomial logistic regression analysis was used to evaluate the consumers' preference for poultry attributes. Consumers had a preference for warm poultry meat, government certification, and product information label. The WTP for warm poultry meat was the highest which indicates that freshness is very important for the consumers to ensure quality. The ordinary least square analysis indicated that the market channel had an influence on the WTP for warm and chilled poultry meat, WTP for no certification, and the WTP for poultry meat without a product information label. This study shows that understanding the WTP for poultry meat attributes enables the government to make the poultry supply safer using the price mechanism.

Chapter 7 provides a synthesis of the main findings, and a reflection on the methodologies and data used in Chapters 2-6. The chapter discusses the implications for policy and future studies. The main conclusions of this thesis are summarized as follows:

- Poultry production in Western Java is organized in a highly complex structure. Four different value chains can be distinguished: the integrator chain, the semi-automated slaughter chain, the controlled slaughter-point chain, and the private slaughter-point chain. This complex structure is responsible for the existence of a market for sick poultry that has a very negative influence on HPAI control.

- Traders need to be involved in the design and implementation of HPAI control measures, since they are the informal chain leaders in the controlled slaughter-point and the private slaughter-point chains.

- A combination of a value chain analysis with expertise-based estimates for HPAI introduction and transmission did identify critical actors in the epidemiology of HPAI. The method can easily be applied to study the structure of endemic contagious disease problems in developing countries having inadequate resources for extensive epidemiological research. 
- The main reason for consumers in Western Java to have a preference for the less safe, wet poultry markets, is their perception of freshness.

- A push strategy, as an incentive mechanism, should be designed in such a way that it pays attention to the interactions between actors in a value chain and their impact on introduction and transmission of disease.

- A pull strategy as an incentive mechanism for consumers forcing producers to improve their production environment into higher levels of biosecurity is expected to be less effective than a push strategy targeting producers. 


\section{Acknowledgements}

During my time as a lecturer of Bogor Agricultural University with a non-permanent status, having a scholarship and study abroad was considered as a mission impossible. Many efforts was taken, but it faced many hurdles. However, it did not stop me from pursuing the opportunity. One day, a called from Dr. Arief Daryanto gave me an open door to a new endeavor. It was about $\mathrm{PhD}$ opportunity in his project with the Faculty of Veterinary Medicine with regards or animal health economics and management. It was not something that already certain. As a person with limited knowledge on animal health, I had to compete with a more experience veterinarian to be selected by the committee from Utrecht University and Wageningen University and Research. In this event, I met Prof Henk Hogeveen for the first time. I am sincerely thank Dr. Arief Daryanto for opening the opportunity and Prof Henk Hogeveen for having a confidence on me to do $\mathrm{PhD}$ under his supervision. After that I received the letter of acceptance, but that was not the end of the struggle. I had to find a grant. Then another door was open from Indonesia Endowment Fund for Education (LPDP) Ministry of Finance Republic of Indonesia. I would like to thank to LPDP for the valuable financial supports. I would like also to thank Prof. Alfonse Oude Lansink, chair of Business Economics Group for permitting and facilitating my $\mathrm{PhD}$ education in his group.

$\mathrm{PhD}$ trajectory was a bumpy road and seemed very long without any ending. The help and support of many people was essential to complete this thesis. First of all, it is beyond any doubt that I owe great intellectually debt to my promotor Prof Henk Hogeveen for all the constant encouragements. You pushed me beyond my knowledge and also beyond your field. I was surprise when you said "this is my time to learn from you". Then I realized that was one of your methods to encourage me. Your passion in teaching and research showed me that becoming a lecturer is able to shape the future for human being. It is not about money, but it is about how we can contribute to a better future. So many times that you acted like a father figure, one of the example is when you assisted my family to come to the Netherlands. You are very well understood the meaning to have a family by my side during this $\mathrm{PhD}$ trajectory. I would like to thank Alessandro Bonanno as my first and the only daily supervisor that I had during my $\mathrm{PhD}$. Even we met for a short period, but we had a lot of discussions. I would like to thank my paranymps, Esmée Janssen, and Aum Anto for being a great help during my $\mathrm{PhD}$ time and my defense. Also Gumi for being the "head of family" for my defense. Asep Rakhmat, Roni Jayawinangun, Widya Pratomo and Indhy Aidha for the supports in my research! 
When working in the BEC office, I met a lot of people at the secretariat who supported me. Thank you Anne Houwers who took care of me, granted almost all of my requests and always checked on me in the fifth floor. Jeannette Lubbers, thank you for took care of me. Your nice words and smile always cheered me up. Natasha, Claudia and Ilona thanks for the supports.

I would like to thank to all my colleagues at Business Economics group, especially Nurul Suhaimi who I can shared many things, for example "first supervisor", courses, problems and foods. Gumi who became my "avian influenza family". Moreover, Luis and Diana as the only officemate that I had, Xudong for every discussion we had, Frederic for your review on my paper, Beshir for all the coffee and nice talks, Xiaomei for the memories in France, Mariska, Alisa, Eliana, Ngoc, Frazen, Tsion, Laya, Jamal, Felix, Niels, Jaap, Eva, Simon, Lien, Tariku, Tadesse, Marlous, Sabine, mas Adam, Kevin, Zhengcong, Thomas and Kirstin who made the atmosphere more enjoyable.

Settling down in a university after 12 years was not an easy task. I met my Indonesian friends and became one big family. I would like to thank Pak Iman Nawireja and Mbak Pini Wijayanti who were kind enough to help me to start my day one of PhD life. "The guardian of the galaxy" friends: mbak Titis, mbak Tika, mbak Dichan, Ika, mbak Vivi and mbak Eva, with "Pejantan Tangguh" kang Fajar and kang Yuda I would like to thank all of you for being my family in the Netherlands and shared a lot of laughs, tears and memories. Indonesian $\mathrm{PhD}$ family at Wageningen, Teh Novi dan kang Indra, pak Waldi, pak Dadan dan teh nia, kang Dasep, bli Indra, Hikmah, Nani, Belinda, Nuning, mbak Nila, Hatchi, mas Alim dan mbak Ayu, mbak Dian Ratri, mbak Gendis, mas Satria dan mbak Fitri, pak Taufik, pak Ery, pak Sakti, pak Panca, bang Emil, pak Gede, mbak Aritta, mas Agung, Pak Yo, mas Reo, pak Ahmad, mas Ayusta, mbak Ita dan mas Anto, mbak Saritta, Uda Zukri dan Uni Eli for the friendship and of course for the foods. I would like to thank Yasin Taklim Family, especially Pak Eko and mbak Andra, mas Faris and mbak Fifi, mas Sahri and mbak Amik, Iqbal, Atina, Wenty and Gerald, Ilya, mas Yitno and mbak Astin, Raushan and mbak Icha. At last, thank you for the fun with you "Centrum mania" friends, mas Ikrom, mas Firin, mbak Windi, ceu Vina dan ceu Mega. I would like to thank my Malaysian friends, Nurul and Hafeez, Ashikin and Sharul, Nazri, Zulkhairi and Lini for the hospitality and the friendship and took me in Malaysian community.

I would like to thank also to Prof. Bambang Hari Wibisono for his support during his time as Attaché Educational and Cultural Affairs of the Republic of Indonesia, and Mbak Dr. Wahida 
Agricultural Embassy of Indonesia and Mission of Indonesia to the EU for her attention. My friends at Indonesian Students Association in The Netherlands, mas Yance and mbak Umi, mas Hadi, mas Andrea, bung Arie, bung Ulil, Lisa, Andien, and Isna. I would like to thank big family of PCI NU in the Netherlands, especially Kyai Hasyim Subadi, Mas Fikri, mas Latif, mas Syahril, bang Ucok.

Thanks to Allah SWT and Rasulullah SAW, I would like to dedicate this thesis to my family. I would not be standing here without my parents, Aat Satria Kamil and Nani Haerani who gave endless loves, cares, and continuous supports for me and my family. I thank you both of you for gave me so much. I know that I could never pay it back. I also thank my beloved wife, Aulia Anggraini, and my children, Shaquille Rashad Ali Ammar, Rafique Rashid Zizou Ammar and Maritza Husna Ammar for their unconditional loves, whole hearted and shared memories in Indonesia and the Netherlands. I love you all. Lastly, I would like to thank oom Gatot Megantoro and tante Ratna Dewi with their children who gave many loves and supports for me and my family.

Wageningen, 13 March 2019

Dikky Indrawan 


\section{About the author}

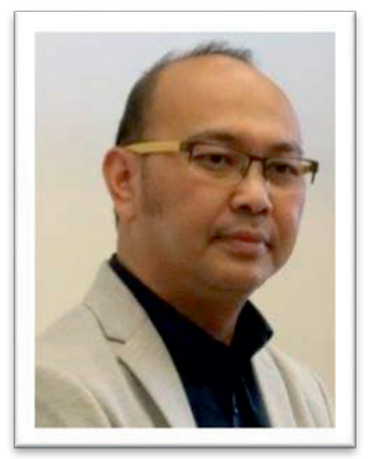

Dikky Indrawan was born on 17 December 1974 in Samarinda, East Kalimantan, Indonesia. He obtained his bachelor degrees in agricultural resources economic from Faculty of Agriculture at Bogor Agricultural University in 1997. Since 1997, he became a researcher and a consultant in many private and government projects. He obtained his master degree with a summa cum laude in agribusiness management from Bogor Agricultural University in 2002. In 2011, he joined an executive development program in effective partnership management at Maastricht School of Management, The Netherlands. Until 17 March 2014, he was a non-permanent staff at Department of Management Faculty of Economics and Management, Bogor Agricultural University. In this department, he taught many courses, namely Introduction of Management, Marketing Management, Strategic Management and Risk Management. In addition he assisted several courses, such as Research Methodology and Management Information System. He was also a junior researcher at Center for Sustainable Business Competitiveness (CSBC) in Bogor Agricultural University and Center for Tropical Animal Studies (CENTRAS) in Bogor Agricultural University.

In 2013, he received LOA from Prof Henk Hogeveen to pursue doctoral degree at Business Economics Group, Wageningen School of Social Science, Wageningen University and Research, The Netherland. The LOA was given through an endorsement from Veterinary Faculty and Business School in Bogor Agricultural University. After many difficulties to find a grant, on May 2014, he received a scholarship from Indonesia Endowment Fund for Education (LPDP) Ministry of Finance Republic of Indonesia to continue his doctoral study. He started his PhD program on 1 September 2014 on A value chain perspective to the control of Avian Influenza in the Western Java poultry sector. During his $\mathrm{PhD}$ program, he developed his knowledge and interest in value chain governance, marketing channel and consumers' behavior related to zooneses diseases and global one health. Furthermore, he has been the reviewer for Preventive Veterinary Medicine. He was also involved in the establishment of Wageningen Indonesia Scientific Exposure (WISE) in 2016 and 2017. He was actively involved in the initiative of south east Asia chapter of The International Society for Economics and Social Sciences of Animal Health (ISESSAH). After his $\mathrm{PhD}$ graduation he will start as a permanent lecturer at School of Business in Bogor Agricultural University. He can be contacted at e-mail: rdikky@gmail.com 
Dikky Indrawan

Wageningen School of Social Sciences (WASS)

Completed Training and Supervision Plan

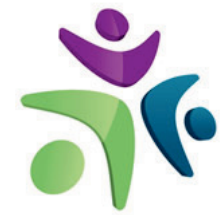

Wageningen School of Social Sciences

\section{Name of the learning activity \\ A) Project related competences}

Department/Institute

Year

ECTS*

Advanced Microeconomics (ECH 32306)

Wageningen University

2014

6

Organization of Agribusiness (BEC 31306)

Wageningen University

2014

6

Advanced Econometrics (AEP-60306)

Wageningen University

2015

6

Applied Economic Modelling for veterinary

Utrecht University

2016

Science

Multidisciplinary perspective perspectives

WASS

2016

on quality improvement in value chains

Choice Experiments in Agricultural and

KU Leuven

2016

0.5

Food Economics

Principles of a Global One Health

WASS

2016

1

\section{B) General research related competences}

Introduction course

Writing PhD Research Proposal

The Dutch - Indonesian programme on

Food Security on Livestock

"A Value Chain Analysis As A Tool To Evaluate Highly Pathogenic Avian Influenza (HPAl) Intervention Strategies"

"Towards a Restructured Poultry Supply Chain in Western Java"

"A Value Chain Analysis As A Tool To Evaluate Highly Pathogenic Avian Influenza (HPAI) Intervention Strategies"

"The Choice of Poultry Market Channel and The Consumer Purchase Behaviour due to HPAl "

"Combining value chain analysis with epidemiology of Highly Pathogenic Avian Influenza (HPAI)'

"The interaction of Urban Agriculture and Infectious Diseases"

"Why Is The Control of HPAl in Western Java Not Effective? A Value Chain Perspective"
WASS

2014

Wageningen University

2015

6

Wageningen Economic Research

2014-2018

\section{5}

World Poultry Congress 2016, 2016

Beijing China

Wageningen Indonesian Scientific Exposure (WISE) 2016, Wageningen, The Netherlands

The International Society for

2017

Economics and Social Sciences of Animal Health (ISESSAH) 2017, Aviemore, Scotland

WASS PhD Day 2017,

Wageningen, The Netherlands

Workshop on Global One Health, SPIN Project-Veterinary Faculty, Bogor Agricultural University, Indonesia

Indonesian Scientific Seminar

2017. Wageningen, The Netherlands 
"Linking supply chain governance,

The 15th International Symposium 2018

1

biosecurity and epidemiology in the context of Veterinary Epidemiology and

of HPAl control in Western Java: A value

Economics (ISVEE 15), Chiang Mai,

chain perspective"

Thailand

\section{C) Career related competences/personal development}

Scientific Writing WGS

2015

1.8

Reviewing Scientific Paper

WGS

2016

0.1

Information Literacy including EndNote

WGS

2017

0.6

Introduction

Project and Time Management

WGS

2017

Student thesis supervision

BEC

2016-2017

1

Wageningen Indonesian Scientific Exposure Wageningen University

2016-2017 (WISE) 2016-2017 committee

\section{Total}

${ }^{*}$ One credit according to ECTS is on average equivalent to 28 hours of study load 
The research described in this thesis was financially supported by Indonesia Endowment Fund for Education (LPDP), Ministry of Finance, Republic of Indonesia and was part of the Royal Netherlands Academy of Arts and Sciences (KNAW) SPIN3-JRP-61 Project "Incentives driving the transmission of Highly Pathogenic Avian Influenza virus H5N1 in the Indonesian poultry chain".

Cover design by Dikky Indrawan and Roni Jayawinangun Printed by proefschriftmaken on FSC-certified paper 